\title{
EFFECT OF MICROWAVE HYDROLYSIS ON TRANSFORMATION OF STEROIDAL HORMONES DURING ANAEROBIC DIGESTION OF MUNICIPAL SLUDGE CAKE
}

by

\author{
Hanna Hamid \\ B.Sc., Bangladesh University of Engineering and Technology, 2009 \\ A THESIS SUBMITTED IN PARTIAL FULFILLMENT \\ OF THE REQUIREMENTS FOR THE DEGREE OF \\ MASTER OF APPLIED SCIENCE \\ in \\ The College of Graduate Studies \\ (Civil Engineering)
}

THE UNIVERSITY OF BRITISH COLUMBIA

(Okanagan)

February 2013

(C) Hanna Hamid, 2013 


\begin{abstract}
This research evaluates the fate of 16 steroidal (estrogenic, androgenic and progestogenic) hormones during advanced anaerobic digestion of municipal sludge cake generated at the Kelowna's wastewater treatment plant using microwave (MW) pretreatment. Effect of sludge pretreatment temperature $\left(80,120,160^{\circ} \mathrm{C}\right.$ ), digester operating temperature (mesophilic at $35 \pm$ $2^{\circ} \mathrm{C}$, thermophilic at $55 \pm 2^{\circ} \mathrm{C}$ ) and sludge retention time (SRT: 20, 10, 5 days) were studied employing eight lab-scale semi-continuously fed digesters. To determine the potential effect of MW hydrolysis, hormones were quantified in sludge (total) and supernatant (soluble) phases of the digester influent and effluent streams. Seven of 16 hormones were above reporting limit (RL) in one or more of the samples. Hormone concentrations upto $1,640 \mathrm{ng} / \mathrm{L}$ and $2491 \mathrm{ng} / \mathrm{g}$ (for androstenedione, (Ad)), respectively, were detected in soluble and total phases of the influents. Microwave hydrolysis resulted in both release and attenuation of hormones in the soluble phase. High accumulations (upto 30 times for androstenedione (Ad) of the influent concentration) of hormones observed in the effluents of un-pretreated (control) digesters suggested that anaerobic digestion was inefficient to remove these compounds. Simultaneous accumulation and removal of $17 \beta$-estradiol (E2) and estrone (E1) as well as progesterone (Pr) and androstenedione (Ad) indicated possible transformations among the hormones. At a 20-day SRT, thermophilic digesters contained overall less concentration of steroidal hormones in their digestate supernatants to be recycled to the beginning of the treatment plant. However, mesophilic digesters seemed to perform better in terms of total decrease of hormones and would likely to have lower concentrations in their dewatered digestates to be disposed of via land application at same SRT (20 days). Microwave pretreatment increased total chemical oxygen demand (TCOD) volatile solids (VS) removals and methane production compared to un-pretreated (control) digesters. However, improvements were more prominent at the shortest SRT of 5 days.
\end{abstract}




\section{Preface}

Abridged version of chapter 2 was submitted to the journal Water Research on April 22, 2012 and was accepted for publication on August 2, 2012. The full citation of the article was "Hamid, Hanna and Eskicioglu, Cigdem, 2012. Fate of estrogenic hormones in wastewater and sludge treatment: A review of properties and analytical detection techniques in sludge matrix. Water Research 46(18), 5813-5833. http://dx.doi.org/10.1016/j.watres.2012.08.002.”

Abstracts based on some results of chapter 3 were submitted for presentations in Water Environment Federation (WEF) Residuals and Biosolids 2013 Conference (May 5-8, 2013, Nashville, Tennessee) and International Water Association (IWA) $13^{\text {th }}$ World Congress on Anaerobic Digestion (June 25-28, 2013, Santiago de Compostela, Spain). Also, an abridged version of chapter 3 has been submitted to Water Research as a journal paper and currently it is under review. 


\section{Table of Contents}

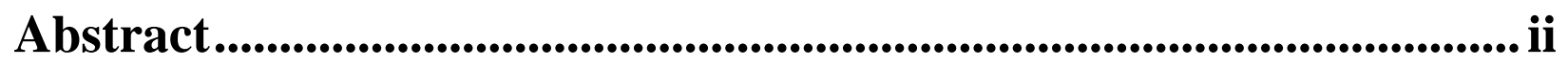

Preface (...........................................................................................................................iii

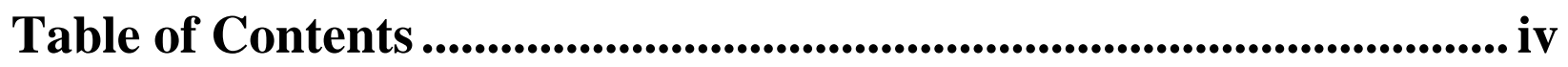

List of Tables ........................................................................................... vii

List of Figures................................................................................................................. viii

List of Abbreviations ..................................................................................... $\mathrm{x}$

List of Symbols .............................................................................................................. $\mathrm{xi}$

Acknowledgements .................................................................................. xii

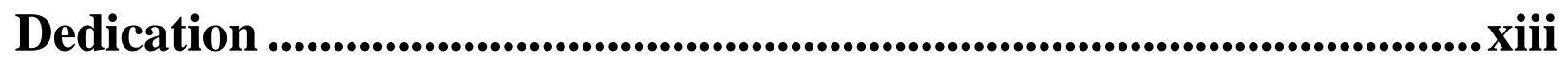

Chapter 1 Introduction ............................................................................................. 1

1.1 Background .....................................................................................................................1

1.2 Motivation for research ................................................................................................2

1.3 Objectives...................................................................................................................

1.4 Thesis organization ..............................................................................................................4

Chapter 2 Literature Review .............................................................................. 5

2.1 Introduction .........................................................................................................................5

2.2 Properties of hormones as endocrine disrupters ............................................6

2.3 Health effects of steroidal compounds ...............................................................10

2.4 Screening program and regulatory aspects of EDC.....................................11

2.5 Sources and pathways of hormones in environment ......................................12 
2.6 Removal pathways for steroidal compounds .........................................15

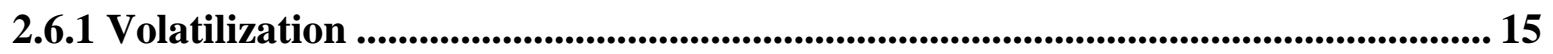

2.6.2 Biodegradation by sewage bacteria .......................................................................................... 15

2.6.3 Adsorption ....................................................................................................................... 20

2.7 Fate of steroidal compounds in engineered processes...............................22

2.7.1 Fate of steroidal compounds during conventional WWTPs ..................................... 22

2.7.2 Fate of estrogenic compounds during sludge stabilization ........................................ 29

2.8 Analytical techniques for steroidal compounds in sludge samples..........33

2.9 Summary ...................................................................................................................................39

Chapter 3 Effect of microwave hydrolysis on transformation of steroidal hormones during anaerobic digestion of municipal sludge

cake

3.1 Materials and methods ..............................................................................41

3.1.1 Substrate and inocula ............................................................................................................. 41

3.2.2 Microwave pretreatment ......................................................................................................... 43

3.2.3 Digester studies................................................................................................................................. 45

3.3 Analytical techniques....................................................................................................46

3.3.1 Characterization of influent and effluent ......................................................................... 46

3.3.2 Hormone analysis............................................................................................................................... 47

3.3.3 Calculations ............................................................................................................................................... 48

3.4 Results and discussion ...............................................................................................52

3.4.1 Occurrence of steroids in anaerobic digester streams............................................... 52

3.4.2 Effects of microwave pretreatment on steroids in digester feed.............................. 57

3.4.3 Effects of microwave pretreatment on digester performance .................................. 58 
3.4.3 Effects of pretreatment and anaerobic digester operating conditions on hormone

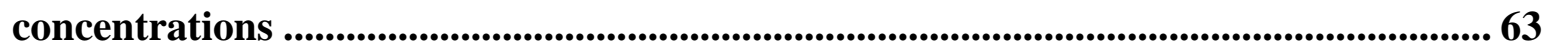

3.5 Summary .............................................................................................................. 71

Chapter 4 Conclusions and perspectives ..................................................... 72

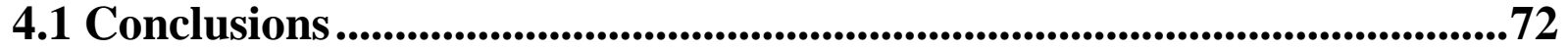

4.2 Thesis contributions.................................................................................74

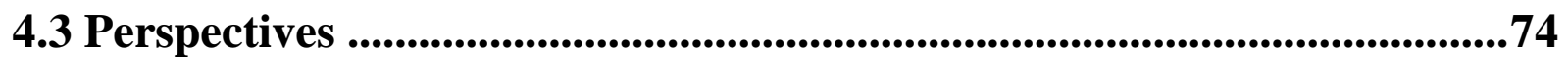

References .................................................................................................................. 76

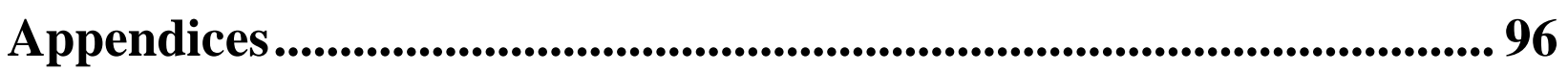

Appendix A: Calibration charts ..............................................................................96

Appendix B: Analytical detection of hormones .....................................................98

Appendix C: Analysis of variance ......................................................................106 


\section{List of Tables}

Table 2.1 Physical and chemical properties, relative binding affinity and surrogate standard

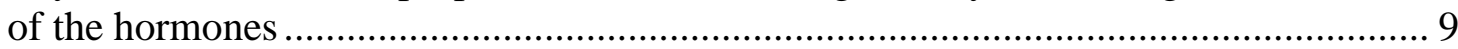

Table 2.2 Estimates of estrogen excretion by humans (per person) in $\mu \mathrm{g} / \mathrm{day}$.............................. 13

Table 2.3 Estimated total daily estrogen excretion of different livestock species .........................14

Table 2.4 Biodegradation kinetic constants for estrogens......................................................... 19

Table 2.5 Occurrence and fate of some hormones in wastewater treatment plants (WWTPs) .... 23

Table 2.6 Analytic techniques for estrogenic compounds ............................................................ 38

Table 3.1 Characterization of raw (control) and pretreated digester feed after dilution................ 45

Table 3.2 Method detection limits, reporting limits and quantification references for

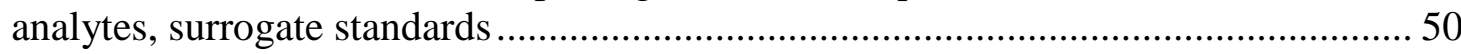

Table 3.3 Concentration (ng/L) of steroidal hormones in soluble phase of digester influent

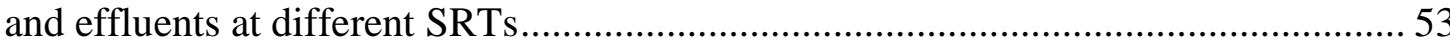

Table 3.4 Concentration (ng/g) of steroidal hormones in total phase of digester influent and effluents at different SRTs ....................................................................................... 55

Table 3.5 Biogas composition (\%) at various sludge retention times (SRTs)............................... 63

Table 3.6 Analysis of Variance for removal efficiency of progesterone (Pr) from total phase.... 68

Table B.1 Quality control acceptance criteria ………….........................................................98

Table B.2 Reporting limit (RL) of steroidal hormones in supernatant (ng/L) of influent and

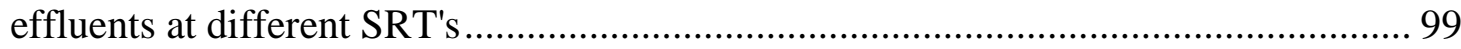

Table B.3 Reporting limit (RL) of steroidal hormones in total phase ( $\mathrm{ng} / \mathrm{g})$ of influent and effluents at different SRT's.................................................................................... 101

Table B.4 Total solids (TS) concentrations (\%,w/w) of the influent and effluent samples

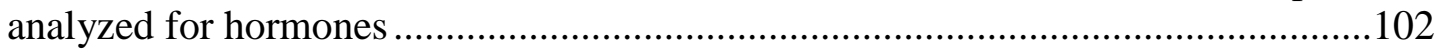

Table C.1 Analysis of Variance for Removal efficiency of androstenedione (Ad) from

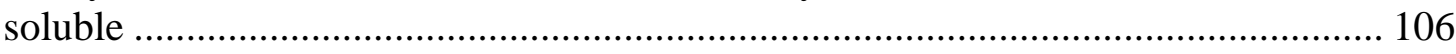

Table C.2 Analysis of Variance for Removal efficiency of estrone (E1) from soluble phase ... 106 


\section{List of Figures}

Figure 2.1 Chemical structures of some natural and synthetic hormones …………..................... 8

Figure 2.2 Sources and pathways of steroidal hormones in environment .................................. 12

Figure 2.3 Proposed metabolic pathway of E2 by sewage bacteria............................................ 17

Figure 2.4 Typical setup of a wastewater treatment plant showing wastewater sludge production and the split arrows indicate EDC release/transformation during various unit processes of treatment......................................................................... 26

Figure 2.5 Steps of anaerobic digestion process …………………………………………...... 30

Figure 3.1 Existing process flow diagram in City of Kelowna wastewater treatment plant ........ 42

Figure 3.2 a) Ethos microwave station $\left(2.45 \mathrm{GHz}, 0\right.$ - 1200 Watt, $25-300^{\circ} \mathrm{C}, 0$ - 35 bars); b) heating and cooling profiles of the microwave unit................................................... 44

Figure 3.3 One of the eight lab-scale semi-continuous anaerobic digesters................................. 46

Figure 3.4 Experimental methodology showing sampling locations........................................... 49

Figure 3.5 Flow chart of analytical determination of steroidal hormones in solid and liquid

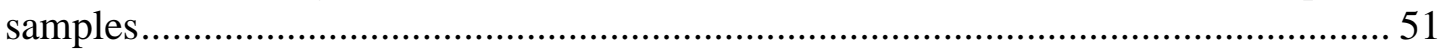

Figure 3.6 Effect of microwave (MW) pretreatment on waste sludge cake solubilization ...........57

Figure 3.7 Effect of microwave (MW) on hormone concentrations in the a) soluble (liquid) phase and b) total (solid) phase of the influent ...........................................................59

Figure 3.8 Daily biogas productions (normalized to volatile solids (VS) content of the feed) of control (fed with unpretreated) and MW160 (fed with microwave pretreated sludge at $\left.160^{\circ} \mathrm{C}\right)$ thermophilic (TH) and mesophilic (ME) digesters at STP (1 atm, $0^{\circ} \mathrm{C}$ ) during the 20,10 and 5 days of sluge retention time (SRT).

Figure 3.9 Total chemical oxygen demand (TCOD) removal efficiencies at sludge retention

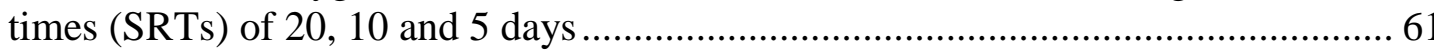

Figure 3.10 Volatile solids (VS) removal efficiencies at sludge retention times (SRTs) of 20, 10 and 5 days

Figure 3.11 Average daily biogas and methane production rate at different sludge retention time (SRT) at STP 
Figure 3.12 Concentrations of a) estrone (E1) and b) 17 $\beta$-estradiol (E2) in soluble phases of the influent and effluents at different sludge retention times (SRTs)

Figure 3.13 Concentrations of androstenedione (Ad) in a) soluble phase and b) total phase of the influent and effluents at different sludge retention times (SRTs)

Figure 3.14 Concentrations of progesterone (Pr) in a) soluble phase and b) total phase of the influent and effluents at different sludge retention times (SRTs)

Figure 3.15 Total hormone concentrations (estrone (E1), 17 $\beta$-estradiol (E2), androstenedione (Ad) and progesterone (Pr)) in the a) soluble phase (supernatant) and b) total phase (sludge) of the influent/digester feed and effluent at 20 days SRT.

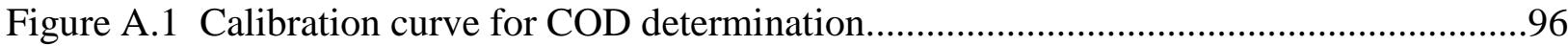

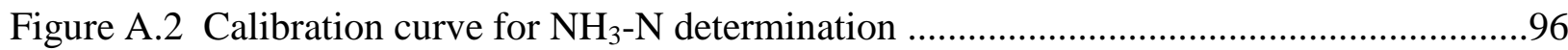

Figure A.3 Calibration curve for biogas measurement via manometer at $\mathrm{STP}\left(0^{\circ} \mathrm{C}, 1 \mathrm{~atm}\right) \ldots \ldots . .97$

Figure B.1 Concentrations of testosterone (Tr) in a) soluble phase and b) total phase of the influent and effluents at different sludge retention times (SRTs)....

Figure B.2 Concentrations of androsterone (An) in a) soluble phase and b) total phase of the influent and effluents at different sludge retention times (SRTs)

Figure B.3 Concentrations of mestranol (Ms) in a) soluble phase and b) total phase of the influent and effluents at different sludge retention times (SRTs).

Figure C.1 Normal probability plot for analysis of variance of removal efficiency of androstenedione (Ad) from soluble phase

Figure C.2 Normal probability plot for analysis of variance of removal efficiency of estrone (E1) from soluble phase

Figure C.3 Normal probability plot for analysis of variance of removal efficiency of progesterone (Pr) from total phase. 


\section{List of Abbreviations}

Ad

ADD

An

AOB

APCI

AS

ASE

CAS

COD

DHT

E1

E2

E3

EE2

EDC

$\mathrm{Eq}$

Eqn

ESI

GC

GPC

HRT

HRTh

KPCC

$\mathrm{LC}$

MAE

MDL

MS

Ms

MW

OLR

Pr

PS

RL

SCOD

SDL

SPE

SRT

TCOD

$\operatorname{Tr}$

TS

TVFA

TWAS

VFA

WAS

WWTP

YES
Androstenedione

Androstadienedione

Androsterone

Ammonia oxidizing bacteria

Atmospheric pressure chemical ionization

Activated sludge

Accelerated solvent extraction

Chemical abstract services

Chemical oxygen demand

17 $\beta$-hydroxy-androstanedieneone

Estrone

$17 \beta$-estradiol

Estriol

17a-ethinylestradiol

Endocrine disrupting compound

Equilin

Equilenin

Electrospray ionization

Gas chromatography

Gel permeation chromatography

Hydraulic retention time

Hormone replacement therapy

Kelowna Pollution Control Center

Liquid chromatography

Microwave assisted extraction

Method detection limit

Mass spectrometry

Mestranol

Microwave

Organic loading rate

Progesterone

Primary sludge

Reporting limit

Soluble chemical oxygen demand

Sample specific detection limit

Solid phase extraction

Sludge retention time

Total chemical oxygen demand

Testosterone

Total solids

Total volatile fatty acids

Thickened waste activated sludge

Volatile fatty acids

Waste activated sludge

Wastewater treatment plant

Yeast estrogen screen 


\section{List of Symbols}

$\begin{array}{ll}\mathrm{C} & \text { Total compound concentration } \\ \mathrm{C}_{\mathrm{s}} & \text { Concentration in solids } \\ \mathrm{C}_{\mathrm{w}} & \text { Concentration in water } \\ \mathrm{k} & \text { Reaction rate constant } \\ \mathrm{K}_{\mathrm{d}} & \text { Distribution coefficient } \\ \mathrm{K}_{\mathrm{F}} & \text { Freundlich parameter } \\ \mathrm{K}_{\mathrm{OM}} & \text { Distribution coefficient normalized to organic matter } \\ \mathrm{K}_{\mathrm{OC}} & \text { Distribution coefficient normalized to organic carbon content } \\ \mathrm{K}_{\mathrm{ow}} & \text { Octanol /water partition coefficient } \\ \mathrm{OC} & \text { Percentage of organic carbon } \\ \mathrm{pKa} & \text { Acid dissociation constant } \\ \text { TSS } & \text { Total suspended solids } \\ \text { VSS } & \text { Volatile suspended solids }\end{array}$




\section{Acknowledgements}

First of all, I would like to thank almighty Allah for giving me the strength and courage to complete this project.

Next, my heartfelt gratitude goes to my supervisor, Dr. Cigdem Eskicioglu, for her enduring patience, guidance and motivation throughout the last two years of my graduate study. Whenever I needed her, she was always there for me. Our late afternoon meetings have always been a source of great inspiration for me. I would also like to extend deepest gratitude to my committee members, Dr. Rehan Sadiq and Dr. Bahman Naser for their valuable advice and time.

In addition, I am very much grateful to the fellow students of my research team Neda Mehdizadeh, Piero Galvagno, Kafi Wahidunnabi and Mariel Barrantes Leiva. My especial thanks go to Shashank Gupta, summer intern in Dr. Eskicioglu's research group. This research would not have been possible without their help and support.

Last but not the least; I am thankful to my family members and friends for their unconditional love and encouragement throughout my entire life. 


\section{To my father and mother}




\section{Chapter 1 Introduction}

\subsection{Background}

In Canada, approximately 388,700 dry tones of biosolids are produced yearly; about $43 \%$ of which is land applied. This percentage is expected to increase as different municipalities are recognizing land application to be the most sustainable and environment friendly disposal option for biosolids, as opposed to landfilling and incineration (Apedaile, 2001). However, in addition to existing environmental and health concerns, presence of some natural hormones, pharmaceutical and personal care products in biosolids are causing public opposition against the beneficial reuse of biosolids (Citulski and Farahbakhsh, 2010). A number of these compounds are known to interfere with the natural functioning of endocrine system in human and animals and are called endocrine disrupting compounds (EDCs) (Hansen et al., 1998; Tyler et al., 2005). Among these, natural steroidal hormones have been characterized to be the most potent of all EDCs (Legler et al., 1999; Legler et al., 2002a; Legler et al., 2002b). Some studies show that although steroidal hormones have the potential to undergo transformations in agricultural settings, they are likely to persist long enough to impact the water quality of runoff (Yang et al., 2012). Furthermore, others indicate that hormone leaching and runoff can result in after land application of manure (Kjaer et al., 2007; Jenkins et al., 2009).

Most commonly used processes for volatile content stabilization of biosolids include digestion, alkali stabilization, composting and heat drying (Tchobanoglous et al., 2002). Among these, anaerobic digestion is a biosolids treatment method that converts the organic waste into methane-enriched biogas and fertilizer by combined action of a mixed community of microorganisms (Botheju and Bakke, 2011). Stabilization of high-strength organic waste, production of heat or electricity by recovered methane, and reduced greenhouse gas emissions have made anaerobic digestion more favorable in today's world. Major drawbacks of conventional anaerobic digestion, such as longer digestion retention time requirement $(20-50$ days), low organic degradation efficiency $(20-50 \%)$ are often thought to be associated with hydrolysis, which is one of the three stages of anaerobic digestion (i.e., hydrolysis, acetogenesis and methanogenesis) (Tyagi and Lo, 2011). Recent developments in this field indicate that thermal (i.e., conventional and microwave (MW) heating) (Ge et al., 2010; Wett et al., 2010; Yu 
et al., 2010), mechanical (e.g., high pressure homogenizer, sonication, stirred ball mills (Onyeche, 2006; Wood et al., 2009; Salsabil et al., 2010) and chemical (e.g., acidic and alkaline, ozonation.) (Lin et al., 2009; Kim and Youn, 2011) pretreatments applied to complex organic waste (i.e. industrial and municipal secondary sludge, manure) prior to anaerobic digestion can substantially accelerate the hydrolysis of biosolids and subsequent methane recovery in smaller digesters. Different processes, e.g., bulking and foaming, dewatering, conditioning, are also shown to improve after pretreatment (Muller, 2000; Tyagi and Lo, 2011). Due to the aforementioned advantages, a number of proprietary advanced hydrolysis processes are currently being applied at the full-scale, i.e., Cambi ${ }^{\mathrm{TM}}$, Microsludge ${ }^{\mathrm{TM}}$, Sonix ${ }^{\mathrm{TM}}$, OpenCEL ${ }^{\mathrm{TM}}$ (Jolly and Gillard, 2009; Pilli et al., 2011). Among these, thermal hydrolysis methods are reported to show improved pathogen destruction and dewaterability in addition to higher improvement in methane recovery compared to other pretreatment methods (Pino-Jelcic et al., 2006; Carballa et al., 2009; Yu et al., 2009).

\subsection{Motivation for research}

To date, conventional performance parameters, such as organics removal, methane recovery, pathogen removal, dewaterability, have been the focus of almost all the studies dealing with thermal hydrolysis in lab- or full-scale advanced anaerobic digester operations to treat municipal biosolids. A large research gap exists regarding the effects of thermal hydrolysis on fate and removal of micropollutants, e.g., steroidal hormones, in municipal waste sludge streams during advanced anaerobic digestion. Only a few studies have reported fate and removal of estrogenic hormones (e.g. estrone (E1), 17ß-estradiol (E2), estriol (E3) and 17 $\alpha$-ethinylestradiol (EE2))

from full-scale conventional anaerobic digesters (Andersen et al., 2003; Muller et al., 2010; Ifelebuegu, 2011). Furthermore, only one study has reported the loadings of androstenedione (Ad), testosterone (Tr), progesterone (Pr), mestranol (Ms) and androsterone (An) in full-scale sludge digesters (Furlong et al., 2010). Regarding the effect of thermal hydrolysis on hormones, a single study exits using conventional heating (Carballa et al., 2006), where removal efficiencies of E1, E2 and EE3 in pilot-scale mesophilic and thermophilic digesters utilizing mixed municipal waste sludge were reported.

As the pretreatments disintegrate the complex polymeric network in waste sludge samples, it is likely that some hormones, initially encapsulated within the polymeric network, may be 
released into the soluble phase and render themselves more or less biodegradable depending on the changes on their molecular structures at different pretreatment conditions (low or elevated temperatures, mechanical shear, or chemical dose). Furthermore, as sludge pretreatments solubilize organics (hormones), it could be postulated that there is a potential to shift the ultimate disposal route of residual hormones in digestate from a landfill or agricultural land to main wastewater stream. As wastewater treatment plants (WWTPs) incorporating thermal hydrolysis prior to anaerobic digestion may contain higher solubilized hormones in their digestates, there may be higher concentration of hormones recycled back to the head of the treatment train with the digester centrate.

\subsection{Objectives}

The general objective of this work was to study the effect of MW hydrolysis on fate and removal of 16 steroidal hormones (synthetic and natural displayed in Table 2.1) during advanced anaerobic digestion of municipal sludge cake sampled from Kelowna's WWTP. The effect of sludge cake pretreatment temperature $\left(80,120,160^{\circ} \mathrm{C}\right)$, digester operating temperature (mesophilic at $35 \pm 2{ }^{\circ} \mathrm{C}$, thermophilic at $55 \pm 2^{\circ} \mathrm{C}$ ) and sludge retention time (SRT: 20, 10, 5 days) were evaluated using eight lab-scale semi-continuously fed anaerobic digesters. The main goal set above was achieved by systematically investigating the following:

- Biosolids particulate chemical oxygen demand (COD) solubilization following MW pretreatment at different temperatures

- Concentration of the target steroidal hormones in control (un-pretreated) and pretreated digester feeds in sludge (total) and supernatant (soluble) phases

- Mesophilic and thermophilic anaerobic digestion of un-pretreated and MW pretreated municipal sludge cake (at SRTs of 20,10 and 5 days) to evaluate

$\checkmark$ Organic removal efficiency

$\checkmark$ Biogas and methane recovery

$\checkmark$ Concentration of target hormones in the effluent of control and pretreated digesters in sludge (total) and supernatant (soluble) phases 


\subsection{Thesis organization}

The thesis has been organized into four chapters. Chapter 1 provides a brief background and motivation for this research. General and specific objectives of this study are also outlined in this chapter. In chapter 2, literature involving physiochemical properties, source, pathway and fate of steroidal hormones in different units of WWTPs are reviewed. Furthermore, effects of advanced anaerobic digestion with MW pretreatment on different sludge (municipal and industrial) are also discussed here. Chapter 3 presents materials and methods along with the results addressing the objectives of the study. Final conclusions, thesis contributions and recommendations for future research are summarized in the chapter 4. 


\section{Chapter 2 Literature Review}

\subsection{Introduction}

Some natural and synthetic compounds are attracting attention due to their interferences with the usual functioning of the endocrine system in humans and animals. Collectively these are called endocrine disrupting compounds (EDCs). When present in environment above a certain (threshold) concentration, these compounds can cause adverse health effects on wildlife (Hansen et al., 1998; Tyler et al., 2005). EDCs mainly consist of natural and synthetic hormones and their metabolites. Several non-steroidal and synthetic compounds e.g., plasticizer, flame retardants, surfactants, and pesticides etc., as well as some pharmaceutical and personal care products also exhibit endocrine disruption potency (Caliman and Gavrilescu, 2009). Among these different classes of endocrine disrupters, human and animal waste born hormones, often known as endogenous steroidal hormones, has been characterized by very high endocrine disrupting potency. Compared to the exogenous endocrine disrupters, such as the organochlorine pesticides

and industrial compounds, endogenous hormones has been found to be $10^{2}-10^{7}$ times more potent (Legler et al., 1999; Legler et al., 2002a; Legler et al., 2002b).

Municipal wastewater is the main disposal pathway for the human waste born estrogenic and androgenic compounds. In addition, synthetic hormones widely used as oral contraceptives, hormone replacement therapy and anabolic steroids are ingested in humans and after excretion enter the wastewater stream. Optimizing the removal of micropollutants like steroidal hormones is not a design criterion for conventional wastewater and sludge treatment plants. Upon wastewater treatment, stabilized biosolids (treated sewage sludge) may act as source of these micropollutants due to incomplete removal from solid and/or liquid phase of wastewater. Studying the fate of these chemicals throughout different unit treatment processes is important to determine the removal and incoming load of steroidal hormones to the environment. The goal of this chapter is to provide a state-of the-art review of the current treatment techniques employed in wastewater and biosolids treatment and their performances regarding removal of these compounds. Furthermore, the current practices and the challenges involved in analytical determination of these compounds in biosolids samples are also highlighted. 


\subsection{Properties of hormones as endocrine disrupters}

Natural steroids in mammals are biosynthesized from cholesterol, a 27 carbon precursor. As these hormones are lipids, following their synthesis and transportation, they pass through cell wall and bind with respective receptors to bring changes within cells. Based on the binding receptors, steroids can be categorized into five groups: androgens, estrogens, progestagens, glucocorticoids and mineralocorticoids (Martin et al., 1998). Steroidal hormones share the same tetracyclic network consisting of three six carbon and one five carbon ring (Figure 2.1). All of them have oxygen at $\mathrm{C} 3$ and a varied substituent at $\mathrm{C} 17$. For various substituent, different compounds are formed with either $\alpha$ or $\beta$ depending on where they are situated below or above the plane of the molecule (Considine and Considine, 1984). In addition to natural hormones, a number of synthetic hormones from humans and animals, as well as some estrogen mimicking compounds derived from plants also act as endocrine disruptors. Considering their origins, these compounds can be grouped as following:

- Natural steroidal hormones: estrone (E1), 17ß-estradiol (E2), testosterone etc.

- Synthetic hormones: 17 $\alpha$-ethinylestradiol (EE2), diethylstilbestrol, 19norethindrone etc.

- Phyto- and mycoestrogens: daidzein, genistein, zearalenone etc.

Table 2.1 (Liu et al., 2009a) shows potencies of some synthetic and natural estrogenic hormones relative to E2. These values are obtained using a yeast-based in vitro bioassay (YES assay). YES utilizes a human estrogen receptor recombinant engineered with a betagalactosidase reporter (Routledge and Sumpter, 1996). The potencies vary depending on the type of bioassay used and the method of determination; however studies indicate EE2 and E2 to be of most potent estrogenic compounds, followed by E1 and estriol (E3) (Folmar et al., 2002). These natural and synthetic hormones are primarily of concern because very low concentration (ng/L range) has been proven to adversely affect a number of aquatic species (Panter et al., 1998; Irwin et al., 2001). In addition, relative binding affinity determined by estrogen receptor ligand competitive binding assay (ER-binding assay) or androgen receptor ligand competitive binding assay (AR-binding assay) for a number of hormones are also presented in Table 2.1. Physiochemical properties of these compounds (Table 2.1) play a significant role in determining their fate in natural and engineered environment. As indicated in Table 2.1, steroids are poorly 
soluble in water (Liu et al., 2009a). The octanol/water partition coefficient $\left(K_{o w}\right)$, defined as the ratio of concentration of a compound in $n$-octanol and water under equilibrium condition at a specific temperature, are also shown in Table 2.1. Since the distribution of organic compounds between water and other natural solids are often considered as a partitioning process between the aqueous and organic phase, $\log K_{o w}$ values are used to roughly predict the sorption (Carballa et al., 2004). $\log K_{o w}$ values for steroidal hormones vary between 2.5 to 4.0. As a result, they are often cited as moderately hydrophobic (Jones-Lepp and Stevens, 2007) and have a tendency to partition with solid phase.

Majority of the total estrogenic and androgenic hormones produced by the body are excreted in conjugated form by urinary route (Adlercreutz et al., 1987). Prior to excretion via urine, conjugated estrogens are formed by glucuronide and/or sulfate groups at the position(s) of C3 and/or C17. These polar conjugates are biologically inactive and more soluble in water compared to their corresponding free or un-conjugated counterpart. Despite conjugated estrogens being the predominant form while leaving human body, studies (D'Ascenzo et al., 2003; Gomes et al., 2005; Reddy et al., 2005) indicate free estrogens and sulfate conjugates are dominant species in the influent and effluent of WWTP. This suggests deconjugation occurs somewhere between excretion and discharge of the effluent from WWTP. In fact, deconjugation has been shown to be a natural process and fecal bacteria such as Escherichia coli (E. coli) are able to deconjugate estrogens by synthesizing large quantities of the enzyme $\beta$-glucuronidase (Adlercreutz and Martin, 1980). The recalcitrant nature of sulphate conjugates along the wastewater treatment train can be explained by weaker arylsulfatase activity of $E$. coli compared to $\beta$-glucuronidase (Shackleton, 1986). 


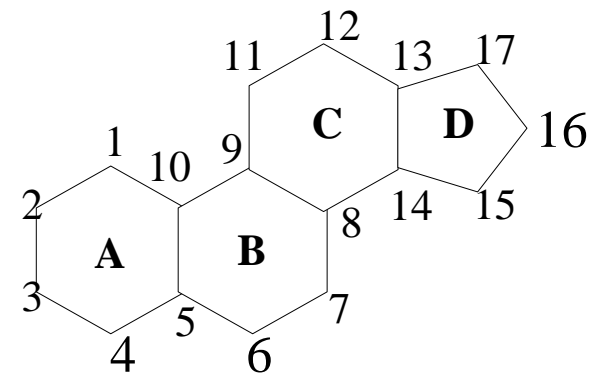

Steroid backbone

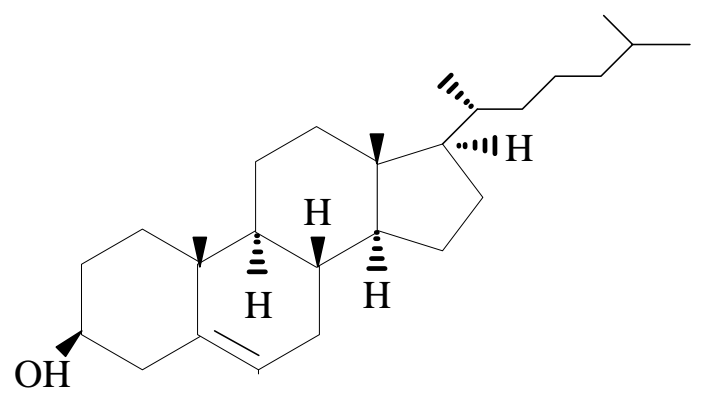

Cholesterol<smiles>O=C1CC[C@@H]2[C@@H]1CC[C@@H]1c3ccc(O)cc3CC[C@H]12</smiles>

Estrone (E1)
$\mathrm{OH}$

17 beta-estradiol (E2)

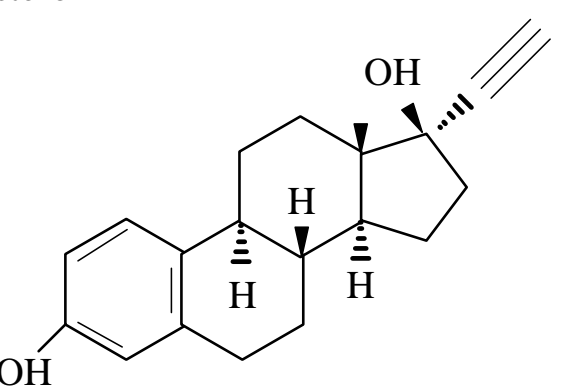

17 alpha-ethinylestradiol (EE2)

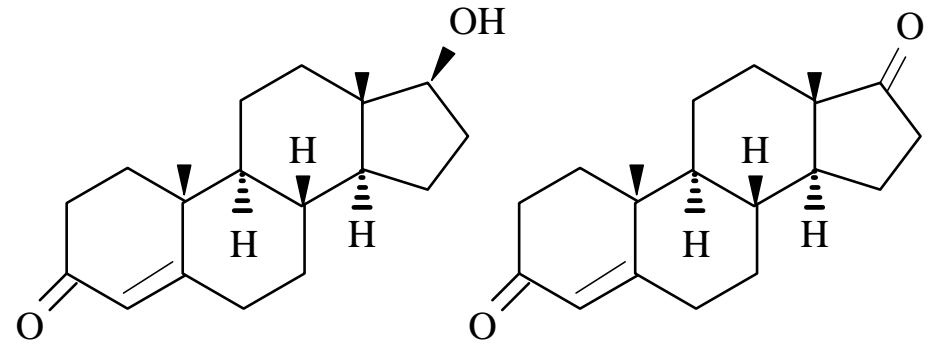

Testosterone (Tr)

Androstenedione (Ad)<smiles>C[C@]12CC[C@@H](O)C[C@]1(O)CC[C@@H]1[C@@H]2CC[C@H]2C(=O)CC[C@H]12</smiles>

Androsterone (An)<smiles>C#C[C@]1(O)CC[C@H]2[C@H]3CCc4cc(OC)ccc4[C@H]3CC[C@H]21</smiles>

Mestranol (Ms)

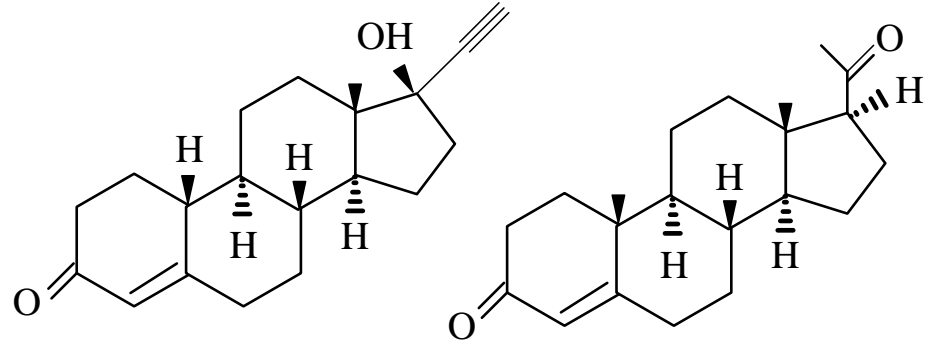

Norethindrone

Progesterone (Pr)

Figure 2.1 Chemical structures of some natural and synthetic hormones 
Table 2.1 Physical and chemical properties, relative binding affinity and surrogate standard of the hormones ${ }^{\mathrm{a}}$ (Liu et al., 2009a)

\begin{tabular}{|c|c|c|c|c|c|c|c|c|c|}
\hline Hormone & Category & CAS & $\begin{array}{c}\text { Mol. } \\
\text { wt. } \\
\text { (g/mol) }\end{array}$ & $\begin{array}{l}\mathbf{L o g} \\
\mathbf{K}_{\mathrm{ow}}\end{array}$ & $\begin{array}{l}\text { Melt. pt. } \\
\left({ }^{\circ} \mathbf{C}\right)\end{array}$ & $\begin{array}{c}\mathbf{H}\left(\mathbf{P a}^{-\mathbf{m}^{3}}\right. \\
\left.. \mathrm{mol}^{-1}\right)\end{array}$ & RBA (ER) & $\begin{array}{l}\text { RBA } \\
\text { (AR) }\end{array}$ & $\begin{array}{c}\text { YES } \\
\text { potency }\end{array}$ \\
\hline Allyl trenbolone & Progestogen (S) & $850-52-2$ & 310.43 & $-{ }^{d}$ & 120 & - & & - & - \\
\hline Norethindrone & Progestogen (S) & $68-22-4$ & 298.4 & 2.97 & $203-204$ & - & $1.5 \times 10^{-03}$ & 0.146 & - \\
\hline Norgestrel & Progestogen (S) & $6533-00-2$ & 312.45 & - & $205-207$ & - & - & - & - \\
\hline Progesterone (Pr) & Progestogen $(\mathrm{N})$ & $57-83-0$ & 314.5 & 3.87 & $128.5-131$ & - & - & 0.0359 & - \\
\hline Androstenedione (Ad) & Androgen $(\mathrm{N})$ & $63-05-8$ & 286.4 & - & $170-173$ & - & - & $2.41 e^{-}-3$ & - \\
\hline Androsterone (An) & Androgen (N) & $53-41-8$ & 290.4 & 3.69 & $181-184$ & - & - & $5.7 e-4$ & - \\
\hline Testosterone $(\mathrm{Tr})$ & Androgen $(\mathrm{N})$ & $58-22-0$ & 288.4 & 3.32 & 155 & - & - & 0.685 & - \\
\hline Estriol (E3) & Estrogen $(\mathrm{N})$ & $50-27-1$ & 288.4 & 2.45 & 282 & $2.0 \times 10^{-11}$ & 0.33 & $3.2 \mathrm{e}^{-4}$ & $.024^{\mathrm{c}}$ \\
\hline Mestranol (Ms) & Estrogen $(\mathrm{S})$ & $72-33-3$ & 310.43 & - & $150-151$ & - & - & - & - \\
\hline 17 $\alpha$-dihydroequilin & Estrogen $(\mathrm{N})$ & $651-55-8$ & 270.4 & - & $155-158$ & - & - & - & - \\
\hline Equilenin & Estrogen $(\mathrm{N})$ & $517-09-9$ & 266.33 & - & 258.5 & - & - & - & - \\
\hline Equilin & Estrogen $(\mathrm{N})$ & $474-86-2$ & 268.4 & 3.35 & $238-240$ & - & 0.289 & $1.05 e^{-}-3$ & - \\
\hline $17 \alpha$-estradiol & Estrogen $(\mathrm{N})$ & $57-91-0$ & 272.4 & 4.01 & $216-219$ & - & 0.801 & $8.85 e^{-4}$ & $.3^{\mathrm{c}}, .075$ \\
\hline 17ß-estradiol (E2) & Estrogen $(\mathrm{N})$ & $50-28-2$ & 274.4 & 4.01 & $173-179$ & $6.3 \times 10^{-7}$ & 1 & 0.66 & 1 \\
\hline Estrone (E1) & Estrogen $(\mathrm{N})$ & $53-16-7$ & 270.4 & 3.13 & $254.5-256$ & $6.2 \times 10^{-7}$ & 0.44 & $1.3 e^{-3}$ & $.38^{\mathrm{c}}, 1$ \\
\hline 17 $\alpha$-ethinylestradiol (EE2) & Estrogen $(\mathrm{S})$ & $57-63-6$ & 296.4 & 3.67 & $182-184$ & $3.8 \times 10^{-7}$ & 1.4 & $4.28 e^{-}-3$ & $1.19^{\mathrm{c}}, 1.5$ \\
\hline
\end{tabular}




\subsection{Health effects of steroidal compounds}

Studies revealed that the major health effects associated with exposure of different fish species to estrogenic compounds include altered sexual development, presence of intersex species, changed mating behavior. High incidence of intersexuality has been reported in wild roach (Rutilus rutilus) population and freshwater fish walleye (Sander vitreus) in the rivers receiving effluent from domestic and municipal WWTP that contains estrogenic hormones (Purdom et al., 1994; Jobling et al., 1998; Pollock et al., 2010). Elevated plasma vitellogenin levels in fathead minnows (Pimephales promelas) after 21 days exposure to E1 and E2 at environmentally relevant concentration accompanied by an inhibition of testicular growth has been observed (Panter et al., 1998). Chronic exposure of fathead minnows to environmentally relevant concentration of EE2 resulted in feminization of the males through vitellogenin production that led to a near collapse of the species in the experimental lake area near northwestern Ontario, Canada (Kidd et al., 2007). Early exposure to EE2 at a concentration of $9.86 \mathrm{ng} / \mathrm{L}$ resulted in diminished courting behavior of female zebrafish (Danio rerio) resulting in reduced female reproductive success (Coe et al., 2010). In a field study, elevated levels of vitellogenin in female painted turtle (Chrysemys picta) exposed to E2 has been reported (Irwin et al., 2001), which may have implication in terms of reproductive fitness and shifting energy allocation from other survival needs in turtles. Phytoestrogens present on a certain strain of clover caused severe infertility in sheep grazing on them (Adams, 1998). Effect of estrogenic hormones on plant growth has been studied to a much lesser extent compared to wildlife. Treatment with E1 and E2 influenced the root and shoot growth in potato plant and sunflower seedlings, as well as, altered the morphology and flowering patterns (Janeczko and Skoczowski, 2005; Brown, 2006). Although, compared to estrogens, adverse effects of other steroids (e.g., androgen, progestogen etc.) are studied to a lesser extent, studies reported exposure to pulp and paper mill effluent in river resulted in masculinization of fish (Jenkins et al., 2003; Fan et al., 2011).

Despite the compelling evidence on wildlife, adverse health effects of estrogenic hormones on human are still a debatable issue. Some studies have reported lower sperm count, declining male reproductive health and breast cancer as an aftermath of increased exposure to endogenous and exogenous estrogenic compounds (Ahmed, 2000; Delbes et al., 2006; McLachlan et al., 2006) while others refuted this, suggesting other factors, e.g. geographic variation, cultural factors, as more important players in sperm count decline than these pollutants (Fisch and 
Goluboff, 1996; Safe, 2000). Systematic investigation of health effects on human involves many challenges, e.g. lag time between exposure and manifestation of clinical disorder, age and duration of exposure (Lopez, 2010).

\subsection{Screening program and regulatory aspects of EDC}

The issue of ubiquitous presence of EDCs in environment and their potential to harm human and animal health has forced the government of different countries to develop testing protocols and strategies. Programs establishing testing procedure and regulatory framework for risk assessment of EDCs include, a two-tier Endocrine Disruptor Screening Program of the U.S. Environmental Protection Agency (USEPA), the Strategic Programs on Endocrine Disruptors of the Japan Environment Agency, and the Joint Working Group on Endocrine Disrupters Testing and Assessment sponsored by the Organization for Economic Cooperation and Development (Hecker and Hollert, 2011). Endocrine Disruptor Screening Program, undertaken by USEPA, is currently developing in vitro and in vivo assays to identify/clarify substances relative to their potential interaction with endocrine systems (Tier 1) and then developing dose-response relationships in animal models (Tier 2) (U. S. Environment Protection Agency, 2011). Endocrine Disrupters Testing and Assessment developed a five-level conceptual framework for testing and assessment of potential EDCs, each level corresponding to a different level of biological complexity (Organization for Economic Co-operation and Development, 2002). Canadian government is supporting both institutional and academic research through international cooperation for developing standardized test method (Office of Auditor General of Canada, 2011). In 2010, Environment Canada has published a proposed Wastewater Systems Effluent Regulations in the Canada Gazette, Part I, which is expected to reduce the discharge of micropollutants associated with WWTP effluent employing secondary or equivalent treatment (Environment Canada, 2011). While there is some progress made in the testing procedure and chemical risk assessment, no efforts have been made in terms of environmental risk assessment of these compounds concerning their discharge with the effluent in relation to drinking water safety and agricultural

practices. Furthermore, to date no regulatory values exists for these compounds (Hecker and Hollert, 2011). 


\subsection{Sources and pathways of hormones in environment}

As previously mentioned, human and animal excreta is cited to be the main source of steroidal hormones in aquatic environment (de Mes et al., 2005; Jobling et al., 2006). The plantprocessing industry, including bio-ethanol and bio-diesel production, also significantly contributes towards the presence of phytoestrogens in surface water bodies (Lundgren and Novak, 2009). As shown in Figure 2.2, after excretion, the natural and synthetic hormones and their metabolites eventually reach WWTP. The treated solid and liquid fraction of the wastewater act as potential entry routes of these compounds in the environment.

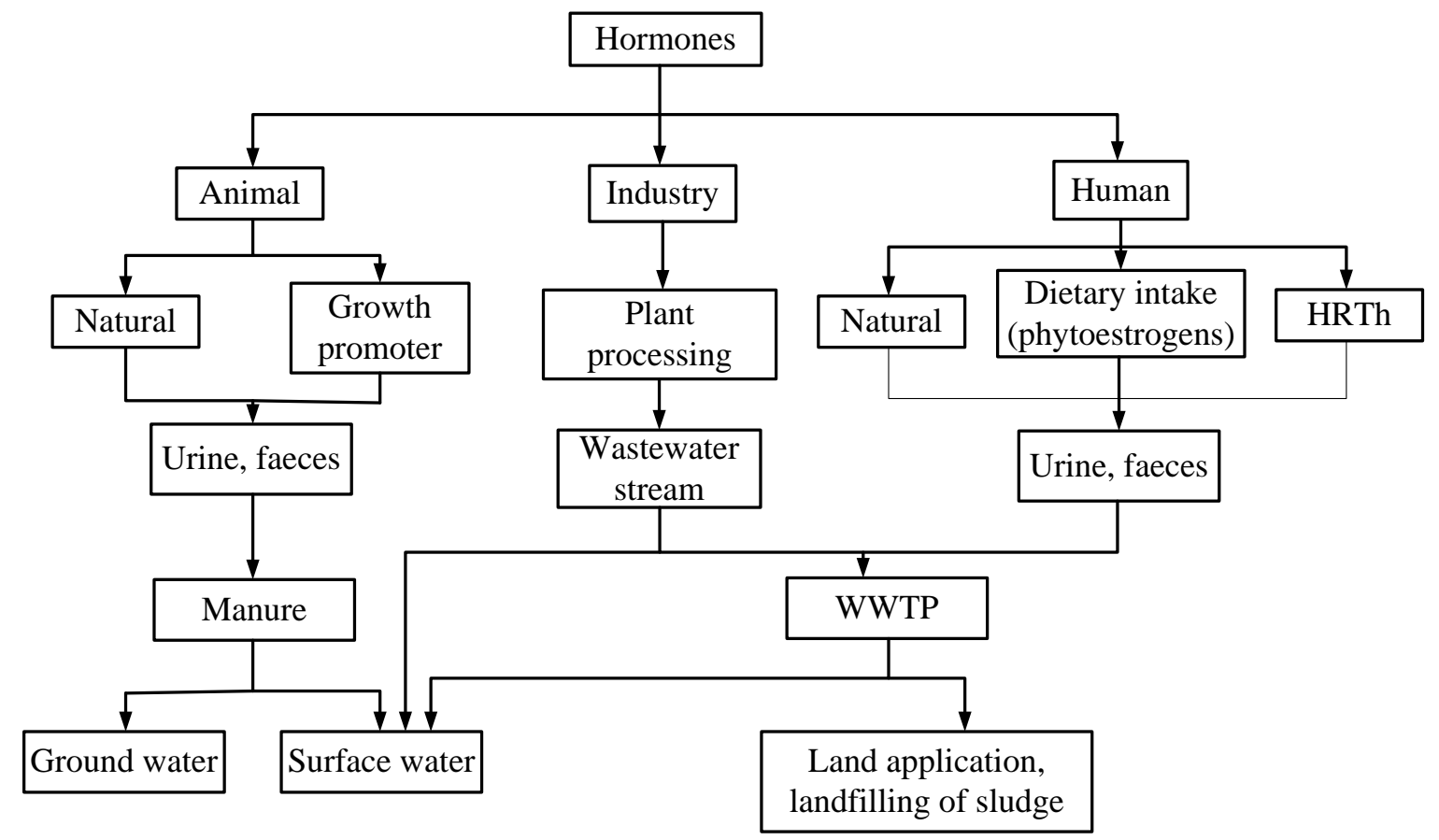

Figure 2.2 Sources and pathways of steroidal hormones in environment (HRTh: hormone replacement therapy, WWTP: wastewater treatment plant)

Among the 18 natural estrogens excreted by human urine, E1, E2 and E3 are shown to account for $66-82 \%$ estrogenicity of the urine in different population group (e.g, male, menstruating female, menopausal female etc.). Average daily excretion rates of these three estrogenic and major androgenic hormones are given in Table 2.2. It is evident from Table 2.2 that the average excretion rate of estrogenic hormones for a menstruating female is about twice compared to a male, whereas, excretion rate of androgenic hormones are more than double in males compared to a female. However, excretion rate of estrogenic hormones can be very high 
(upto $6 \mathrm{mg} /$ day) during pregnancy in women. In addition to the natural estrogenic compounds, synthetic estrogens used in pharmaceuticals are also ingested and reach the WWTP via human waste. As a result, hormone concentrations measured in the wastewater is affected greatly by demographics of that particular community.

Widely used synthetic estrogen in contraceptive pill, EE2, is considered as a major contributor to the total estrogenicity of sewage effluent (Cargouet et al., 2004; Kidd et al., 2007). EE2 is engineered from E2 by adding an ethinyl group at C17 (Figure 2.1) position resulting in a compound that is much more resistant to biodegradation compared to parent natural hormone (Clouzot et al., 2008). Johnson and Williams (2004) developed a Pharmaceutical Assessment and Transport Evaluation model integrating excretion rate data of different population groups to predict input concentrations of EE2 in WWTPs. Starting with a dose of $26 \mu \mathrm{g} / \mathrm{day}$, $43 \%$ was predicted to be metabolized within the body, $27 \%$ excreted as conjugated molecules, and $30 \%$ as free form. Considering transformation and biodegradation in the pathway towards WWTP, the model estimates $40 \%$ of the total EE2, about $10.5 \mu \mathrm{g} /$ day, reaches the sewage influent.

Table 2.2 Estimates of estrogen excretion by humans (per person) in $\mu \mathrm{g} / \mathrm{day} *$ (Johnson et al., 2000; Liu et al., 2009b)

\begin{tabular}{lcccccc}
\hline & E1 & E2 & E3 & Tr & An & Ad \\
\hline Males & 1.6 & 3.9 & 1.5 & 56.65 & 3340 & 3.4 \\
Menstruating females & 3.5 & 8 & 4.8 & & & \\
Menopausal females & 2.3 & 4 & 1 & 6.78 & 1570 & N.A \\
Pregnant women & 259 & 600 & 6000 & & & \\
\hline
\end{tabular}

*E1: estrogen, E2: 17 $\beta$-estradiol, E3: estriol, Tr: testosterone, An: androsterone, Ad: androstenedione, N.A: not available.

Hormone replacement therapy (HRTh) involving oral intake of estrogens, progesterone and sometimes testosterone, can contribute to the total estrogenicity of municipal wastewater. HRTh is available in various forms, the most common being the conjugated equine estrogens (brand names Premarin ${ }^{\circledR}$ and Prempro®), a mixture of estrogens derived from the urine of pregnant mares. This mixture contains estrone sulfate that naturally occurs in women and metabolites of the B-ring unsaturated estrogens, equilin (Eq) and equilenin (Eqn) that are specific to horses (Tyler et al., 2009). Although there is a declining trend towards the use of HRTh since 2002, a recent study by Kim et al. (2007) showed that in the USA, approximately $17 \%$ of women aged 50 and greater (and up to $25 \%$ of women aged $50-59$ ) remain on HRTh. Only one study has 
been found evaluating the effect of conjugated equine estrogens from HRTh in four WWTPs in UK and reported their estrogenic potencies (Tyler et al., 2009). The same study also reported equine estrogen Eqn, and its metabolite $17 \beta$-dihydroequilenin (17 $\beta$-Eqn) to be present in all the influent and $83 \%$ of the effluent samples at concentrations upto $26 \mathrm{ng} / \mathrm{L}$. When applied to in vitro estrogen receptor in fish, their potency varied between 2.4 to $3490 \%$ of that of E2. Also 21 days exposure of Eqn and 17 $\beta$-Eqn induced estrogenic responses including hepatic growth and vitellogenin production at concentrations as low as $0.6-4.2 \mathrm{ng} / \mathrm{L}$.

Recent studies indicated that the amount of steroidal hormones excreted by livestock is on the same order or often more than human excretion rate (Liu et al., 2012b). The yearly production of manure in the USA is 133 million tons (dry weight basis). That is 13-fold more solid waste compared to the human sanitary waste production (Burkholder et al., 2007). Different estrogens are common to different species of animals. 17 $\alpha$-E2, E1, E3 are found in excreta of cattle, whereas, other animal species (poultry and swine) mainly excrete E2, E1, and E3 (Wise et al., 2011). Table 2.3 shows daily excretion rate for estrogenic compounds for different livestock. Organic contaminants from animal waste can enter the environment through seepage from poorly constructed manure lagoon, overflow of lagoons in care of extreme rainfall events or runoff from recent application to agricultural fields (Burkholder et al., 2007). Several studies have reported or estimated the contribution of livestock to total estrogenicity of waterways. In UK, Johnson et al. (2006) estimated about $1 \%$ of the estrogens excreted by animals reaches water assuming the estrogenic compounds behaves like herbicides, which is about $15 \%$ of all estrogens in water.

Table 2.3 Estimated total daily estrogen excretion of different livestock species ( $\mu \mathrm{g} /$ day) (Wise et al., 2011)

\begin{tabular}{lcccc}
\hline Species & Type & $\begin{array}{c}\text { Total estrogen in } \\
\text { urine }(\boldsymbol{\mu g} / \mathbf{d a y})\end{array}$ & $\begin{array}{c}\text { Total estrogen in feces } \\
(\boldsymbol{\mu g} / \mathbf{d a y})\end{array}$ & $\begin{array}{c}\text { Total estrogen } \\
(\boldsymbol{\mu g} / \mathbf{d a y})\end{array}$ \\
\hline \multirow{2}{*}{ Cattle $^{\mathrm{a}}$} & Calves & 15 & 30 & 45 \\
& Cycling cows & 99 & 200 & 299 \\
\hline \multirow{2}{*}{ Pig $^{\mathrm{b}}$} & Pregnant & & $256-7,300$ & $56-111,620$ \\
\hline \multirow{2}{*}{ Sheep $^{\mathrm{a}}$} & Cycling sow & 82 & 21 & 103 \\
& Pregnant & $700-17,000$ & 61 & - \\
\hline
\end{tabular}

${ }^{a}$ Data are estimated as total of estrone (E1), 17ß-estradiol (E2), 17 $\alpha$ - estradiol (E2), estriol (E3) excretions and include hormones from veterinary treatment (Lange et al., 2002)

${ }^{\mathrm{b}} \mathrm{Pig}$ and pregnant cattle data are from (Johnson et al., 2006) 


\subsection{Removal pathways for steroidal compounds}

The possible removal pathways of the hormones from different unit treatment processes include volatilization, biological degradation, abiotic degradation and adsorption onto solids. In the following section, these pathways are discussed in light of previous lab-scale studies.

\subsubsection{Volatilization}

The extent of volatilization of estrogenic compounds can be predicted by the Henry's law constant which is a ratio of the fractions of these compounds dissolved in water and those in air. Compared to volatile organic pollutant (e.g. chlorinated hydrocarbons, aromatics etc.) with value a in the range of $10^{3}$ (Mackay and Shiu, 1981), estrogenic hormones have a small Henry's law constant (Table 2.1); which makes these compounds less susceptible to volatilization under normal pressure and temperature (Khanal et al., 2006; Estrada-Arriaga and Mijaylova, 2010).

\subsubsection{Biodegradation by sewage bacteria}

A number of bacteria for example many actinobacteria species including Arthrobacter, Mycobacterium, Nocardia, and Rhodococcus have been shown to degrade steroidal hormones (Yoshimoto et al., 2004; Donova, 2007; Yang et al., 2011). Different studies investigating biodegradation of estrogens suggest that removal is achieved by the direct use as electron donors by heterotrophs or by co-metabolism (i.e. organic compounds are only modified by microorganisms but not used for growth) by ammonia oxidizing bacteria (AOB) (Vader et al., 2000; Fang et al., 2003; Ren et al., 2007; Estrada-Arriaga and Mijaylova, 2010). Although most of these studies described degradation by first-order reaction kinetics (Shi et al., 2004; Li et al., 2005; Ren et al., 2007; Zeng et al., 2009b) as shown in eq. (2.1), few also suggest pseudo firstorder kinetics (Joss et al., 2004; McAdam et al., 2010) as in eq. (2.2).

$$
\begin{aligned}
& \frac{d C}{d t}=k \times S \\
& \frac{d C}{d t}=k \times S \times V S S
\end{aligned}
$$

Where, $\mathrm{C}$ is the total compound concentrations ( $\mathrm{ng} / \mathrm{L}), \mathrm{S}$ is the soluble compound concentration $(\mathrm{ng} / \mathrm{L}), \mathrm{t}$ is the time $(\mathrm{d}), \mathrm{k}$ is the reaction rate constant $\left(\mathrm{d}^{-1}\right.$, for eq. (2.1) and L/g VSS $\mathrm{d}$ for eq. (2.2)), and VSS is the volatile suspended solids concentration $(\mathrm{g} / \mathrm{L})$. 
A batch test study (Ternes et al., 1999a) using spiked levels of estrogens in diluted slurry of activated sludge (AS) collected from a full scale WWTP demonstrated that natural estrogens and their glucuronides are readily biodegradable by the microorganisms present in AS under aerobic condition. In this study, E2 spiked in $\mathrm{ng} / \mathrm{mL}$ and $\mu \mathrm{g} / \mathrm{mL}$ range was quantitatively oxidized to E1 and no further degradation products of E1 were identified before its elimination. Also, major portion of the spiked E2 glucuronides were cleaved after coming into contact with AS. In contrast, EE2 appeared to be much more persistent to biodegradation. This finding is supported by Layton et al. (2000), who investigated the removal of estrogenic compounds with laboratory mineralization assays using ${ }^{14} \mathrm{C}$-labeled estrogens with biosolids from four municipal treatment plants and one industrial system. After $24 \mathrm{hrs}$, the mineralization for ${ }^{14} \mathrm{C}$-17 $\alpha$-ethinylestradiol and ${ }^{14} \mathrm{C}-17 \beta$-estradiol were $20 \%$ and $75 \%$, respectively. The difference in mineralization $(84 \%$ versus $4 \%$ ) of ${ }^{14} \mathrm{C}$ - $17 \beta$-estradiol using municipal and industrial biosolids in the same study also indicates the importance of adapted microbial population in biodegradation. Fuji et al. (2002) and Yoshimoto et al. (2004) isolated Rhodococcus zopfii and Rhodococcus equi from waste AS, that were able to degrade $100 \mathrm{mg} / \mathrm{L}$ of E2 to $1 \mathrm{mg} / \mathrm{L}$ after $24 \mathrm{hr}$. After investigating the fate of E2 and its 5 metabolites in a slurry of AS, Lee and Liu (2002) confirmed the biodegradation of these compounds under both aerobic and anaerobic conditions, aerobic being the more favorable with higher degradation rates. This study also affirms the previous finding of E1 being the major metabolite of E2 and identified a new metabolite X1 at the early stage of degradation. According to proposed pathway (Figure 2.3), degradation of E2 by sewage bacteria appeared to initiate at $\mathrm{C} 17$ at D ring, leading to the formation of E1. E1 is further oxidized into a labile metabolite with lactone structure (X1) and finally to carbon dioxide through a tricarboxylic acid cycle.

Previous studies indicate $\operatorname{Tr}$ to be easily degraded by manure-borne bacteria under various environmental condition with mainly three degradation products (i.e., androstenedione (Ad), androstadienedione (ADD), 17 $\beta$-hydroxy-androstanedieneone (DHT)). For steroids with 3-oxo4-ene structures such as $\operatorname{Tr}$ and Ad, degradation usually occurs through B ring cleavage involving 9ß-hydroxylation and 1(2)-dehydrogenation (Donova, 2007; Yang et al., 2011). In a recent study, swine manure-borne culture has been shown to completely mineralize $\operatorname{Tr}$ (initial concentration $3 \mathrm{mg} / \mathrm{L}$ ) to $\mathrm{CO}_{2}$ within $29 \mathrm{hrs}$, following a lag phase of $22 \mathrm{hrs}$ under aerobic condition (Yang et al., 2011). In addition to the three above mentioned products, 9 $\alpha$ -

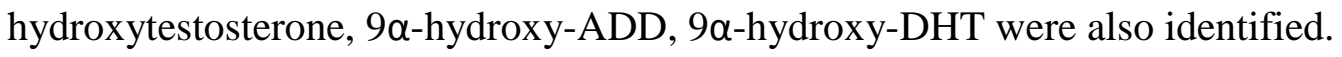



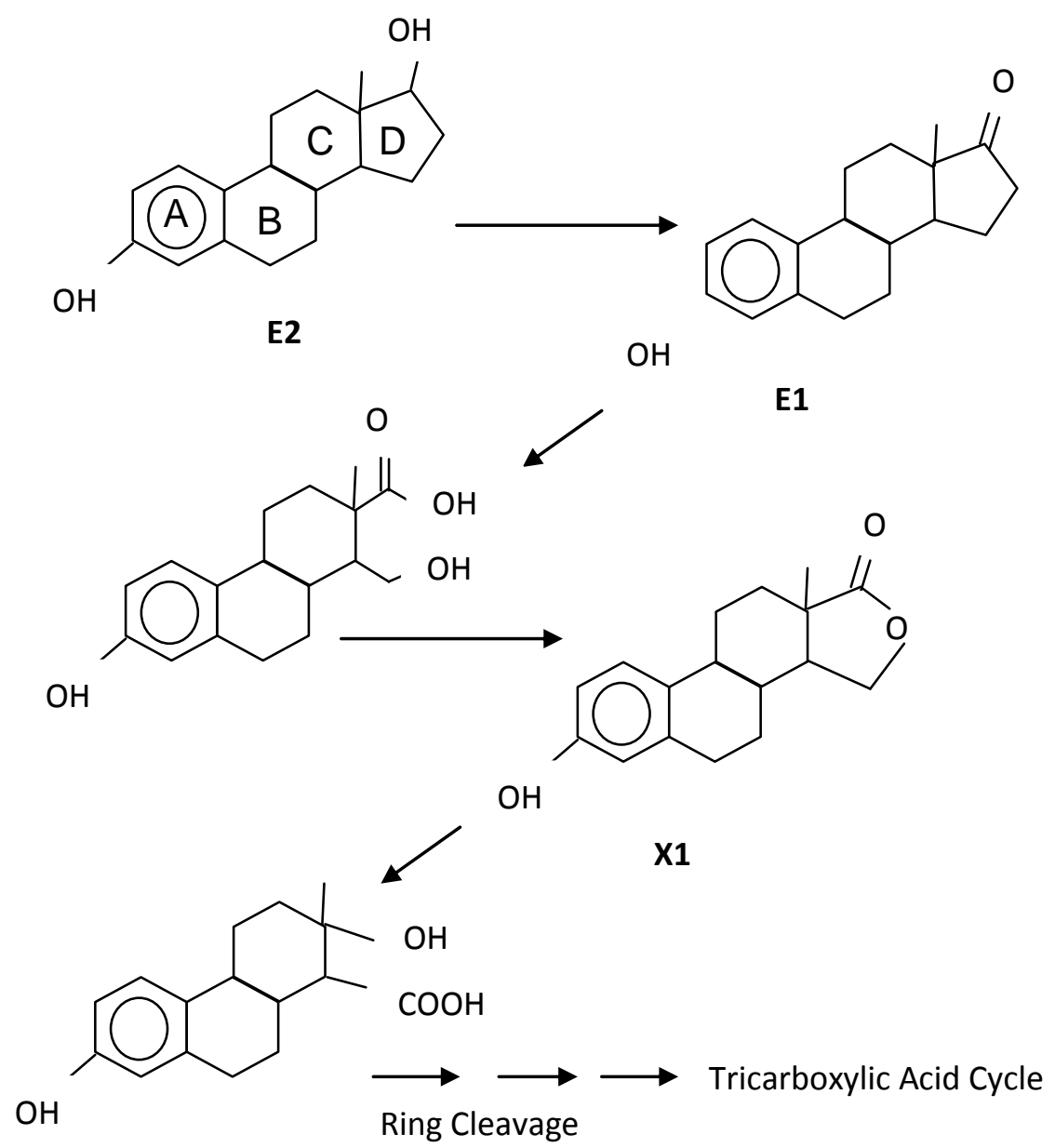

Figure 2.3 Proposed metabolic pathway of E2 by sewage bacteria (Lee and Liu, 2002)

Several studies have reported that pure AOB cultures (Shi et al., 2004; Skotnicka-Pitak et al., 2009), enriched ammonia oxidizing cultures (Vader et al., 2000; Yi and Harper, 2007; Forrez et al., 2009) and nitrifying activated sludge (Ren et al., 2007; De Gusseme et al., 2009) are able to bio-transform comparatively recalcitrant synthetic estrogen EE2 at elevated concentration (> $50 \mu \mathrm{g} / \mathrm{L}$ ), which may explain the augmented removal of estrogens in WWTP employing nitrification. The authors suggested that co-metabolism by the ammonium mono-oxygenase enzyme in presence of other organic substance was responsible for EE2 degradation. On the contrary, another study (Gaulke et al., 2008) claimed that pure cultures of AOB, such as $N$. europae and Nitrosospira (Ns.) multiformis, were not able to degrade EE2 at low concentrations typical for AS. The apparent degradation of EE2 reported in the previous studies was in fact abiotic transformation and heterotrophs are mainly responsible for EE2 removal in a full-scale 
plant. However, a more recent study (Khunjar et al., 2011) demonstrated that both AOB and heterotrophic cultures are able to biodegrade EE2 (feed concentration $500 \mathrm{ng} / \mathrm{L}$ ). Although, AOB biodegraded EE2 at a faster rate, heterotrophs were able to mineralize the compound as well as some AOB produced metabolites of EE2 suggesting both of these cultures may function cooperatively to enhance removal of these compounds.

The effect of redox condition (i.e. aerobic, anoxic and anaerobic) on biodegradation has been also studied by Joss et al. (2004). Their study revealed that both E1 and E2 are biodegraded under all the three redox conditions, with aerobic being the most favorable for biodegradation. In contrast, substantial EE2 degradation is observed only under aerobic condition. A change in condition from anaerobic to anoxic and anoxic to aerobic corresponds to an increase by a factor 3 to 5 in E1 degradation rate, while in case of E2, this is less than 3. The biodegradation kinetic constants reported by several studies under different experimental conditions are shown in Table 2.4. Another bench-scale study under anaerobic-anoxic-oxic AS system by Li et al. (2011) substantiated E2 being biodegradable in all three conditions and EE2 accumulating under anaerobic condition. Elevated temperature has been shown to favor the degradation of estrogens (Li et al., 2005; Zeng et al., 2009b). Li et al. (2005) found a similar temperature co-efficient to that of biochemical oxygen demand, which varied between 1.026 to 1.09 , for a temperature range of $5^{\circ} \mathrm{C}-35^{\circ} \mathrm{C}$ during an aerobic biodegradation study of E2. 
Table 2.4 Biodegradation kinetic constants for estrogens under different experiment condition*

\begin{tabular}{|c|c|c|c|c|}
\hline Hormones & Agent/matrix type & Rate constants & Experimental condition & References \\
\hline E1, E2, EE2 & $\begin{array}{l}\text { Conventional } \\
\text { activated sludge }\end{array}$ & $\begin{array}{c}\text { Pseudo first order rate constant, } \\
\mathrm{k}_{\mathrm{E} 1}: 162 \pm 25 \mathrm{~L} / \mathrm{g} \mathrm{SS}{ }^{\mathrm{b}} . \mathrm{d}, \mathrm{k}_{\mathrm{E} 2}: 350 \pm 42 \mathrm{~L} / \mathrm{g} \mathrm{SS} \\
\mathrm{d}, \mathrm{k}_{\mathrm{EE} 2}: 8 \pm 2 \mathrm{~L} / \mathrm{g} \mathrm{SS} . \mathrm{d} \\
\mathrm{k}_{\mathrm{E} 1}: 30 \pm 10 \mathrm{~L} / \mathrm{g} \mathrm{SS} . \mathrm{d}, \mathrm{k}_{\mathrm{E} 2}: 460 \pm 60 \mathrm{~L} / \mathrm{g} \mathrm{SS} . \mathrm{d} \\
\mathrm{k}_{\mathrm{EE} 2}: 1.2 \pm 0.3 \mathrm{~L} / \mathrm{g} \mathrm{SS} . \mathrm{d} \\
\mathrm{k}_{\mathrm{E} 1}: 10 \pm 1 \mathrm{~L} / \mathrm{g} \mathrm{SS} . \mathrm{d}, \mathrm{k}_{\mathrm{E} 1} \cdot \mathrm{red}^{\mathrm{a}}: 52 \pm 2 \mathrm{~L} / \mathrm{g} \mathrm{SS} . \\
\mathrm{d}, \mathrm{k}_{\mathrm{E} 2}: 175 \pm 10 \mathrm{~L} / \mathrm{g} \mathrm{SS} . \mathrm{d}, \mathrm{k}_{\mathrm{EE} 2}: 1.2 \pm 0.3 \mathrm{~L} / \mathrm{g} \\
\text { SS. d }\end{array}$ & $\begin{array}{l}\text { Batch studies, aerobic } \\
\text { condition } \\
\text { Batch studies, anoxic } \\
\text { condition } \\
\text { Batch studies, anaerobic } \\
\text { condition }\end{array}$ & Joss et al. (2004) \\
\hline $\begin{array}{l}\text { E1, E2, E3, } \\
\text { EE2 }\end{array}$ & $\begin{array}{l}\text { Nitrosomonas } \\
\text { europaea } \\
\text { from nitrifying } \\
\text { activated sludge }\end{array}$ & $\begin{array}{l}\text { First order reaction rate constant, } \mathrm{k}_{\mathrm{E} 1}: 0.056 \mathrm{~h}^{-1} \text {, } \\
\mathrm{k}_{\mathrm{E} 2}: 1.3 \mathrm{~h}^{-1}, \mathrm{k}_{\mathrm{E} 3}: 0.030 \mathrm{~h}^{-1}, \mathrm{k}_{\mathrm{EE} 2}: 0.035 \mathrm{~h}^{-1}\end{array}$ & $\begin{array}{l}\text { Batch studies with initial } \\
\text { concentration of } 1 \mathrm{mg} / \mathrm{L}\end{array}$ & Shi et al. (2004) \\
\hline E2, EE2 & $\begin{array}{l}\text { Cultures established } \\
\text { from lake water and } \\
\text { sediments }\end{array}$ & $\begin{array}{l}\text { No anaerobic degradation of EE2 } \\
\text { over long incubation period (over } \\
\text { three years), E2 transformation rate of E2 to E1 } \\
\text { under all four anaerobic } \\
\text { conditions varied between } 99-176 \mu \mathrm{gL}^{-1} \text { day }^{-1}\end{array}$ & $\begin{array}{l}\text { Initial concentration } 5 \mathrm{mg} / \mathrm{L}, \\
\text { methanogenic, sulphate-, iron-, } \\
\text { and nitrate-reducing anaerobic } \\
\text { conditions }\end{array}$ & $\begin{array}{l}\text { Czajka and } \\
\text { Londry (2006) }\end{array}$ \\
\hline E2 & $\begin{array}{l}\text { Acclimated aerobic } \\
\text { activated sludge }\end{array}$ & $\begin{array}{c}\text { First order reaction rate constant, } \mathrm{k}_{\mathrm{E} 2}: 3.54- \\
3.47 \mathrm{~h}^{-1} \text { (did not change in investigated } \\
\text { temperature change) }\end{array}$ & $\begin{array}{c}\text { Initial concentration varied } 5- \\
15 \mu \mathrm{g} / \mathrm{L} \text { at temperature range } \\
10-30^{\circ} \mathrm{C} .\end{array}$ & $\begin{array}{l}\text { Zeng et al. } \\
\text { (2009b) }\end{array}$ \\
\hline E1, E2, EE2 & $\begin{array}{l}\text { Nitrifying activated } \\
\text { sludge from } \\
\text { a membrane } \\
\text { bioreactor }\end{array}$ & $\begin{array}{l}\text { Pseudo first order rate constant, } \mathrm{k}_{\mathrm{E} 1}: 38.400 \pm \\
3.601 \mathrm{~L} / \mathrm{g}_{\mathrm{vss}} \cdot \mathrm{d}, \mathrm{k}_{\mathrm{E} 2}: 47.040 \pm 3.924 \mathrm{~L} / \mathrm{g}_{\mathrm{vss}} . \mathrm{d} \\
\mathrm{k}_{\mathrm{EE} 2}: 6.720 \pm 4.101 \mathrm{~L} / \mathrm{g}_{\mathrm{vss}} \cdot \mathrm{d}\end{array}$ & $\begin{array}{l}\text { Initial concentration varied } \\
\text { between } 126-170 \mathrm{ng} / \mathrm{L}\end{array}$ & $\begin{array}{l}\text { Estrada-Arriaga } \\
\text { and Mijaylova } \\
\text { (2010) }\end{array}$ \\
\hline $\operatorname{Tr}$ & $\begin{array}{l}\text { Culture enriched } \\
\text { from swine manure }\end{array}$ & $\begin{array}{l}\text { First-order mineralization rate constant, } \\
\text { k: } 0.005 \text { to } 0.072 \mathrm{~h}^{-1}\end{array}$ & $\begin{array}{l}\text { Aerobic condition, } 3 \mathrm{mg} / \mathrm{L} \\
\text { initial concentration at } 22^{\circ} \mathrm{C}\end{array}$ & $\begin{array}{l}\text { Yang et al. } \\
\text { (2011) }\end{array}$ \\
\hline
\end{tabular}

"SS: suspended solids, VSS: volatile suspended solids, E1: estrone, E2: 17 $\beta$-estradiol, E3: estriol, EE2: 17 $\alpha$-ethinylestradiol, Tr: testosterone ${ }^{a} \mathrm{E} 1$ is reduced to $\mathrm{E} 2$ under anaerobic condition 


\subsubsection{Adsorption}

Adsorption to sewage sludge is important because it represents a removal pathway with the excess sludge and often cited as the first stage of biodegradation. Batch experiments of adsorption at multiple concentrations usually involves construction of sorption isotherms and determining a characteristics value (Clara et al., 2004). Distribution coefficient $\left(K_{d}\right)$ is the most commonly used characteristics value, defined as a ratio of equilibrium concentration of a dissolved adsorbate in a two-phase system consisting of sewage sludge and water as shown in eq. (2.3):

$K_{d}=\frac{C_{s}}{C_{w}}$

Where, $C_{S}$ is the concentration in the solids in $\mathrm{ng} / \mathrm{kg}$ and $C_{W}$ is the concentration in water in $\mathrm{ng} / \mathrm{l}$. Often Freundlich sorption isotherm is used to define partition of a compound between two phases as described by following:

$C_{s}=K_{F} \times C_{w}{ }^{n}$

$K_{F}$ and $n$ are called Freundlich parameters and in case of linear isotherms $(\mathrm{n}=1), K_{F}$ corresponds to $K_{d}$ value. In some studies, the $K_{d}$ value is normalized to organic matter $\left(K_{O M}\right)$ and/ organic carbon content $\left(K_{O C}\right)$ of the sorbent (eqs. (2.5) and (2.6)).

$K_{O M}=K_{d} \times \frac{T S S}{V S S}$

$K_{O C}=K_{d} \times \frac{100}{\% O C}$

Where, VSS and TSS are volatile and total suspended solid concentrations respectively. $O C$ represents the percentage of organic carbon present in the sewage sludge.

Clara et al. (2004) and Andersen et al. (2005) investigated sorption of E1, E2, E3 and EE2 onto activated sewage sludge and developed Freundlich sorption isotherms. From the fitted data, the Freundlich parameter, $n$, is found to be near unity, suggesting that the sorption of estrogenic compounds can be described by linear adsorption. The calculated distribution coefficient $\left(\log K_{d}\right)$ for the estrogens varied from 2.60 to 2.84 and is well within the range where sorption is a 
relevant removal process. Despite the high initial concentration, the batch experiments did not reach saturation indicating very high adsorption potential of sewage for estrogenic hormones (Clara et al., 2004). In another study, Ren et al. (2007) described sorption of E1, E2, E3, EE2 and equol onto sewage sludge deactivated by heat treatment. Although batch experimental data fitted well to Freundlich isotherm, in contrast to previous studies, they observed sorption behavior independent of the $K_{o w}$ values of respective compounds. Thermodynamic analysis suggested that sorption of estrogens can be regarded as an exothermic, reversible and physical process, whereas, sorption of equol was an endothermic, irreversible, chemical process. Zheng et al. (2009b) studied sorption and biodegradation of E2 simultaneously, under aerobic conditions in both activated and inactivated sludge. The experimental data agreed well with both Freundlich and linear model, conforming to the previous studies. Concentration profiles of E2 in aqueous, solid and mixed liquor revealed that removal was achieved by sorption onto solid and subsequent biodegradation by the microorganisms. No significant difference has been found between the sorption onto activated and inactivated sludge (Clara et al., 2004; Zeng et al., 2009a; StevensGarmon et al., 2011). Measured sorption (expressed in terms of $K_{d}$ and $\log K_{o c}$ ) of estrogenic and androgenic hormones were reported to be comparable between the primary sludge (PS) and WAS in a WWTP and between nitrifying activated sludge of two different WWTPs (StevensGarmon et al., 2011). For E1, E2 and EE2, $K_{d}$ varied from 533 to $1550 \mathrm{~L} / \mathrm{kg}$ SS, which is higher compared to the $K_{d}(130$ to $170 \mathrm{~L} / \mathrm{kg} \mathrm{SS})$ of androgenic hormones (e.g., Tr and Ad).

The effect of redox condition on adsorption has been studied by Li et al. (2011), who demonstrated that compared to anoxic and aerobic, anaerobic condition favored the sorption. Thus, recalcitrant estrogens like EE2 are prone to accumulation in sewage sludge under anaerobic condition. Zeng et al. (2009b) observed that sorption of E2 decreased with increasing temperature suggesting the reactions of exothermic nature. For a reduction of $10^{\circ} \mathrm{C}$ temperature, they observed $20 \%$ increases in both $K_{d}$ and $K_{F}$. Besides the temperature effect, Clara et al. (2004) studied sorption behavior of estrogens at high $\mathrm{pH}$ and found no detectable change up to $\mathrm{pH}$ 9. However, 30 to $50 \%$ of the initially adsorbed estrogens were desorbed between $\mathrm{pH} 9$ to 10 , which corresponds to the range of $p K a$ values of the compounds studied. This is of special interest during sludge digestion which sometimes involves application of lime to elevate the $\mathrm{pH}$ of the sludge. Although readily biodegradable nature of most of the estrogenic hormones suggest that biodegradation plays a more significant role than sorption (Andersen et al., 2005; Li et al., 
2005), sorption is likely to be important in the case of persistent compounds and under anoxic or anaerobic conditions. Under anaerobic condition $K_{d}$ values of estrogenic compounds (E1, E2 and EE2) in digested sludge are shown to be in the same range ( $\left.\log K_{d}: 2.1-2.9\right)$ of that of in PS and WAS. Despite the changes in operating condition of the digesters (e.g. SRT, temperature, pretreatment etc.), the sorption properties remained unaffected (Carballa et al., 2008).

\subsection{Fate of steroidal compounds in engineered processes}

Although current WWTPs are designed on the basis of nitrogen, carbon and phosphorous removal, partial removal of EDCs have been attained in many cases. Table 2.5 presents a wide variation in removal performances of existing WWTP in different countries. These variations emphasize the importance of site-specific parameters on the removal of these compounds. The data in Table 2.5 also show the presence of these compounds in the effluents in varying concentration, which is considered to be the most significant pathway through which steroidal compounds enter the environment. This indicates the need for optimizing the existing facilities in terms of their operational parameters such as SRT, and hydraulic retention time (HRT) etc.

Typical municipal WWTPs consist of preliminary, primary and secondary treatment units; in addition, tertiary treatment is often included in the case of discharging the effluent in surface water bodies. Although each unit contributes more or less to the overall removal efficiency of the plant, secondary treatment, namely biological treatment, plays the most important role in removing steroidal hormones (Andersen et al., 2003; Koh et al., 2008). In the following sections, the fates of these compounds are discussed along the treatment train in a conventional AS system.

\subsubsection{Fate of steroidal compounds during conventional WWTPs}

\subsubsection{Preliminary treatment}

As preliminary treatment removes very little or no organic substances, it is unlikely to impart a significant effect of preliminary treatment on the incoming hormone loading to a WWTP (Khanal et al., 2006; Teske and Arnold, 2008). Figure 2.4 shows a conventional WWTP with the possible release or transformation of the EDCs in various unit processes indicated by dotted arrows. In addition to the PS and WAS, the liquid phase is also a potential source of EDCs. 
Table 2.5 Occurrence and fate of some hormones in wastewater treatment plants (WWTPs) (concentration expressed in ng/L)*

\begin{tabular}{|c|c|c|c|c|c|c|}
\hline Target hormone & Influent & Effluent & $\begin{array}{c}\text { Removal } \\
(\%)\end{array}$ & Treatment process & Sample type & References \\
\hline \multicolumn{7}{|l|}{ Estrogens } \\
\hline \multirow{8}{*}{ Estrone (E1) } & 40 & $-^{\mathrm{d}}$ & 83 & ASS & $\begin{array}{l}\text { Flow proportional } \\
\text { composite }\end{array}$ & Ternes et al. (1999b) \\
\hline & $25-132$ & $2.5-8.2$ & -22 to 95 & $\operatorname{ASS}(12-14 \mathrm{hr})^{\mathrm{b}}$ & $\begin{array}{l}\text { Flow proportional } \\
\text { composite }\end{array}$ & Baronti et al. (2000) \\
\hline & 44 & 17 & 61 (mean) & $\operatorname{ASS}(12-14 \mathrm{hr})$ & $\begin{array}{l}\text { Time proportional } \\
\text { composite }\end{array}$ & $\begin{array}{l}\text { D'Ascenzo et al. } \\
\text { (2003) }\end{array}$ \\
\hline & $29-670$ & N.D ${ }^{c}-72$ & $\begin{array}{l}-111 \text { to } \\
100\end{array}$ & $\begin{array}{c}\text { ASS, ASS+N, P removal, } \\
\text { MBR }\end{array}$ & $\begin{array}{l}\text { Flow proportional } \\
\text { composite }\end{array}$ & Clara et al. (2005) \\
\hline & $20-130$ & $<0.3-11$ & - & $\begin{array}{c}\mathrm{ASS}+\mathrm{N}, \mathrm{P}(\text { chemical }) \\
\text { removal }\end{array}$ & $\begin{array}{l}\text { Flow proportional } \\
\text { composite }\end{array}$ & Vethaak et al. (2005) \\
\hline & $57.8-83.3$ & $6.3-49.1$ & $41-89$ & TF, ASS & Grab & $\begin{array}{l}\text { Chimchirian et al. } \\
\text { (2007) }\end{array}$ \\
\hline & $64.5-116.0$ & $22.4-8.6$ & $81-86$ & $\begin{array}{c}\text { ASS, ASS+N removal, RBC, } \\
\text { Oxidation ditch }\end{array}$ & $\begin{array}{l}\text { Flow proportional } \\
\text { composite }\end{array}$ & Ifelebuegu (2011) \\
\hline & 20.2 & 10.2 & $\begin{array}{c}49.5 \\
(\text { mean })\end{array}$ & ASS & $\begin{array}{c}\text { Time proportional } \\
\text { composite }\end{array}$ & Zhang et al. (2011) \\
\hline \multirow{7}{*}{$\begin{array}{l}17 \beta \text {-Estradiol } \\
\text { (E2) }\end{array}$} & 21 & - & 99.9 & ASS & $\begin{array}{l}\text { Time proportional } \\
\text { composite }\end{array}$ & Ternes et al. (1999b) \\
\hline & $4.0-25$ & $0.35-3.5$ & $59-98$ & $\operatorname{ASS}(12-14 \mathrm{hr})$ & $\begin{array}{c}\text { Flow proportional } \\
\text { composite }\end{array}$ & Baronti et al.(2000) \\
\hline & 11 & 1.6 & 85 (mean) & $\operatorname{ASS}(12-14 \mathrm{hr})$ & $\begin{array}{l}\text { Time proportional } \\
\text { composite }\end{array}$ & $\begin{array}{l}\text { D'Ascenzo et al. } \\
\quad(2003)\end{array}$ \\
\hline & $35-125$ & N.D -30 & $44-100$ & $\begin{array}{c}\text { ASS, ASS+N, P removal, } \\
\text { MBR }\end{array}$ & $\begin{array}{l}\text { Flow proportional } \\
\text { composite }\end{array}$ & Clara et al. (2005) \\
\hline & $2.4-26$ & $0.2-14.7$ & $\begin{array}{l}-18.5 \text { to } \\
98.8\end{array}$ & $\begin{array}{l}\text { ASS, ASS+N removal, } \\
\text { Lagoon }(3 \text { to }>150 \mathrm{hr})\end{array}$ & $\begin{array}{l}\text { Flow proportional } \\
\text { composite }\end{array}$ & Servos et al. (2005) \\
\hline & $17-150$ & $<0.8$ & - & $\begin{array}{c}\mathrm{ASS}+\mathrm{N}, \mathrm{P}(\text { chemical }) \\
\text { removal }\end{array}$ & $\begin{array}{l}\text { Flow proportional } \\
\text { composite }\end{array}$ & Vethaak et al. (2005) \\
\hline & $15.67-82.55$ & $0.9-3.9$ & $83-97$ & $\begin{array}{c}\text { ASS, ASS+N removal, RBC, } \\
\text { Oxidation ditch }\end{array}$ & $\begin{array}{l}\text { Flow proportional } \\
\text { composite }\end{array}$ & Ifelebuegu (2011) \\
\hline
\end{tabular}


Table 2.5 Continued from previous page

\begin{tabular}{|c|c|c|c|c|c|c|}
\hline Target hormone & Influent & Effluent & $\begin{array}{c}\text { Removal } \\
(\%)\end{array}$ & Treatment process & Sample type & References \\
\hline $17 \alpha-\mathrm{E} 2$ & $<0.7-15$ & $<0.4$ & $-^{\mathrm{d}}$ & $\begin{array}{c}\mathrm{ASS}+\mathrm{N}, \mathrm{P}(\text { chemical }) \\
\text { removal }\end{array}$ & $\begin{array}{c}\text { Flow proportional } \\
\text { composite }\end{array}$ & Vethaak et al. (2005) \\
\hline \multirow{4}{*}{ Estriol (E3) } & $24-188$ & $0.43-18$ & $77-99$ & $\operatorname{ASS}(12-14 \mathrm{hr})$ & $\begin{array}{l}\text { Flow proportional } \\
\text { composite }\end{array}$ & Baronti et al. (2000) \\
\hline & 72 & 2.3 & 97 (mean) & $\operatorname{ASS}(12-14 \mathrm{hr})$ & $\begin{array}{l}\text { Time proportional } \\
\text { composite }\end{array}$ & $\begin{array}{l}\text { D'Ascenzo et al. } \\
\text { (2003) }\end{array}$ \\
\hline & $23-660$ & $\begin{array}{l}\text { N.D }{ }^{\mathrm{c}}- \\
275\end{array}$ & $18-100$ & $\begin{array}{c}\text { ASS, ASS+N, P removal, } \\
\text { MBR }\end{array}$ & $\begin{array}{l}\text { Flow proportional } \\
\text { composite }\end{array}$ & Clara et al. (2005) \\
\hline & $138-381$ & $<1-4.9$ & $>7$ & $\begin{array}{l}\text { ASS, ASS+N, P removal, } \\
\quad \text { MBR }(1.2-13.7 \mathrm{hr})^{\mathrm{b}}\end{array}$ & $\begin{array}{l}\text { Flow proportional } \\
\text { composite }\end{array}$ & Drewes et al. (2005) \\
\hline \multirow{6}{*}{$\begin{array}{l}17 \alpha- \\
\text { ethinylestradiol } \\
(E E 2)\end{array}$} & $0.40-13$ & N.D. -1.7 & $52-100$ & $\operatorname{ASS}(12-14 \mathrm{hr})$ & $\begin{array}{l}\text { Flow proportional } \\
\text { composite }\end{array}$ & Baronti et al. (2000) \\
\hline & $<0.3-5.9$ & $<0.3-2.6$ & - & $\begin{array}{c}\mathrm{ASS}+\mathrm{N}, \mathrm{P}(\text { chemical }) \\
\text { removal }\end{array}$ & $\begin{array}{l}\text { Flow proportional } \\
\text { composite }\end{array}$ & Vethaak et al. (2005) \\
\hline & $3-70$ & N.D -5 & $33.3-100$ & $\begin{array}{c}\text { ASS, ASS+N, P removal, } \\
\text { MBR }\end{array}$ & $\begin{array}{l}\text { Flow proportional } \\
\text { composite }\end{array}$ & Clara et al. (2005) \\
\hline & $<0.7-14.4$ & $<0.7-4.1$ & $71-93$ & $\begin{array}{l}\text { ASS, ASS+N, P removal, } \\
\quad \operatorname{MBR}(1.2-13.7 \mathrm{hr})\end{array}$ & $\begin{array}{l}\text { Flow proportional } \\
\text { composite }\end{array}$ & Drewes et al. (2005) \\
\hline & 6.3 & N.D & 55 & ASS & $\begin{array}{l}\text { Time proportional } \\
\text { composite }\end{array}$ & Zhang et al. (2011) \\
\hline & $0.5-1.54$ & $0.3-0.5$ & $41-58$ & $\begin{array}{c}\text { ASS, ASS+N removal, RBC, } \\
\text { Oxidation ditch }\end{array}$ & $\begin{array}{c}\text { Flow proportional } \\
\text { composite }\end{array}$ & Ifelebuegu (2011) \\
\hline $\begin{array}{l}16 \alpha- \\
\text { hydroxyestrone }\end{array}$ & 1.0 & - & 68 & ASS & $\begin{array}{c}\text { Flow proportional } \\
\text { composite }\end{array}$ & Ternes et al. (1999b) \\
\hline $\begin{array}{l}17 \alpha- \\
\text { dihydroequilin }\end{array}$ & $23.8 \pm 3.2$ & $23.6 \pm 0.6$ & 1.0 & TF, ASS & Grab sample & $\begin{array}{l}\text { Chimchirian et al. } \\
(2007)\end{array}$ \\
\hline \multicolumn{7}{|l|}{ Androgens } \\
\hline \multirow{2}{*}{$\begin{array}{l}\text { Androstenedione } \\
\text { (Ad) }\end{array}$} & $802 \pm 162$ & $\begin{array}{c}18.9 \pm 5.9 \\
8\end{array}$ & 97 & ASS with $\mathrm{N}$ and $\mathrm{P}$ removal & $\begin{array}{l}24 \mathrm{hr} \text { composite } \\
\text { samples }\end{array}$ & Fan et al. (2011) \\
\hline & $31.1 \pm 5.1$ & $5.5 \pm 0.3$ & 82 & ASS with $\mathrm{N}$ and $\mathrm{P}$ removal & $\begin{array}{c}24 \text { hr composite } \\
\text { samples }\end{array}$ & Liu et al. (2012a) \\
\hline
\end{tabular}


Table 2.5 Continued from previous page

\begin{tabular}{|c|c|c|c|c|c|c|}
\hline Target hormone & Influent & Effluent & $\begin{array}{c}\text { Removal } \\
(\%)\end{array}$ & Treatment process & Sample type & References \\
\hline \multirow{2}{*}{$\begin{array}{l}\text { Androsterone } \\
\text { (An) }\end{array}$} & $2264 \pm 492$ & $17.1 \pm 8.0$ & 99 & ASS with $\mathrm{N}$ and $\mathrm{P}$ removal & $\begin{array}{c}24 \mathrm{hr} \text { composite } \\
\text { samples }\end{array}$ & Fan et al. (2011) \\
\hline & $229 \pm 10.6$ & N. D & 100 & ASS with $\mathrm{N}$ and $\mathrm{P}$ removal & $\begin{array}{c}24 \mathrm{hr} \text { composite } \\
\text { samples }\end{array}$ & Liu et al. (2012a) \\
\hline \multirow{2}{*}{ Testosterone (Tr) } & $62.7 \pm 7.3$ & $1.2 \pm 0.2$ & 98 & ASS with $\mathrm{N}$ and $\mathrm{P}$ removal & $\begin{array}{c}24 \mathrm{hr} \text { composite } \\
\text { samples }\end{array}$ & Fan et al. (2011) \\
\hline & $8.9 \pm 1.0$ & $1.5 \pm 0.2$ & 83 & ASS with $\mathrm{N}$ and $\mathrm{P}$ removal & $\begin{array}{c}24 \mathrm{hr} \text { composite } \\
\text { samples }\end{array}$ & Liu et al. (2012a) \\
\hline \multicolumn{7}{|l|}{ Progestagens } \\
\hline \multirow[t]{2}{*}{ Progesterone $(\operatorname{Pr})$} & $33.1 \pm 8.0$ & $5.0 \pm 1.1$ & 84 & ASS with $\mathrm{N}$ and $\mathrm{P}$ removal & $\begin{array}{c}24 \mathrm{hr} \text { composite } \\
\text { samples }\end{array}$ & Fan et al. (2011) \\
\hline & $12.2 \pm 1.9$ & $1.1 \pm 0.1$ & 90 & ASS with $\mathrm{N}$ and $\mathrm{P}$ removal & $\begin{array}{c}24 \mathrm{hr} \text { composite } \\
\text { samples }\end{array}$ & Liu et al. (2012a) \\
\hline
\end{tabular}




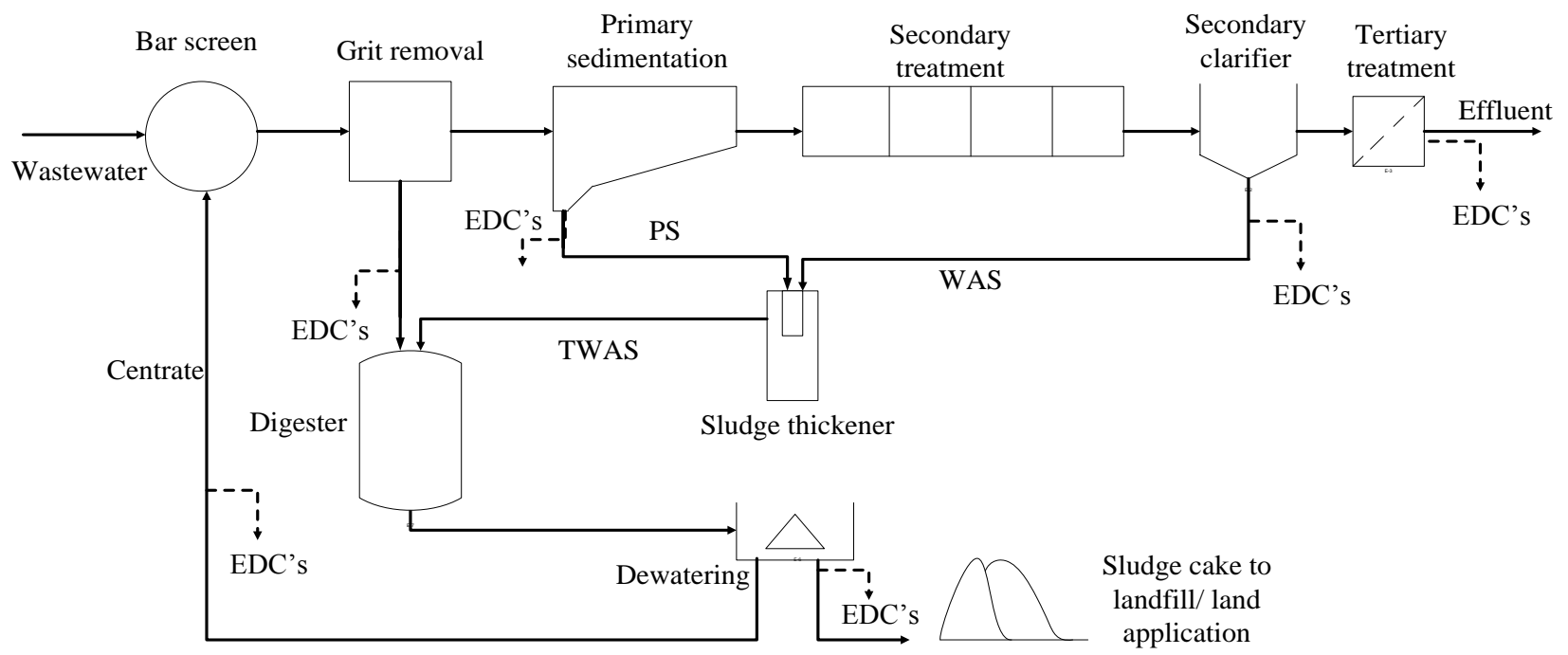

Figure 2.4 Typical setup of a wastewater treatment plant showing wastewater sludge production and the split arrows indicate EDC release/transformation during various unit processes of treatment (Barnabe et al., 2009) (EDC's: endocrine disrupting compounds, PS: primary sludge,

WAS: waste activated sludge, TWAS: thickened WAS)

\subsubsection{Primary treatment}

Possible removal pathways of steroids during primary treatment is by partitioning with fat, oil and grease and/or sorption onto PS and subsequent removal by flotation or sedimentation (Khanal et al., 2006). The degree of target compound removed is largely determined by physiochemical properties of compound, e.g. hydrophobicity, suspended solid content of the wastewater and their settling characteristics, and retention time in the settling tank etc. (Koh et al., 2008). Khanal et al. (2006) described a model to predict the removal of moderately hydrophobic estrogenic compounds (Table 2.1) by sludge sorption and sedimentation. Based on this model, mass of PS, partition coefficient of estrogens and HRT are the three governing factors for estrogen removal during primary treatment. Studies have described the fate of estrogenic compounds during primary treatment with very little (Carballa et al., 2004; Zhang et al., 2011) or no removal at all (Servos et al., 2005; Ying et al., 2008). Interestingly, some of these studies (Carballa et al., 2004; Ifelebuegu, 2011; Liu et al., 2012a) identified an increasing trend of a number hormones (e.g., E1, Ad, An, Pr, Tr) concentration after primary treatment. Deconjugation of the steroid conjugates in the aqueous phase mediated by fecal microbes (e.g, $E$. coli) can attribute to this phenomenon. In addition, transformation of one hormone to another 
(e.g., E3 and E2 transformed to E1) can also contribute to this (Fan et al., 2011; Liu et al., 2012a).

\subsubsection{Secondary treatment}

Secondary or biological treatment plays the most significant role in removing micropollutants like steroidal compounds in a WWTP. During biological treatment, these pollutants are adsorbed onto the micro-flocs and subsequently biodegraded by the microbial growth (Khanal et al., 2006; Zeng et al., 2009b). Therefore, both adsorption and biodegradation determine the fate of hormones in this step. However, the type of process, i.e. trickling filter, AS, bio-contactors etc., also influence the extent of biodegradation by controlling the population dynamics of the microbes. Conventional AS is the most widely used secondary treatment for municipal and industrial wastewater treatment and has been reported to show better attenuation of estrogenic hormones compared to other treatment options. Baronti et al. (2000) reported average removal efficiencies for E1, E2, E3 and EE2 to be $61 \%, 87 \%, 95 \%$ and 85\%, respectively, in six Roman municipal WWTPs with AS process. Similar type of studies (Komori et al., 2004; Chimchirian et al., 2007; Tan et al., 2007; Furlong et al., 2010) suggested efficient removals for E2 and E3, ranging between $90-99 \%$. On the other hand, a variable removal has been observed in case of E1; often a net increase in E1 concentration in the effluent has been reported (Baronti et al., 2000; Carballa et al., 2004; Servos et al., 2005; Hashimoto et al., 2007). Oxidation of E2 to E1 by the microorganisms under aerobic condition and stability of the estrone conjugates, especially sulfate conjugates, are presumably the main reason behind the lower removal of E1 compared to other natural estrogens. Despite being present in smaller concentration than natural estrogens, EE2 persists in the effluent (Table 2.5) because of its recalcitrant nature.

Comparative studies (Ternes et al., 1999b; Servos et al., 2005; Chimchirian et al., 2007; Fernandez et al., 2007) revealed that trickling filter is less effective at removing estrogenic compounds from wastewater than AS system. In an attempt to understand the fate of estrogenic compounds, Servos et al. (2005) studied 18 municipal WWTPs in Canada and found greater concentration of E1 and E2 and increased estrogenicity in the secondary effluent of a trickling filter. Similar observations were made by Svenson et al. (2003) and Fernandez et al. (2007) while investigating the change of estrogenicity in a trickling filter using in-vitro bioassay. In another study (Jiang et al., 2005), an extensive two-stage trickling filter with two-stage post 
sedimentation showed comparable removal with AS system. In addition to AS and trickling filter system, some other biological treatment options (e.g. bio-contactors, oxidation ditch, stabilization pond etc.) mainly used for small, rural areas have been studied for their hormone removal efficiency in several studies (Svenson et al., 2003; Hashimoto et al., 2007; Froehner et al., 2011; Ifelebuegu, 2011). These studies show that, apart from AS system, oxidation ditch is capable of attenuating different classes of steroids successfully (Ifelebuegu, 2011; Liu et al., 2012a) because of the aerobic nature of the treatment and longer SRT/HRT compared to the other processes (Hashimoto et al., 2007).

\subsubsection{Nutrient removal processes}

Conventional AS system with nutrient removal process has been reported to show augmented (ranging between 80 and 100\%, Table 2.5) steroidal hormone removal (Andersen et al., 2003; Fan et al., 2011; Liu et al., 2012a). Natural estrogens are shown to be degraded in both denitrifying and nitrifying conditions; nitrifying being more efficient at removing both natural and synthetic hormones (e.g., EE2) (Andersen et al., 2003). This is in agreement with the findings of Vader et al. (2000), who showed that AS enriched with nitrifying bacteria strains is capable of biodegrading EE2. In contrast to estrogens, androgens and progestagens have shown better removal in anoxic and anaerobic tanks during AS process (Fan et al., 2011; Liu et al., 2012a). A recent study (McAdam et al., 2010) reported biodegradation efficiencies for total estrogens to be $51 \%, 80 \%$ and $91 \%$ for carbonaceous, nitrification/denitrification and nitrification processes, respectively. Despite the lowest degradation efficiency and underdeveloped autotrophic community leading incomplete nitrification, carbonaceous AS actually showed that the highest biomass activity ( $\mu \mathrm{g}$ of estrogen degraded $\mathrm{kg}^{-1}$ of biomass day ${ }^{1}$ ). This implies the importance of heterotrophic community for effective biodegradation; also suggests that process conditions (hormone loading, SRT, HRT etc.) may play a more significant role than nitrification solely.

Sludge retention time and HRT have been postulated to be important parameters for removal of steroidal compounds during biological treatment. Although, no statistical correlation exists between SRT/HRT and removal during biological treatment, an apparent higher removal is associated with longer SRT and HRT (Andersen et al., 2003; Kreuzinger et al., 2004; Servos et al., 2005; Hashimoto et al., 2007). Kreuzinger et al. (2004) hypothesized that higher SRT allows 
the enrichment of slow growing bacteria and provides a more diverse bio-consortium, enabling increased biodegradation of micropollutants compared to biological processes with lower SRT. The resultant relationship from biodegradation data of McAdam et al. (2010) and Koh et al. (2009) suggests that $>70 \%$ biodegradation is achievable employing an SRT > 10 days and more than $80 \%$ biodegradation is possible for SRT over 20 days. Similar findings by Clara et al. (2005) points out a 'critical SRT' of 10 days at a temperature $10^{\circ} \mathrm{C}$, below which low concentration of micropollutants cannot be achieved. In addition to SRT and HRT, Joss et al. (2004) hypothesized the importance of estrogen loading by considering a potential for limited biodegradation caused by competitive substrate inhibition. A moderate positive correlation $\left(\mathrm{r}^{2}=\right.$ 0.55 ) between total estrogen loading and average biomass activity suggests that it is possible to observe concentration dependent removal by applying appropriate loading in a full-scale WWTP (McAdam et al., 2010).

\subsubsection{Fate of estrogenic compounds during sludge stabilization}

Several studies (Joss et al., 2004; Andersen et al., 2005; Khanal et al., 2006) have also pointed out the tendency of steroidal hormones to partition with sludge flocs during biological wastewater treatment because of their moderately high to low $\log K_{o w}$ (ranging between 2.5 4.0) value. Depending on the process utilized for volatile content stabilization, i.e. microbial degradation, chemical oxidation, application of heat, most commonly used digestion processes are anaerobic digestion, aerobic digestion, alkali stabilization, composting and heat drying (Tchobanoglous et al., 2002). The physical, chemical, biological and mechanical changes occurring during biosolids treatment train can influence the adsorption, degradation and to a smaller extent volatilization and photolysis of micropollutants (Barnabe et al., 2009). Due to the complex composition of sludge and associated matrix interferences during quantitative analysis, the number of studies describing fate of EDCs during sludge stabilization process is smaller compared to the fate studies along the liquid stream treatment train. In the following sections, fate of steroids, namely estrogenic compounds, is described during different sludge stabilization processes.

\subsubsection{Anaerobic digestion}

Anaerobic digestion is a biosolids treatment method that converts the organic waste into methane-enriched biogas and fertilizer by combined action of a mixed community of 
microorganisms. Stabilization of high-strength organic waste, production of heat or electricity by recovered methane, and reduced greenhouse gas emissions have made anaerobic digestion more favorable in today's world. As shown in Figure 2.5, anaerobic digestion is mainly a three step process: hydrolysis, acetogenesis and methanogenesis.

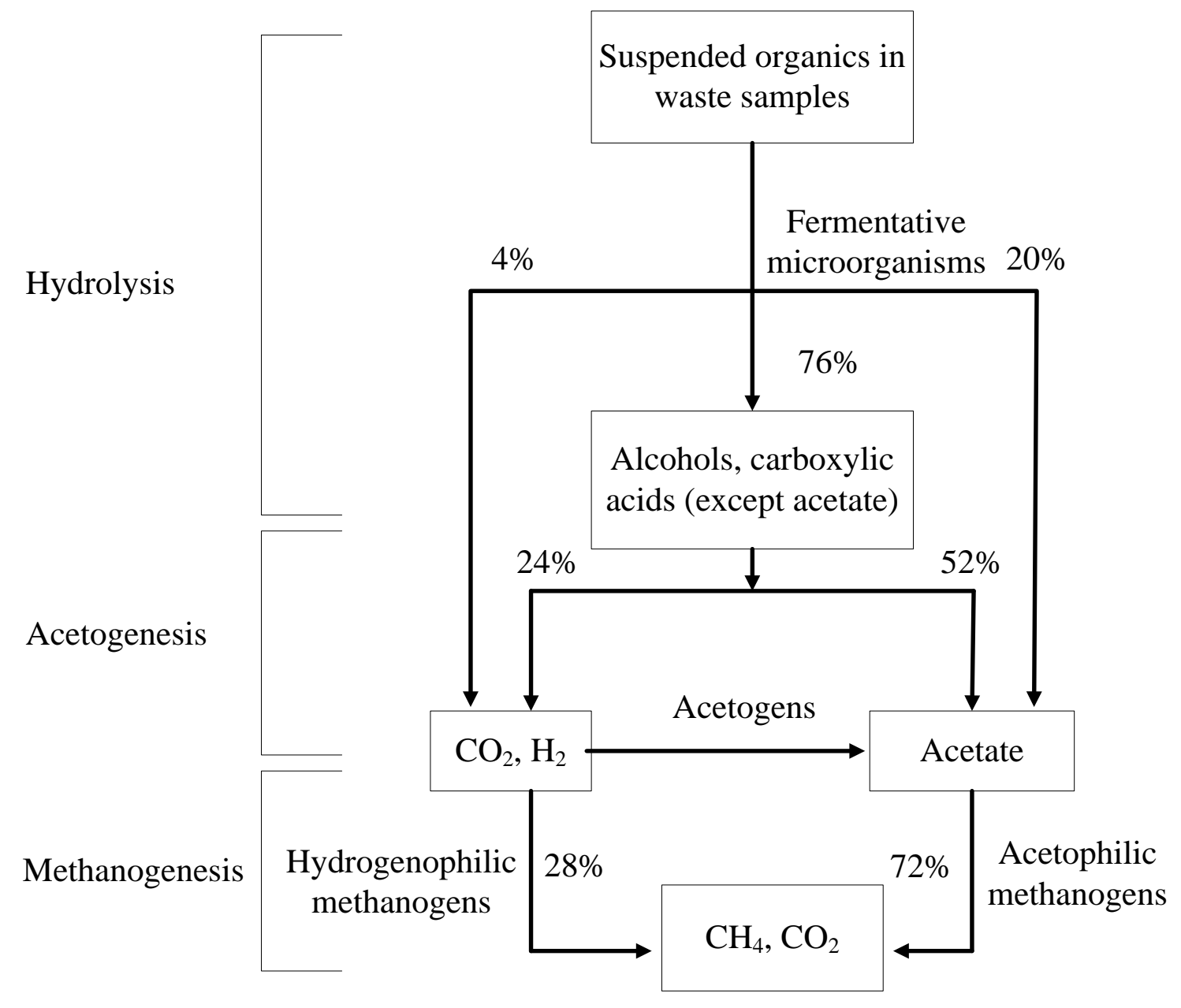

Figure 2.5 Steps of anaerobic digestion process (Droste, 1997)

During hydrolysis, high molecular weight organic substances (e.g., protein, carbohydrates, lipids etc.) are converted to low molecular weight soluble organics (e.g., amino acids and fatty acids) by the action of exocellular enzymes. The hydrolyzed organics then splits up into alcohols and higher organic acids. These compounds are converted into simpler compounds like volatile fatty acids (VFA) (e.g., acetic, propionic, butyric, valeric), $\mathrm{CO}_{2}$ and $\mathrm{H}_{2}$ during the acetogenesis 
phase. Finally, the methane former microorganisms produces $\mathrm{CH}_{4}$ and $\mathrm{CO}_{2}$ utilizing the products of acetogenesis phase (Botheju and Bakke, 2011).

Major drawbacks of conventional anaerobic digestion, such as longer retention time requirement (20 - 50 days), low organic degradation efficiency $(20-50 \%)$ are often thought to be associated with hydrolysis (Tyagi and Lo, 2011). Recent developments in this field indicate that thermal (i.e., conventional and microwave heating) (Ge et al., 2010; Wett et al., 2010; Yu et al., 2010), mechanical (e.g., high pressure homogenizer, sonication, stirred ball mills etc.) (Onyeche, 2006; Wood et al., 2009; Salsabil et al., 2010) and chemical (e.g., acidic and alkaline, ozonation etc.) (Lin et al., 2009; Kim and Youn, 2011) pretreatments applied to complex organic waste (i.e. industrial and municipal sludge, manure) prior to anaerobic digestion can substantially accelerate the hydrolysis of biosolids and subsequent methane recovery in digesters with smaller volume/foot print. Different processes, e.g., bulking and foaming, dewatering, conditioning, are also shown to improve after pretreatment (Muller, 2000; Tyagi and Lo, 2011). Due to the aforementioned advantages, there are a number of proprietary advanced hydrolysis processes currently being applied at the full-scale, i.e., Cambi $^{\mathrm{TM}}$, Microsludge ${ }^{\mathrm{TM}}$, Sonix ${ }^{\mathrm{TM}}$, OpenCEL ${ }^{\mathrm{TM}}$ (Jolly and Gillard, 2009; Pilli et al., 2011).

Among different pretreatment techniques, thermal hydrolysis is one of the most commonly used techniques in full-scale application. Thermal energy disrupts the gel like structure of sludge, releases the lined water and improves anaerobic digester performance (Skiadas et al., 2005). In addition to increased methane recovery, improved pathogen destruction and dewaterability has also been observed after thermal pretreatment (Pino-Jelcic et al., 2006; Carballa et al., 2009; Yu et al., 2009). Although conventional heating involving high temperature and pressure has been used so far in the full-scale, a growing interest can be identified towards application of thermal hydrolysis by microwave (MW) irradiation in lab-scale digesters. This is mostly because of its volumetric and uniform heating with rapid processing time (Mudhoo and Sharma, 2011). Initially, MW irradiation (below boiling point of water) at $2.45 \mathrm{GHz}$ using kitchen type MW oven has shown to effectively break the complex polymeric network of WAS and disintegrate the organic macromolecules (e.g., protein, polysaccharides and nucleic acids). Later, pretreatment of thickened WAS (TWAS) with bench-scale MW unit and pressure sealed vessel resulted in $31 \%$ higher biogas production and $75 \%$ improvement in dewaterability at a 
temperature of $175^{\circ} \mathrm{C}$ (Eskicioglu et al., 2009). More recent studies have suggested that in addition to municipal sludge, degradation and methane yield of industrial sludge (e.g., pulp and paper mill, food wastes etc.) can also be enhanced using MW pretreatment before anaerobic digestion (Beszedes et al., 2011; Saha et al., 2011).

\subsubsection{Fate of steroidal hormones during anaerobic and aerobic digestion}

One of the earliest studies in this field by Holbrook et al. (2002) investigated the changes in total estrogenicity using YES assay in two full-scale sludge treatment facilities employing a doublestage mesophilic anaerobic digestion $\left(35 \pm 2{ }^{\circ} \mathrm{C}\right)$ and a combined three-stage thermophilic $(55 \pm$ $2^{\circ} \mathrm{C}$ ) followed by two-stage mesophilic aerobic digestion. The study revealed an increasing trend of estrogenicity during both mesophilic anaerobic and thermophilic aerobic stages; only mesophilic aerobic treatment showed a slight decrease in estrogenicity. Also, the recycled liquid stream of aerobic digestion showed more estrogenicity compared with that of the anaerobic digestion and is likely to contribute to the influent estrogenicity of the WWTP. About 5 to $10 \%$ of the total influent estrogenicity was present in the processed biosolids. This is similar to the $9 \%$ of $\mathrm{E} 1,1 \%$ of $\mathrm{E} 2$, and $6 \%$ of total E1+E2 being removed with WAS in another study (Braga et al., 2005). In contrast to high removal rate $(75 \%$ - 85\%) reported in pilot-scale study (Carballa et al., 2006), Muller et al. (2010) found no significant (around 30\% - 40\%) removal of three natural $(\mathrm{E} 1+\mathrm{E} 2+\mathrm{E} 3)$ hormones in a full-scale anaerobic digester with similar feed (65:35, v/v, PS:WAS $)$. Also, EE2 concentration increased from below detection limit in the mixed sludge (feed) to $>2$ ng. $\mathrm{g}^{-1} \mathrm{dw}$ in the digested sludge indicating dewatering can result in increase of the estrogen levels in dehydrated sludge, especially in the case of the most hydrophobic estrogens, E2 and EE2 suggesting that the thermal-pressurized treatment applied for stabilization was responsible to increase the extractability of the most tightly bound estrogens. So far, the most comprehensive study in this field by Furlong et al. (2010) suggested aerobic digestion removed most of the natural and synthetic estrogenic compounds successfully and corresponding to $18 \%$ reduction of estrogenicity observed in the YES bioassay. In contrast, thermophilic and mesophilic anaerobic digestion resulted a net increase in estrogenicity as measured by YES bioassay and the contribution of estrogenic hormones to total estrogenicity more than doubled after anaerobic digestion. The well documented transformation of E2 to E1 under different redox conditions (Ternes et al., 1999a; Joss et al., 2004) could not account for high levels of E1 observed in some digested sludge samples. Therefore, the high levels of E3 led to a proposed transformation 
pathway of E3 to E1. If E3 is a potential source of E1 formation, some sludge digestion processes may actually increase the estrogenicity while decreasing estrogen concentration, because of higher estrogenic potency of E1 than E3. Ifelebuegu (2011) analyzed mixed liquor sludge and anaerobically digested sludge in two WWTPs in UK and found a removal efficiency varying between $10 \%-32 \%$ for E1, E2 and EE2. Regarding the effect of pretreatments on hormone removal, Carballa et al. (2006) and Carballa et al. (2007) studied the behavior of 13 micropollutants including estrogens during pilot-scale anaerobic digestion of 70:30, v/v, PS:WAS, preceded by different pre-treatment options, i.e. thermal, alkaline and ozonation. Despite higher biogas production and organic removal from pretreated digesters, little or no effect of operational parameters (temperature, SRT of digesters) and pretreatment condition was observed on the removal efficiencies $(>75 \%)$ of these compounds.

\subsubsection{Chemical sludge stabilization}

Literature describing the fate of estrogenic compounds during sludge stabilization processes, other than aerobic and anaerobic digestion is scarce. Ivashechkin et al. (2004) suggested that alkali stabilization may actually result in removal of estrogenic compounds from the sludge phase to the supernatant due to desorption induced by high $\mathrm{pH}$. In two sampling campaigns in a full-scale lime stabilization process, the lime stabilization appeared to be more effective during winter than in the summer (Furlong et al., 2010). The authors observed most of the monitored estrogenic compounds decreased in the samples; however, the total estrogenicity activity measured by YES bioassay increased approximately four fold, suggesting the need for further research.

\subsection{Analytical techniques for steroidal compounds in sludge samples}

So far, a number of studies developed methods on analytic determination of steroids in water matrices and review of these studies can be found elsewhere (Briciu et al., 2009; KozlowskaTylingo et al., 2010). In this section only the studies reporting concentration of steroids in sludge samples has been reviewed due to the relevance to this research. Inadequacy of the studies addressing fate of the micropollutants during sludge digestion can be attributed to the difficulties associated with quantification of these compounds in sludge phase. Inherent complexity associated with the composition of sludge and very low concentration of these pollutants make it challenging to measure the trace organic contaminants, e.g., estrogens, androgens etc. with high 
accuracy and confidence (Citulski and Farahbakhsh, 2010). Detection and measurement of different natural and synthetic hormones in any sludge sample involves sample stabilization, extraction of the target compounds from sludge matrix, cleaning up the sample and finally quantification. Although sample preparation and adequate clean up steps are of immense importance to minimize the matrix interference during the final quantification step, extensive extraction and clean up may as well result in loss of analytes (Gomes et al., 2004).

After collection, immediate stabilization of the sludge samples is necessary to minimize the microbial activity. Otherwise, degradation of the target compounds, e.g., conversion of E2 to E1, would cause inaccurate measurements (Gomes et al., 2004). Previous literature suggests use of lyophilisation or freeze drying (Ternes et al., 2002; Muller et al., 2008; Nieto et al., 2008; Chiu et al., 2009), autoclaving (Braga et al., 2005) and addition of formaldehyde (Muller et al., 2010) as options for sample preservation techniques.

Quantitative analysis of steroidal compounds in biosolids requires effective as well as selective extraction of target analytes from the matrix constituents. Traditional extraction techniques such as the well-known Soxhlet extraction, sonication (Ternes et al., 2002; Braga et al., 2005; Fan et al., 2011; Liu et al., 2011) and rotary shaking (Gomes et al., 2004; Chiu et al., 2009) have previously been used to extract these compounds from sludge samples. In terms of solvent selection, non-polar and polar aprotic organic solvents such as hexane, acetone, ethyl acetate, are usually used during solvent extraction because of the moderate hydrophobic nature of the target compounds (Citulski and Farahbakhsh, 2010). The major drawbacks of the traditional extraction techniques include longer extraction time and very high solvent consumption. However, a more recent technique called accelerated solvent extraction (ASE) is now being increasingly used for extracting estrogens from sludge samples (Muller et al., 2008; Nieto et al., 2008; Fernandez et al., 2009). In ASE, pressure is applied in the extraction cells to achieve high temperature. By decreasing viscosity and increasing diffusion coefficient of the solvent, high temperature disrupts the analyte-matrix interaction. Also, the high pressure provides better penetration of the solvent in the matrix, which in turn increases the extraction efficiency (Camel, 2001).

Microwave assisted extraction (MAE) is another technique that has been used in several studies to extract estrogenic compounds from river and marine sediments (Liu et al., 2004; 
Labadie and Budzinski, 2005; Hibberd et al., 2009). Greater than $80 \%$ recovery in sediment samples (Matejicek et al., 2007; Hibberd et al., 2009) promotes MAE as a good candidate to extract estrogenic compounds from sludge samples as well. Compared to traditional methods, MAE has the advantage of smaller solvent requirements, reduced extraction time, and multiple sample extractions (Hibberd et al., 2009). Although, the recommended solvents for Soxhlet and sonication can be used for ASE (Camel, 2001), special attention has to be given to the microwave absorbing properties of solvents in MAE. The selected solvent should be able to absorb microwaves but should not over-heat the sample, which may lead to degradation of the analytes. Polar solvents (e.g. methanol, water) have been reported to perform efficiently in MAE (Liu et al., 2004; Labadie and Budzinski, 2005; Matejicek et al., 2007). Due to the reasons explained above, ASE and MAE are advantageous over traditional techniques given that operating parameters, e.g, temperature, pressure, and solvent volume, are optimized considering the nature of sludge matrix that needs to be analyzed.

Mass of the sample used evinced as an important factor to affect recovery of these micropollutants from sludge samples according to related previous studies. Literature suggests extraction of sample amount in a range of $0.1 \mathrm{~g}$ to $1 \mathrm{~g}$ (Table 2.6). Chiu et al. (2009) studied the effect of sample size $(0.1 \mathrm{~g}, 0.2 \mathrm{~g}$ and $0.5 \mathrm{~g})$ on the recovery of estrogens from PS samples and observed that $0.1 \mathrm{~g}$ sludge sample provided $>84 \%$ recovery with excellent repeatability. During quantification of micropollutants, an increase in sample mass is usually associated with increased co-extracted compounds from the matrix and results in matrix interferences during detection techniques (Citulski and Farahbakhsh, 2010). To minimize the effect of co-extracted compounds on quantification, extensive cleanup steps are necessary. As shown in Table 2.6, column chromatography with alumina, silica and florisil as the stationary single layer or in combination has been previously used. Gel permeation chromatography (GPC) is another widely used cleanup technique. In contrast to column chromatography, where separation is achieved by polarity of the compounds, GPC separates the analytes based on their molecular size and is often known as size exclusion chromatography. However most widely used cleanup techniques include solid phase extraction (SPE) alone or in combination with chromatographic techniques. During SPE, the solid phase acts as a selective adsorbent media and separates the analytes from liquid sample. After washing the solid phase to remove any unwanted compounds that has been adsorbed with the target analytes, elution with specific organic solvent is done (Chang et al., 2009). Several 
studies (Ternes et al., 2002; Gomes et al., 2004; Braga et al., 2005) have used octadecyl (C18)bonded silica adsorbent cartridge which is common for reverse phase extraction of non-polar to moderately polar compounds. In addition, another widely used (Muller et al., 2010; Salgado et al., 2010) sorbent is a copolymer of divinylbenzene and vinylpyrrolidone, which has been commercialized under the trade name of Oasis ${ }^{\mathrm{TM}}$-HLB by Waters (Buchberger, 2007). The main reason behind the widespread use of Oasis-HLB is the simultaneous extraction of a wide range of compounds (i.e. acidic, neutral and basic) at neutral pH (Weigel et al., 2004) by a single SPE adsorbent. In addition to the aforementioned solid adsorbents, few studies reported use of aminopropyl bonded silica $\left(\mathrm{LC}-\mathrm{NH}_{2}\right)$ or anion exchange SPE to cleanup the samples after extraction. The selection of eluting solvent to clean and concentrate the analytes must be done carefully. Due to the variation in polarity of steroidal hormones, more polar compounds such as E3 and estrogen conjugates strongly binds them with the stationary phase and needs polar solvents for full recovery (Chiu et al., 2009).

Upon extraction and cleaning, quantification of estrogenic compounds in solid matrix has been achieved by using gas chromatography (GC) or liquid chromatography (LC) followed by mass spectrometry (MS) (Table 2.6). Usually GC/MS(/MS) or LC/MS(/MS) can measure environmental concentration of these micropollutants down to lower ng/L level if efficient extraction and adequate cleanup of the sample are followed (Richardson, 2008). Use of GC/MS in quantifying different EDCs including estrogens is well established. The usual mode of ionization, such as electron impact or chemical ionization, are less susceptible to matrix interferences compared to LC/MS (Buchberger, 2007). However, non-volatile nature of steroidal compounds call for derivatization to give sufficient volatility prior to the injection in GC. For estrogens, silylation is the most commonly used derivatization technique. Among a large number of available silylation reagents, $\mathrm{N}$-(trimethylsilyl) trifluoroacetamide alone or in combination with catalysts, for example trifluoroacetamide/trimethylsilylimidazole/dithioerytrol, is frequently used (Ternes et al., 2002). As shown by Ternes et al. (1999b), use of single GC/MS has a larger possibility of overestimating the environmental concentration, whereas a tandem MS provides better selectivity and requires smaller amount of sample thus decreasing the chances of matrix interferences. Despite the GC being a well established analytical technique, a recent trend towards widespread use of LC/MS (/MS) can be identified. The main advantage of LC is no derivatization, therefore avoids the chances of errors due to side reactions during derivatization 
(Buchberger, 2007). The major drawback is that LC/MS suffers from matrix effects (ion suppression) due to the co-eluting residual matrix constituents, where electrospray ionization (ESI) interface is used and not properly accounted for (Villagrasa et al., 2007). In a recent study, Chiu et al. (2009) has shown that more polar estrogens (E3, E1) exhibited the least signal suppression ( 8 - 18\% versus $10-28 \%$ ) compared to more hydrophobic estrogens such as E2, EE2. Nonetheless, literature proves that extensive cleaning of the samples can actually reduce ion suppression and reliable quantification in the $\mathrm{ng} / \mathrm{L}$ range can be achieved (Nieto et al., 2008; Chiu et al., 2009). Recent development in this field includes use of ultrafast method such as laser diode thermal desorption-atmospheric pressure chemical ionization (LDTD-APCI) coupled to tandem mass spectrometry (MS/MS) (Viglino et al., 2011) to analyze estrogens in different solid matrices including biosolids. This technique uses infrared laser diode to desorb the analyte thermally under atmospheric pressure condition followed by ionization using APCI and introduce the ions directly to the MS thus eliminates the requirement and limitations of liquid mobile phase (Segura et al., 2010). This type of high throughput method can be used for faster and effective quantitative analysis as it is capable of reducing the 5 to $30 \mathrm{~min}$ runs of LC/MS/MS to 10 to $30 \mathrm{sec}$ with good method performance (Viglino et al., 2011). 
Table 2.6 Analytic techniques for estrogenic compounds ${ }^{\mathrm{a}}$

\begin{tabular}{|c|c|c|c|c|c|c|}
\hline Sample & $\begin{array}{l}\text { Sample dry } \\
\text { weight (g) }\end{array}$ & Extraction & Cleaning & $\begin{array}{c}\text { Analytical } \\
\text { technique }\end{array}$ & $\begin{array}{c}\text { Method recovery } \\
\text { ratio }(\%)\end{array}$ & References \\
\hline DS and WAS & 0.5 & $\begin{array}{l}\text { Solvent extraction } \\
\text { with sonication }\end{array}$ & $\begin{array}{l}\text { GPC followed by } \\
\text { silica gel clean up }\end{array}$ & GC-MS/MS & $>70$ & Ternes et al. (2002) \\
\hline DS & 0.2 & $\begin{array}{l}\text { Accelerated solvent } \\
\text { extraction }\end{array}$ & $\begin{array}{l}5 \% \text { deactivated } \\
\text { florisil cleanup }\end{array}$ & LC-MS/MS & $>80$ & Fernandez et al. (2009) \\
\hline WAS & 0.5 & $\begin{array}{l}\text { Solvent extraction } \\
\text { with rotary shaker } \\
\text { (twice) }\end{array}$ & $\begin{array}{l}\text { GPC followed by } \\
\text { SPE }\end{array}$ & $\begin{array}{l}\text { LC/MS or } \\
\text { GC/MS }\end{array}$ & $>75$ & Gomes et al. (2004) \\
\hline PS & 0.1 & $\begin{array}{l}\text { Solvent extraction } \\
\text { with rotary shaker }\end{array}$ & $\begin{array}{l}\text { SPE, GPC, anion- } \\
\text { exchange SPE }\end{array}$ & LC-MS/MS & $>84$ & Chiu et al. (2009) \\
\hline PS and WAS & - & $\begin{array}{c}\text { Accelerated solvent } \\
\text { extraction }\end{array}$ & 2 step SPE & GC-MS & $>90$ & Muller et al. (2008) \\
\hline Raw sewage & $\begin{array}{l}50 \text { mL sludge } \\
\text { sample }\end{array}$ & $\begin{array}{l}\text { Solvent extraction } \\
\text { with sonication }\end{array}$ & SPE & GC-MS & $75-95$ & Braga et al. (2005) \\
\hline Sludge & 1.0 & $\begin{array}{c}\text { Accelerated solvent } \\
\text { extraction }\end{array}$ & Microfiltration & LC-MS/MS & $>81$ & Nieto et al. (2008) \\
\hline
\end{tabular}

aDS: digested sludge; WAS: waste activated sludge; PS: primary sludge; GC: gas chromatography; MS: Mass spectrometry; LC: liquid chromatography; SPE: solid phase extraction; GPC: gel permeation chromatography 


\subsection{Summary}

This chapter presented a review of the sources and occurrence of steroidal compounds as well as their fate during the entire wastewater treatment train. Different batch- and full-scale plant studies indicated biodegradation and sorption of estrogenic and androgenic compounds onto the sludge as relevant removal pathways in WWTPs. Although numerous studies investigating fate of steroidal hormones exist in liquid treatment train of the WWTPs, a research gap has been identified regarding the fate studies during sludge stabilization. This may have been caused mostly because of the difficulties associated with quantifying these micropollutants in sludge at very low level concentrations. Very few studies available in this field investigated the removal and change in estrogenicity during conventional aerobic and anaerobic digestion only. Although, studies indicated inefficient removal from solid phase especially in case of anaerobic digestion, effects of operating parameters, e.g. temperature, SRT, on the attenuation process are not well understood. Also, fate and removal of steroidal hormones are yet to be studied during emerging advanced sludge digestion process for example anaerobic digestion preceded by thermal, mechanical or chemical pretreatments; that are applied at the full-scale for enhanced biodegradation, pathogen removal and sludge dewaterability. Moreover, data on androgenic and progestogenic hormones are scarce. Considering these, the intent of this research was to study the fate and removal of steroidal hormones during anaerobic digestion of municipal waste sludge followed by MW pretreatment (hydrolysis) at a range of pretreatment temperature and digester temperature and SRTs. 


\section{Chapter 3 Effect of microwave hydrolysis on transformation of steroidal hormones during anaerobic digestion of municipal sludge cake}

This chapter aims at quantification of steroidal hormones in Kelowna's municipal sludge cake before and after conventional and advanced digestion coupled with a thermal hydrolysis for enhanced biodegradation and improved digestate (remaining material after digestion utilized as soil amendment) quality. The City of Kelowna operates a sewage treatment plant called Kelowna Pollution Prevention Centre (KPPC). The solid by-products (waste sludge) from the KPPC, produced at an average rate of 2.5 truckloads a day, are dewatered, and then hauled to a composting facility located near the City of Vernon. The stabilized compost material is marketed under the name of Ogogrow as a soil amendment. In recent years, with the alignment of the BC's Energy Plan for reducing greenhouse emissions and for the goal of obtaining energy selfsufficiency by 2020, the City has begun to consider the implementation of an anaerobic digester, an alternative biosolids treatment method to composting. Anaerobic digester converts organic waste, such as biosolids, into a methane rich biogas and fertilizer by a group of microorganisms. Under this scenario, methane recovered from the biosolids during anaerobic digestion can be utilized as part of the landfill biogas system for electricity generation. The anaerobic digester would achieve around 50\% volume reduction of biosolids (experimentally determined in this chapter) and the remaining materials part can be utilized as fertilizer or hauled to the composting facility for further treatment depending on the quality of soil amendment desired.

The benefits of implementing an anaerobic digester versus maintaining the status quo are unclear from the point of removal of contaminants of emerging concern, i.e. hormones, personal care products, pharmaceuticals. The strategic decisions concerning the waste management options require laboratory testing for quantification of target compounds (main goal of this chapter) before and after different digester scenarios. Therefore, the objective of this work was to study the effect of microwave (MW) hydrolysis on fate and removal of 16 steroidal hormones (synthetic and natural) during advanced anaerobic digestion of municipal sludge cake (biosolids). The effect of sludge cake pretreatment temperature $\left(80,120,160^{\circ} \mathrm{C}\right)$, digester operating temperature (mesophilic at $35 \pm 2^{\circ} \mathrm{C}$, thermophilic at $55 \pm 2^{\circ} \mathrm{C}$ ) and digester sludge retention 
time (SRT; 20, 10, 5 days) were evaluated using eight lab-scale semi-continuously fed anaerobic digesters. To determine the potential effect of MW hydrolysis, hormones were quantified in sludge (total) and supernatant (soluble) phase of the digester influent and effluent streams.

The results showed that, 7 out of 16 hormones were above reporting limit (RL) in one or more of the samples. Hormone concentrations upto 1,640 ng/L and $2491 \mathrm{ng} / \mathrm{g}$ (for androstenedione, (Ad)), respectively, were detected in soluble and total phases of the influents. Microwave hydrolysis resulted in both release and attenuation of hormones in the soluble phase. High accumulations (upto 30 times for androstenedione (Ad) of the influent concentration) of hormones observed in the effluents of un-pretreated (control) digesters suggested that anaerobic digestion was inefficient to remove these compounds. This agrees with the previous studies showing anaerobic digestion resulted in increased estrogenicity of digested sludge. Simultaneous accumulation and removal of $17 \beta$-estradiol (E2) and estrone (E1) as well as progesterone $(\operatorname{Pr})$ and androstenedione (Ad) indicated possible transformation among the hormones. MW pretreatment also enhanced volatile solids (VS) removal and methane production compared to unpretreated (control) digesters; however, improvements were more prominent at the shortest SRT (5 days).

\subsection{Materials and methods}

\subsubsection{Substrate and inocula}

Sewage sludge cake was collected bi-weekly from Kelowna Pollution Control Center (KPCC) (British Columbia (BC), Canada), currently serving more than 94,000 population. In this WWTP (Figure 3.1) after preliminary treatment and primary sedimentation, wastewater flows into a modified Bardenpho unit designed to remove $\mathrm{C}, \mathrm{P}$ and $\mathrm{N}$. The secondary effluent then undergoes UV disinfection before discharging into the Okanagan Lake. Fermented and gravity thickened primary sludge (PS) and waste activated sludge (WAS), thickened by a dissolved air flotation unit, are pumped separately and mixed (40:60, v/v) before dewatering by centrifugation. The dewatered sludge cake with a total solids (TS) content of $17.5 \pm 1 \%(\mathrm{w} / \mathrm{w})$ is used for MW pretreatment to minimize the input energy requirement per dry weight. MW pretreated and un-

pretreated (for controls) sludge cakes were mixed with leachate $(<1 \% \mathrm{TS}$, w/w) collected from Glenmore landfill (BC, Canada) and tap water (3:5 in liquid mixture) to attain a typical feed 
concentration of $3.4 \%$ TS (w/w) for anaerobic digesters. Due to restrictions on land availability and limitations on expansion at the KPCC, a potential digester may be located at the local landfill ( $15 \mathrm{~km}$ from the KPCC). Therefore, in future excess leachate of the landfill can be utilized to dilute the sludge cake stream into the digester.

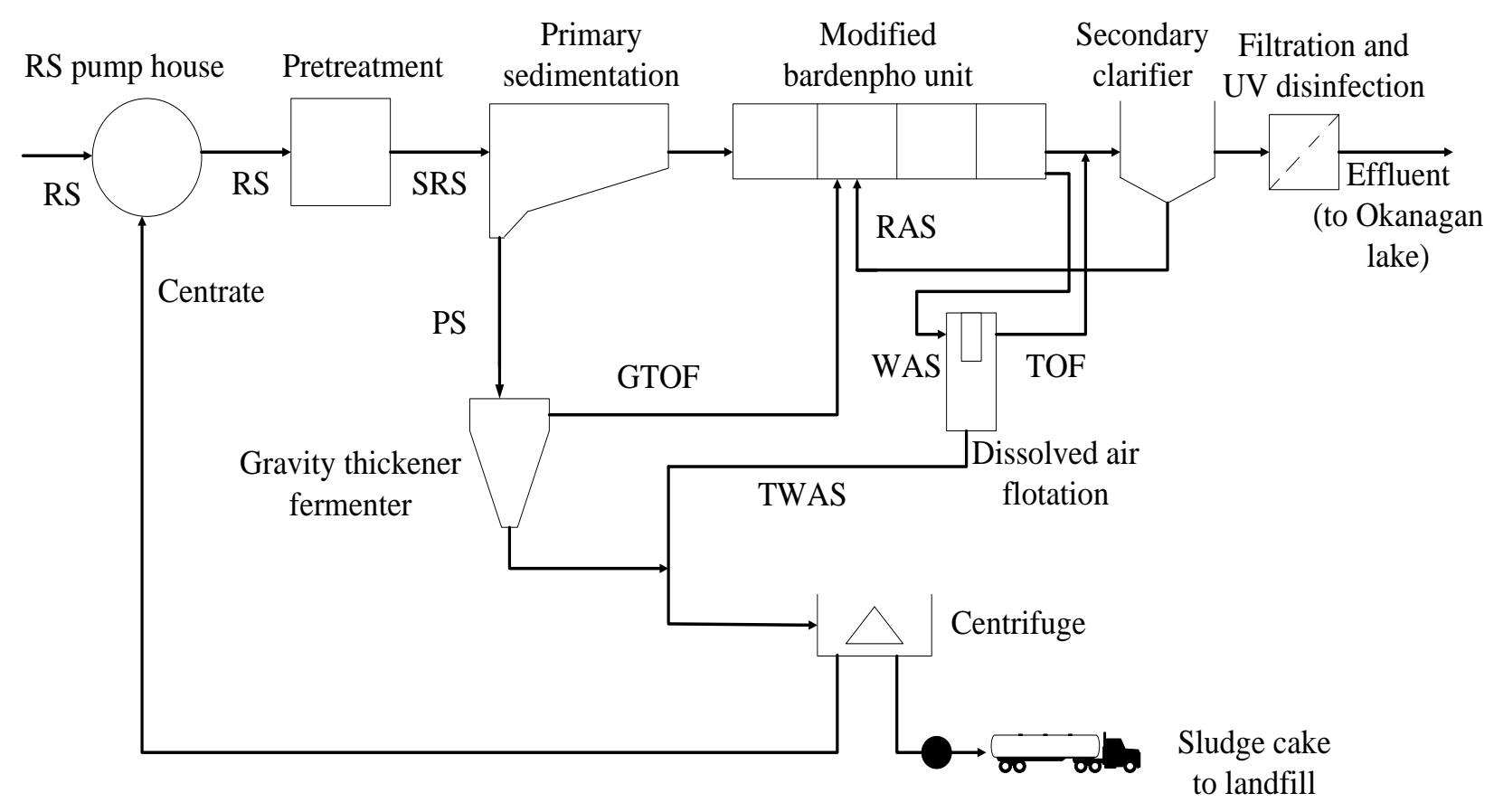

Sampling point

Figure 3.1 Existing process flow diagram in City of Kelowna wastewater treatment plant (GTOF: gravity thickener overflow, PS: primary sludge, RAS: return activated sludge, RS: raw sewage, SRS: screened raw sewage, TOF: thickener overflow, TWAS: thickened waste activated sludge, WAS: waste activated sludge)

For the bench-scale digester studies, the mesophilic and thermophilic inocula were collected from the full-scale anaerobic digesters located at Penticton and Annacis Island WWTPs (BC, Canada), respectively. Prior to actual digester experiments, the inocula were acclimatized to MW pretreated sludge at a temperature of $175^{\circ} \mathrm{C}$ to avoid any possible acute inhibition at elevated hydrolysis temperatures. During acclimation, the initial organic loading rate (OLR) of the digesters was $1.58 \pm 0.27 \mathrm{~g}$ chemical oxygen demand (COD)/L/d at a safe SRT of $20 \mathrm{~d}$. This loading was doubled gradually with a feed concentration ranging between $1.71 \pm 0.15 \%$ to 3.65 $\pm 0.30 \% \mathrm{TS}(\mathrm{w} / \mathrm{w})$. Once the digesters reached steady state (> 10\% variation in biogas 
production) at the final feed concentration, they were maintained at the same condition until the experimentation began. This whole preparation period lasted for a total of 7 months.

\subsubsection{Microwave pretreatment}

A closed-vessel microwave digestion system (ETHOS-EZ, Milestone Inc., Connecticut, USA) operating at $2.45 \mathrm{GHz}$ with maximum power, temperature and pressure of 1200 watts, $300^{\circ} \mathrm{C}$ and 35 bars, respectively was used. ETHOS-EZ is equipped with ATC-400-CE (thermocouple) temperature probe housed in a reference vessel. The unit has 12 pressure sealed vessels $(100 \mathrm{ml}$ each) rotating in a carousal. ETHOS-EZ is easily programmable to heat the sample at different ramping rates and holding times, which allows for optimization of thermal hydrolysis (Figure 3.2).

During hydrolysis, municipal sludge cake was placed in 12 Teflon vessels (45 g each) and irradiated to final desired temperatures of 80,120 and $160^{\circ} \mathrm{C}$. This range of temperature was selected to investigate the thermal effect both above and below boiling point. In order to make the heating profile comparable, a uniform rate of ramping $\left(7.5^{\circ} \mathrm{C} / \mathrm{min}\right)$, a constant holding time ( $1 \mathrm{~min}$ ) and venting time $(25 \mathrm{~min})$ were applied in all three temperatures. After venting, the vessels were cooled down to room temperature $\left(20-22^{\circ} \mathrm{C}\right)$ before opening to avoid any loss of organics by evaporation. The MW irradiated sludge was stored at $4^{\circ} \mathrm{C}$ for digester feed preparation. A previous study investigating the effects of pretreatment temperature $(110,150$ and $\left.175^{\circ} \mathrm{C}\right)$ and ramping rate $\left(3.75\right.$ and $\left.7.5^{\circ} \mathrm{C} / \mathrm{min}\right)$ demonstrated for concentrated TWAS $(11.85 \%$ $\mathrm{TS}$ ) that the ramping rate was not a significant factor in consideration to increased solubilization (Toreci et al., 2010). In accordance with this, the higher ramping rate $\left(7.5^{\circ} \mathrm{C} / \mathrm{min}\right)$ was chosen, which could also minimize the energy input/loss during heating. Table 3.1 displays the characterization of digester feed streams before and after MW pretreatment and dilution. 
a)

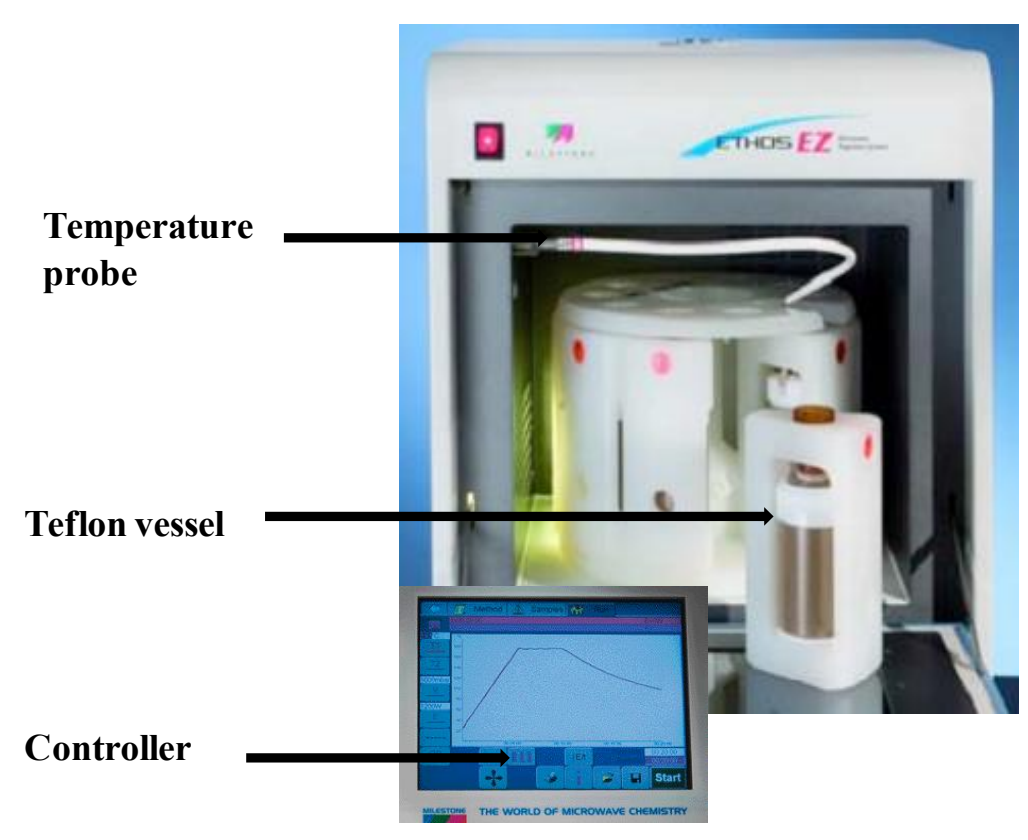

b)

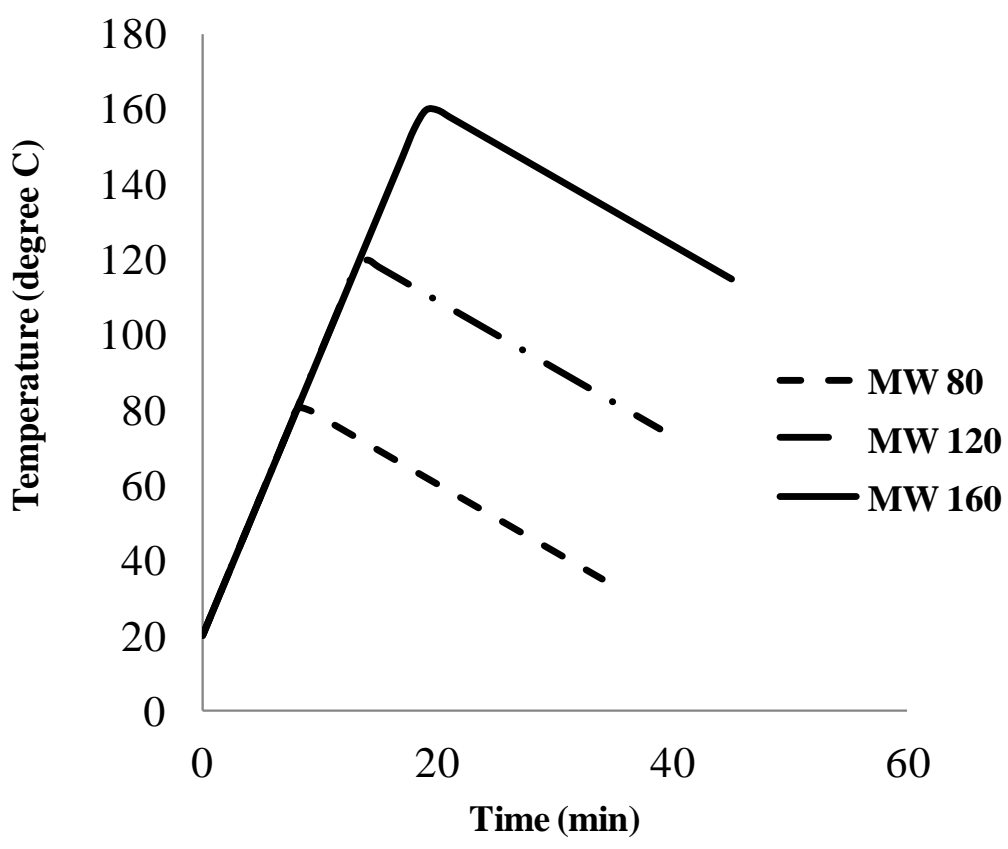

Figure 3.2 a) Ethos microwave station (2.45 GHz, 0 - 1200 Watt, $25-300^{\circ} \mathrm{C}, 0-35$ bars); b) heating and cooling profiles of the microwave unit (MW: microwave, 80, 120 and 160: ultimate pretreatment temperatures in ${ }^{\circ} \mathrm{C}$ unit) 
Table 3.1 Characterization of raw (control) and pretreated digester feed after dilution ${ }^{\mathrm{a}}$

\begin{tabular}{|c|c|c|c|c|}
\hline Parameter & Control & MW80 & MW120 & MW160 \\
\hline $\mathrm{pH}$ & $\begin{array}{c}6.66 \\
(0.38,12)^{b}\end{array}$ & $\begin{array}{c}6.71 \\
(0.31,12)\end{array}$ & $\begin{array}{c}6.75 \\
(0.02,12)\end{array}$ & $\begin{array}{c}6.56 \\
(0.25,12)\end{array}$ \\
\hline $\mathrm{TS}(\%, \mathrm{w} / \mathrm{w})$ & $\begin{array}{c}3.48 \\
(0.31,24)\end{array}$ & $\begin{array}{c}3.38 \\
(0.23,24)\end{array}$ & $\begin{array}{c}3.37 \\
(0.28,24)\end{array}$ & $\begin{array}{c}3.42 \\
(0.19,24)\end{array}$ \\
\hline $\mathrm{VS}(\%, \mathrm{w} / \mathrm{w})$ & $\begin{array}{c}2.74 \\
(0.22,24)\end{array}$ & $\begin{array}{c}2.84 \\
(0.01,24)\end{array}$ & $\begin{array}{c}2.78 \\
(0.2,24)\end{array}$ & $\begin{array}{c}2.85 \\
(0.21,24)\end{array}$ \\
\hline TCOD (mg/L) & $\begin{array}{c}34,743 \\
(1677,24)\end{array}$ & $\begin{array}{c}33,149 \\
(3495,24)\end{array}$ & $\begin{array}{c}37,611 \\
(1589,24)\end{array}$ & $\begin{array}{c}33,786 \\
(3327,24)\end{array}$ \\
\hline $\mathrm{SCOD}(\mathrm{mg} / \mathrm{L})$ & $\begin{array}{c}3,222 \\
(67,4)\end{array}$ & $\begin{array}{c}5,342 \\
(62,4)\end{array}$ & $\begin{array}{c}6,324 \\
(17,4)\end{array}$ & $\begin{array}{c}7,084 \\
(125,4)\end{array}$ \\
\hline Alkalinity $\left(\mathrm{mg} \mathrm{CaCO}_{3} / \mathrm{L}\right)$ & $\begin{array}{c}1636 \\
(150,3)\end{array}$ & $\begin{array}{c}1199 \\
(86,3)\end{array}$ & $\begin{array}{c}953 \\
(46,3)\end{array}$ & $\begin{array}{c}968 \\
(58,3)\end{array}$ \\
\hline $\mathrm{NH}_{3}-\mathrm{N}(\mathrm{mg} / \mathrm{L})$ & $\begin{array}{c}668 \\
(21,2)\end{array}$ & $\begin{array}{c}640 \\
(15,2)\end{array}$ & $\begin{array}{c}305 \\
(46,2)\end{array}$ & $\begin{array}{c}430 \\
(26,2)\end{array}$ \\
\hline \multicolumn{5}{|l|}{ Volatile Fatty Acids } \\
\hline Acetic acid (mg/L) & $\begin{array}{c}795 \\
(343,3)\end{array}$ & $\begin{array}{c}552 \\
(316,3)\end{array}$ & $\begin{array}{c}426 \\
(17,3)\end{array}$ & $\begin{array}{c}241 \\
(80,3)\end{array}$ \\
\hline Propionic acid (mg/L) & $\begin{array}{c}390 \\
(301,3)\end{array}$ & $\begin{array}{c}187 \\
(75,3)\end{array}$ & $\begin{array}{c}98 \\
(45,3)\end{array}$ & $\begin{array}{c}69 \\
(39,3)\end{array}$ \\
\hline Butyric acid (mg/L) & $\begin{array}{c}38 \\
(22,3)\end{array}$ & $\begin{array}{c}21 \\
(0,3)\end{array}$ & $\begin{array}{c}10 \\
(1,3)\end{array}$ & $\begin{array}{c}8 \\
(4,3)\end{array}$ \\
\hline
\end{tabular}

\subsubsection{Digester studies}

A total number of eight, side-armed erlenmeyer flasks (Figure 3.3) with total and liquid volumes of 1 and $0.5 \mathrm{~L}$, respectively, were used as semi-continuous flow digesters (fed once a day). Erlenmeyer flasks were sealed with rubber stoppers and side arms were used to feed the reactors. One sampling port was bored into the rubber stopper to withdraw the sludge from the digester. The second sampling port was connected to $2 \mathrm{~L}$ Tedlar bag for biogas collection. The Tedlar bags were equipped with on/off valves and a septum fitting that was used for gas composition sampling. Volume of daily biogas collected was measured by a manometer. Four of the digesters were operated at the mesophilic temperature $\left(35 \pm 2^{\circ} \mathrm{C}\right)$ and the remaining four were kept at the thermophilic condition $\left(55 \pm 2^{\circ} \mathrm{C}\right)$ in temperature controlled shakers $(90 \mathrm{rpm})$. One of the four digesters at each operating temperature was fed with un-pretreated sludge and was called control, while rests of the three were fed with pretreated sludge at 80,120 and $160^{\circ} \mathrm{C}$ temperature. The 
digesters were run for SRTs of 20, 10 and 5 days. At each operational stage, once the steady state ( $<10 \%$ variation in biogas production rate) has been reached, the digesters were maintained under the identical loading for over a period of three SRTs. Effluents were collected during this time as 7-day composite samples in LDPE bottles and refrigerated at $4^{\circ} \mathrm{C}$ for hormone analysis. Chemical oxygen demand (COD), TS, volatile solids (VS), pH, alkalinity, ammonia, total volatile fatty acids (TVFAs) of effluent and feed along with biogas composition were monitored twice a week. Digester $\mathrm{pH}$ and biogas volumes were measured daily.

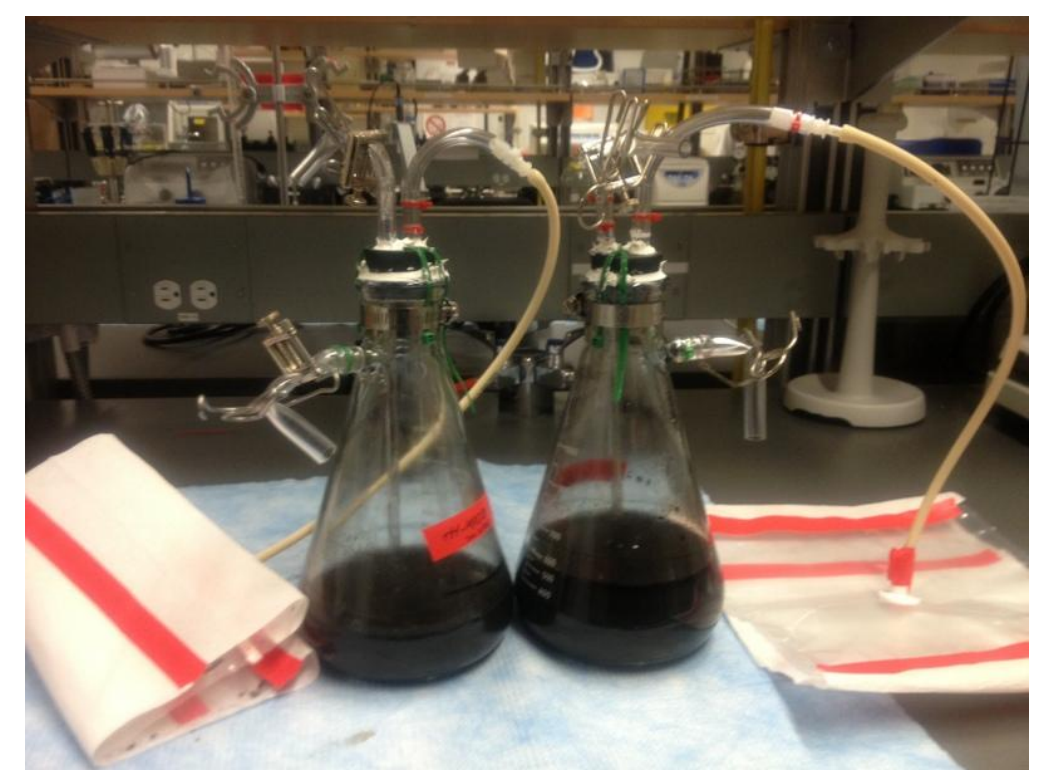

Figure 3.3 Two of the eight lab-scale semi-continuous anaerobic digesters

\subsection{Analytical techniques}

\subsubsection{Characterization of influent and effluent}

Total solids (TS), VS, alkalinity and ammonia were analyzed according to Standard Methods procedure 2540B, 2540E, 2320B and 4500D, respectively (APHA, 2005). The closed reflux colorimetric method was used for COD measurement according to procedure 5250D (APHA, 2005) using Spectronic 20D+ (Thermo-Electron Corporation) spectrophotometer and $600 \mathrm{~nm}$ wavelength absorbencies. Sludge samples were centrifuged for $15 \mathrm{~min}$ at $8,000 \mathrm{rpm}$ and the collected supernatants were used for both ammonia and alkalinity. However, for soluble COD (SCOD) determination, the supernatants were further filtered through $0.45 \mu \mathrm{m}$ pore-sized membrane discs. 
To measure the TVFAs (summation of acetic, propionic and butyric acids), the supernatants were first filtered through membrane discs $(0.2 \mu \mathrm{m}$ pore size $)$ and then injected into an Agilent 7890A Gas Chromatograph (GC). The GC contains a capillary column (Agilent 19091F-112, HP-FFAP polyethylene glycol TPA column length $x$ ID: $25 \mathrm{~m} \times 320 \mu \mathrm{m}$ ) and a flame ionization detector (oven, inlet and outlet temperatures: 200, 220 and $300^{\circ} \mathrm{C}$, respectively, carrier gas flow rate: $25 \mathrm{~mL}$ helium/min) and is equipped with an auto-sampler (Agilent 7693A). The method developed by Ackman (1972) used iso-butyric acid as an internal standard.

An Agilent 7820A GC with a thermal conductivity detector (oven, inlet and outlet temperatures: 70,100 and $150^{\circ} \mathrm{C}$, respectively) and packed column (Agilent G3591-8003/80002) was used to determine the biogas composition $\left(\mathrm{CH}_{4}, \mathrm{CO}_{2}, \mathrm{O}_{2}, \mathrm{~N}_{2}\right.$ percentages) in the headspace of digesters using helium as the carrier gas (flow rate: $25 \mathrm{~mL} / \mathrm{min}$ ). The method was developed by Van Huyssteen (1967).

\subsubsection{Hormone analysis}

Digester effluent and influent samples were centrifuged at 8,000 rpm for $20 \mathrm{~min}$ and the supernatants were collected and filtered through $1 \mu \mathrm{m}$ filter papers. The filtrate $(<1 \mu \mathrm{m})$, which represents the soluble fraction of sample, along with collected influent and effluent samples were used for hormone analysis (Figure 3.4). Digester operation, sampling, centrifugation/filtration was done at the Environmental Engineering Laboratory in the School of Engineering (UBC Okanagan Campus) and samples were shipped in coolers packed with dry ice via overnight courier to a commercial laboratory (AXYS Analytical Services Ltd., Sidney, BC) for extraction/clean-up and subsequent hormone quantification by an LC-MS/MS. Currently, an LCMS/MS is not available at the School of Engineering. Firstly, samples were spiked with surrogates (Table 3.2) and adjusted to the required $\mathrm{pH}$ (2.0) to prevent deuterium-hydrogen exchange occurring between the sample and labeled surrogates. The sludge samples were extracted by sonication with aqueous buffered acetonitrile and with pure acetonitrile, concentrated by rotary evaporation, and diluted with ultra-pure water to $200 \mathrm{~mL}$. Aqueous samples and the diluted extracts of sludge samples were cleaned-up using hydrophilic lipophilic balanced (HLB) solid phase extraction (SPE) cartridges. After addition of recovery standards, the extract was filtered and analyzed by Waters 2795 (or Waters 2695) High Pressure Liquid Chromatograph equipped with a Micromass Quattro Ultima Mass Spectometer and workstations 
running QuanLynx/Masslynx software (LC-MS/MS). The instrument described required a total of two different LC runs in positive and negative ionization modes to analyze a total of 16 hormones displayed in Table 3.2. Instrument calibration was performed using a series of calibration solutions ( 6 points) covering the working concentration range of the instrument $(0.2$ $\mathrm{ng} / \mathrm{mL}$ to $3,000 \mathrm{ng} / \mathrm{mL}$ ) specific for the individual compounds of interest. The LC-MS/MS was run in multiple reaction monitoring mode and quantification was performed by recording the peak areas of the applicable daughter ion of specified parent ion/daughter transitions (AXYS, 2012). The detailed extraction and cleanup steps are provided in Figure 3.5. The concentrations

obtained from the analysis were reported in ng. $\mathrm{g}^{-1}$ dry weight (total phase) and ng.L $\mathrm{L}^{-1}$ (soluble phase) unit.

Ongoing precision recovery (OPR) standards (spiked matrix of the analytes) and procedural blanks were used for quality control purpose. Laboratory performance in terms of OPR recovery and blank levels were compared to established performance criteria (Appendix B, Table B.1). Method detection limits (MDLs) of quantification (Table 3.2) were the levels, at which analytes could be detected in absence of interferences. However, due to complex nature of sludge matrix, a number of compounds other than target analytes present in the sample may affect detection performance. To account for the matrix interferences, sample specific detection limits (SDLs) of the target hormones were determined for each sample run. The SDLs varied mainly depending on the sample type and size and were calculated as the analyte concentration corresponding to a peak with 3:1 signal to noise ratio. The reporting limit (RL) for each target compound was defined as the lowest calibration standard which is higher than MDL, or the SDL, whichever was greater.

\subsubsection{Calculations}

For more than duplicate data points, mean and standard deviation were reported. To determine the significant factors, multi-factor analysis (digester operating temperature, pretreatment temperature and SRT) of variance was used, with $\mathrm{p} \leq 0.05$ for hormones Ad, Pr and E1. Removal efficiency [based on eq. (3.1)] was considered as the response variable for these analyses. During removal efficiency calculations, below detection limits concentrations were assumed to be equal to the RL for that specific sample. Also, total phase concentrations of the analytes initially determined in ng/g were converted into ng/L unit using their TS concentrations (Appendix B, 
Table B.4) for removal efficiency calculation. As the digester feed was prepared in the same manner, and feed characterization results in terms of typical parameters, i.e., TS/VS, CODs etc. showed variations less than $\pm 9 \%$ during the experimental period (January - May, 2012), influent hormone concentrations were assumed to remain the same in the digester feed for the three SRTs studied. As previously mentioned, digester effluent samples were 7-day composite samples.

Removal efficiency $(\%)=\frac{C_{i}-C_{e}}{C_{i}} \times 100$

Where, $C_{i}$ is the concentration of hormone in total $(\mathrm{ng} / \mathrm{L})$ or soluble $(\mathrm{ng} / \mathrm{L})$ phase of the influent, $C_{e}$ is the concentration of hormone in total $(\mathrm{ng} / \mathrm{L})$ or soluble $(\mathrm{ng} / \mathrm{L})$ phase of the effluent.

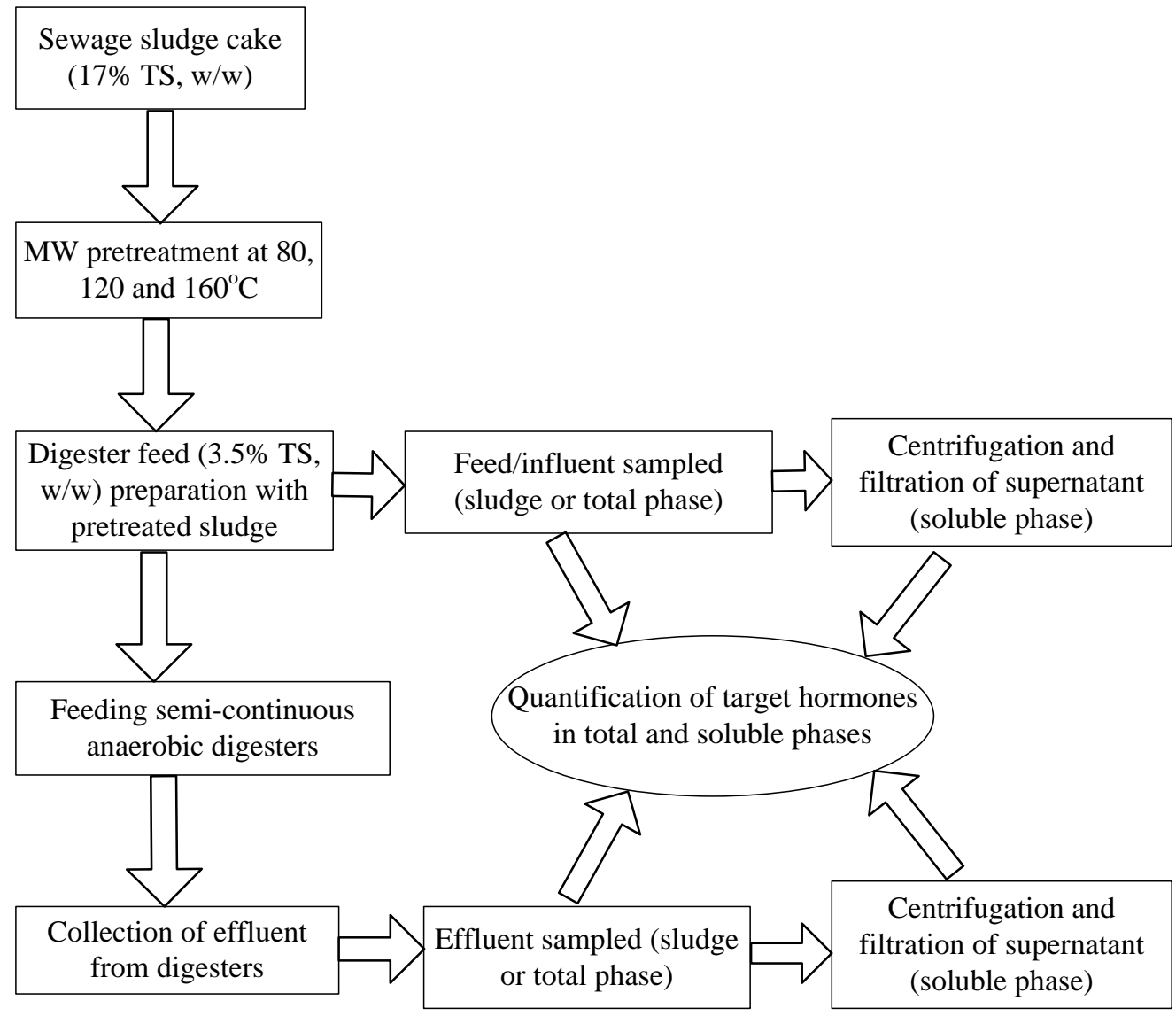

Figure 3.4 Experimental methodology showing sampling locations

(MW: microwave, TS: total solids) 
Table 3.2 Method detection limits, reporting limits and quantification references for analytes, surrogate standards*

\begin{tabular}{|c|c|c|c|c|c|}
\hline \multirow{3}{*}{$\begin{array}{l}\text { Matrix } \\
\text { Units (sample size), (extract volume) } \\
\text { Analyte (ESI positive) }\end{array}$} & \multicolumn{2}{|c|}{ Liquid (supernatant) } & \multicolumn{2}{|c|}{ Solid (sludge) } & \multirow{3}{*}{ Quantified against } \\
\hline & \multicolumn{2}{|c|}{$\mathrm{ng} / \mathrm{L}(0.250 \mathrm{~L}),(4000 \mathrm{uL})$} & \multicolumn{2}{|c|}{$\mathrm{ng} / \mathrm{g}(0.5 \mathrm{~g}),(4000 \mathrm{uL})$} & \\
\hline & MDL & $\mathbf{R L}$ & MDL & $\mathbf{R L}$ & \\
\hline Allyl Trenbolone & 2.64 & 3.2 & 1.32 & 1.6 & $\mathrm{~d}_{6}$-Norethindrone \\
\hline Androstenedione & 1.76 & 8.0 & 0.88 & 4.0 & $\mathrm{~d}_{6}$-Norethindrone \\
\hline Androsterone & 30.3 & 80.0 & 15.1 & 40.0 & $\mathrm{~d}_{6}$-Norethindrone \\
\hline Estriol & 175 & 240 & 88 & 120.0 & $\mathrm{~d}_{6}$-Norethindrone \\
\hline Mestranol & 100 & 64.0 & 50 & 32.0 & $\mathrm{~d}_{6}$-Norethindrone \\
\hline Norethindrone & 2.58 & 80.0 & 1.29 & 40.0 & $\mathrm{~d}_{6}$-Norethindrone \\
\hline Norgestrel & 6.1 & 16.0 & 3.1 & 8.0 & $\mathrm{~d}_{6}$-Norgestrel \\
\hline Progesterone & 3.02 & 16.0 & 1.51 & 8.0 & $\mathrm{~d}_{9}$-Progesterone \\
\hline Testosterone & 1.57 & 3.2 & 0.79 & 1.6 & $\mathrm{~d}_{6}$-Norethindrone \\
\hline \multicolumn{6}{|l|}{ Analyte (ESI negative) } \\
\hline $17 \alpha$-Dihydroequilin & 8.3 & 16.0 & 4.1 & 8.0 & $\mathrm{~d}_{4}-17 \beta$-Estradiol \\
\hline Equilenin & 2.64 & 3.2 & 1.32 & 1.6 & $\mathrm{~d}_{4}-17 \beta$-Estradiol \\
\hline Equilin & 11.7 & 32.0 & 5.9 & 16.0 & $\mathrm{~d}_{4}-17 \beta$-Estradiol \\
\hline $17 \alpha$-Estradiol & 6.6 & 16.0 & 3.3 & 8.0 & $\mathrm{~d}_{4}-17 \beta$-Estradiol \\
\hline 17ß-Estradiol & 14.9 & 16.0 & 7.4 & 8.0 & $\mathrm{~d}_{4}-17 \beta$-Estradiol \\
\hline Estrone & 11.7 & 16.0 & 5.9 & 8.0 & $\mathrm{~d}_{4}-17 \beta$-Estradiol \\
\hline $17 \alpha$-Ethinylestradiol & 38.5 & 20.0 & 19.25 & 10.0 & $\mathrm{~d}_{4}$-Ethinylestradiol \\
\hline \multicolumn{6}{|l|}{ Surrogate standard } \\
\hline $\mathrm{d}_{6}$-Norethindrone & & & & & ${ }^{13} \mathrm{C}_{3}$-Atrazine \\
\hline $\mathrm{d}_{6}$-Norgestrel & & & & & ${ }^{13} \mathrm{C}_{3}$-Atrazine \\
\hline $\mathrm{d}_{9}$-Progesterone & & & & & ${ }^{13} \mathrm{C}_{3}$-Atrazine \\
\hline $\mathrm{d}_{4}-17 \beta$-Estradiol & & & & & ${ }^{13} \mathrm{C}_{6}-2,4,5$-Trichlorophenoxyacetic acid \\
\hline $\mathrm{d}_{4}$-Ethinylestradiol & & & & & ${ }^{13} \mathrm{C}_{6}-2,4,5$-Trichlorophenoxyacetic acid \\
\hline \multicolumn{6}{|l|}{ Recovery standard } \\
\hline${ }^{13} \mathrm{C}_{3}$-Atrazine & & & & & External standard \\
\hline${ }^{13} \mathrm{C}_{6}-2,4,5$-Trichlorophenoxyacetic acid & & & & & External standard \\
\hline
\end{tabular}




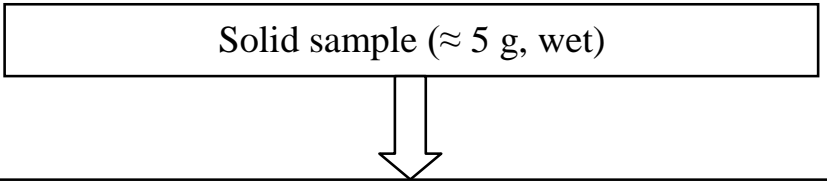

Addition of $15 \mathrm{~mL}$ pH 2.0 phosphate buffer and labeled compounds, vortexing

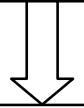

Addition of $20 \mathrm{~mL} \mathrm{CH}_{3} \mathrm{CN}$, sonication of $30 \mathrm{~min}$, centrifuge (approx. $5 \mathrm{~min}$ at $3000 \mathrm{rpm}$ )

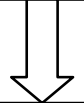

Addition of $15 \mathrm{~mL} \mathrm{pH} 2.0$ phosphate buffer and $20 \mathrm{~mL} \mathrm{CH}_{3} \mathrm{CN}$, vortexing, sonication, centrifugation

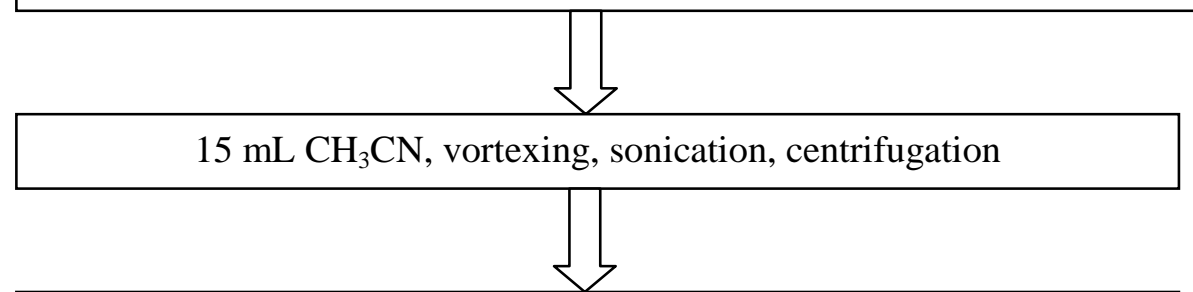

Concentration of extracts by rotary evaporation to $20-30 \mathrm{~mL}$ at $50^{\circ} \mathrm{C}$, dilution with $200 \mathrm{~mL}$ reagent water, addition of $500 \mathrm{mg} \mathrm{Na} \mathrm{N}_{4}$ EDTA

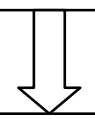

Loading (5-10 $\mathrm{mL} / \mathrm{min})$ of solid extracts and liquid samples to SPE HLB conditioned with $\mathrm{MeOH}(20 \mathrm{~mL})$, Mili-Q water $(6 \mathrm{~mL})$, acidified (pH 2.0) Mili-Q water (6 mL)

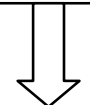

Washing cartridge with $10 \mathrm{~mL}$ water, drying for $5 \mathrm{~min}$, eluting with 12 $\mathrm{mL} \mathrm{MeOH}, 6 \mathrm{~mL}$ acetone: $\mathrm{MeOH}(1: 1)$, drying under $\mathrm{N}_{2}$ stream

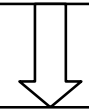

Reconstituting in $3 \mathrm{~mL} \mathrm{MeOH}$, injection of internal standards, diluting to $4 \mathrm{~mL}$ with $0.1 \%$ formic acid buffer, vortexing

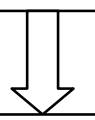

Analysis by LC/MS/MS in MRM mode under ESI+ and ESI- condition

Figure 3.5 Flow chart of analytical determination of steroidal hormones in solid and liquid samples (SPE: solid phase extraction, HLB: hydrophilic lipophilic balanced, MRM: multiple reaction monitoring, ESI: electrospray ionization) 


\subsection{Results and discussion}

\subsubsection{Occurrence of steroids in anaerobic digester streams}

Hormones detected in one or more influent and effluent samples from the lab-scale anaerobic digester utilizing Kelowna sludge cake are presented in Tables 3.3 and 3.4, for both liquid (soluble phase) and solid (total phase) matrixes. Although for most of effluent and influent samples the peak of mestranol (Ms) and androsterone (An) were detected, quantification criteria (Appendix B, Table B.1) were not met. For such cases, concentrations were reported as a ' $\mathrm{K}$ ' flagged value and represented the estimated maximum possible concentration in the soluble phase or total phase matrixes.

During analyses, five of the 16 target hormones were detected in total phases of one or more influent total phase samples. Among these, three were androgenic (Ad, An and Tr), one progestagen (Pr) and one estrogenic (Ms). The majority of the estrogens studied, i.e., E1, E2, E3 and EE2, were below the RL in all the influent samples. Based on the results presented in Table 3.4 , concentrations of $\operatorname{Tr}(4.76-6.29 \mathrm{ng} / \mathrm{g})$ and $\operatorname{Pr}(<4.76-22.7 \mathrm{ng} / \mathrm{g})$ were comparable to previously reported concentrations of hormones in dewatered sludge (Fan et al., 2011; Liu et al., 2011; Liu et al., 2012a); while concentration of $\mathrm{Ad}(<11.9-75.5 \mathrm{ng} / \mathrm{g})$ was slightly higher than the previous studies $(6.7-12 \mathrm{ng} / \mathrm{g})$. Regarding the occurrence of steroids in the soluble phases, six out of 16 hormones were detected in soluble phase of at least one of the influents (Table 3.3). Both E1 and E2 were detected and their concentrations varied in a range of $22.4-92.4 \mathrm{ng} / \mathrm{L}$; while Pr fell below the RL (3.08 - $3.71 \mathrm{ng} / \mathrm{L})$ in the soluble phase. 
Table 3.3 Concentration (ng/L) of steroidal hormones in soluble phase of digester influent and effluents at different SRTs ${ }^{\mathrm{a}}$

\begin{tabular}{|c|c|c|c|c|c|c|c|c|c|c|c|}
\hline \multirow{2}{*}{ Hormones } & \multirow{2}{*}{ Sample } & \multicolumn{4}{|c|}{ Mesophilic } & \multicolumn{4}{|c|}{ Thermophilic } & \multirow{2}{*}{$\begin{array}{c}\text { Lab } \\
\text { blank }\end{array}$} & \multirow{2}{*}{$\begin{array}{c}\text { Spiked } \\
\text { matrix }(\% \\
\text { recovery) }\end{array}$} \\
\hline & & Control & MW80 & MW120 & MW160 & Control & MW80 & MW120 & MW160 & & \\
\hline \multirow{4}{*}{$\begin{array}{l}\text { Androstenedione } \\
\text { (Ad) }\end{array}$} & Influent & 1640 & 480 & $<45.9$ & $<50.3$ & 1640 & 480 & $<45.9$ & $<50.3$ & $<8.00$ & 72.6 \\
\hline & Effluent (20 d) & 732 & 327 & 246 & 156 & 104 & 68.8 & 66.4 & 89.1 & $<13.3$ & 92.1 \\
\hline & Effluent (10 d) & $<18.2$ & $<20.8$ & $<21.4$ & $<22.2$ & 1100 & 1550 & 85.8 & 89.2 & $<20.0$ & 136 \\
\hline & Effluent (5 d) & 1230 & 1370 & 762 & 687 & 703 & 393 & 234 & 413 & $<2.00$ & 71.4 \\
\hline \multirow{4}{*}{$\begin{array}{l}\text { Androsterone } \\
\text { (An) }\end{array}$} & Influent & K 17700 & K 36800 & K 22300 & K 42900 & K 17700 & K 36800 & K 22300 & K 42900 & $<82.2$ & 53.5 \\
\hline & Effluent (20 d) & $<30200$ & $<27200$ & $<30600$ & K 29900 & K 31900 & K 45800 & K 30800 & K 43200 & $<153$ & 88.9 \\
\hline & Effluent (10 d) & K 19500 & K 13400 & K 13200 & K 17400 & K 25000 & K 22700 & K 24300 & K 20100 & K 551 & 170 \\
\hline & Effluent (5 d) & $<890$ & $<807$ & $<613$ & $<271$ & $<1820$ & $<360$ & $<1500$ & $<748$ & $<23.2$ & 64.3 \\
\hline \multirow{4}{*}{ Mestranol (Ms) } & Influent & K 86400 & K 9510 & K 8970 & K 16500 & K 86400 & K 9510 & K 8970 & K 16500 & $<80.0$ & 55.4 \\
\hline & Effluent (20 d) & K 5170 & $<4190$ & $<4800$ & $<4830$ & $<7250$ & $<8500$ & $<3520$ & $<5560$ & $<133$ & 111 \\
\hline & Effluent (10 d) & K 2100 & K 2570 & $<745$ & K 2270 & K 11700 & K 5930 & K 5670 & K 6520 & K 663 & 138 \\
\hline & Effluent (5 d) & K 3700 & K 4280 & K 4210 & K 2770 & K 37800 & K 13700 & K 12600 & K 13600 & K45.9 & 73.7 \\
\hline \multirow{4}{*}{$\begin{array}{l}\text { Progesterone } \\
(\mathrm{Pr})^{\mathrm{b}}\end{array}$} & Influent & $<3.08$ & $<3.12$ & $<3.16$ & $<3.71$ & $<3.08$ & $<3.12$ & $<3.16$ & $<3.71$ & $<3.20$ & 80.3 \\
\hline & Effluent (20 d) & 317 & 218 & 207 & $<5.25$ & 153 & 225 & 154 & 264 & $<5.33$ & 167 \\
\hline & Effluent (10 d) & N.A & N.A & N.A & N.A & N.A & N.A & N.A & N.A & N.A & N.A \\
\hline & Effluent $(5 \mathrm{~d})$ & 359 & 179 & 89.5 & 206 & 1540 & 315 & 245 & 575 & $<0.80$ & 86.4 \\
\hline \multirow{4}{*}{$\begin{array}{l}\text { Testosterone } \\
(\mathrm{Tr})\end{array}$} & Influent & $<3.08$ & 139 & $<3.16$ & $<3.71$ & $<3.08$ & 139 & $<3.16$ & $<3.71$ & $<3.20$ & 72.9 \\
\hline & Effluent (20 d) & $<39.3$ & 136 & 828 & 861 & 405 & 588 & 514 & 965 & $<5.33$ & 90.4 \\
\hline & Effluent (10 d) & $<6.12$ & 46.7 & $<18.2$ & K 396 & K 794 & K 1020 & K 1990 & K 3220 & $<8.00$ & 162 \\
\hline & Effluent $(5 \mathrm{~d})$ & $<62.8$ & $<46.2$ & $<12.0$ & $<75.6$ & $<61.4$ & $<10.6$ & $<48.2$ & $<82.9$ & $<0.80$ & 70.7 \\
\hline
\end{tabular}


Table 3.3 Continued from previous page

\begin{tabular}{|c|c|c|c|c|c|c|c|c|c|c|c|}
\hline \multirow{2}{*}{ Hormone } & \multirow{2}{*}{ Sample } & \multicolumn{4}{|c|}{ Mesophilic } & \multicolumn{4}{|c|}{ Thermophilic } & \multirow{2}{*}{$\begin{array}{c}\text { Lab } \\
\text { blank }\end{array}$} & \multirow{2}{*}{$\begin{array}{l}\text { Spiked matrix } \\
\text { (\% recovery) }\end{array}$} \\
\hline & & Control & MW80 & MW120 & MW160 & Control & MW80 & MW120 & MW160 & & \\
\hline \multirow{4}{*}{$\begin{array}{l}17 \text { beta- } \\
\text { estradiol } \\
\text { (E2) }\end{array}$} & Influent & $<34.0$ & 88.8 & 49.7 & 92.4 & $<34.0$ & 88.8 & 49.7 & 92.4 & $<16.0$ & 96.8 \\
\hline & Effluent (20 d) & $<27.9$ & $<28.0$ & $<27.5$ & $<26.2$ & $<28.4$ & $<30.6$ & $<30.2$ & $<28.5$ & $<26.7$ & 106 \\
\hline & Effluent (10 d) & 27.1 & 65 & 52.2 & 33.3 & 59.3 & 62.9 & 46 & 99.2 & $<40.0$ & 97.2 \\
\hline & Effluent (5 d) & $<60.2$ & $<90.0$ & $<60.2$ & $<42.1$ & $<78.7$ & $<53.1$ & $<53.6$ & $<61.1$ & $<40.0$ & 80.5 \\
\hline \multirow{4}{*}{ Estrone (E1) } & Influent & 58.6 & 28.5 & 22.4 & 36.1 & 58.6 & 28.5 & 22.4 & 36.1 & $<16.0$ & 85.4 \\
\hline & Effluent (20 d) & 94.6 & 100 & 77.9 & 65.9 & 78 & 89.2 & 33 & 59.7 & $<26.7$ & 88.5 \\
\hline & Effluent (10 d) & 112 & 75 & 82.3 & 67.4 & 67.4 & 60.5 & 54.4 & 63 & $<40.0$ & 91.5 \\
\hline & Effluent (5 d) & $<60.2$ & $<90.0$ & $<60.2$ & $<42.1$ & $<78.7$ & $<53.1$ & $<53.6$ & $<61.1$ & $<40.0$ & 84.8 \\
\hline
\end{tabular}

${ }^{\mathrm{a}} \mathrm{K}$ : estimated maximum possible concentration, ' $<$ ': number following this symbol represents the reporting limit (RL), control: un-pretreated, MW: microwave, 80,120 and 160 are the final pretreatment temperatures, lab blank: an aliquot of reagent water that is treated exactly as a sample including exposure to all glassware, equipment, solvents, reagents, internal standards, and surrogates that are used with samples, spiked matrix: matrix containing known quantity of analytes

${ }^{\mathrm{b}}$ Non-quantifiable (NQ) in 10 day SRT effluent 
Table 3.4 Concentration (ng/g of dry weight) of steroidal hormones in total phase of digester influent and effluents at different SRTs ${ }^{\mathrm{a}}$

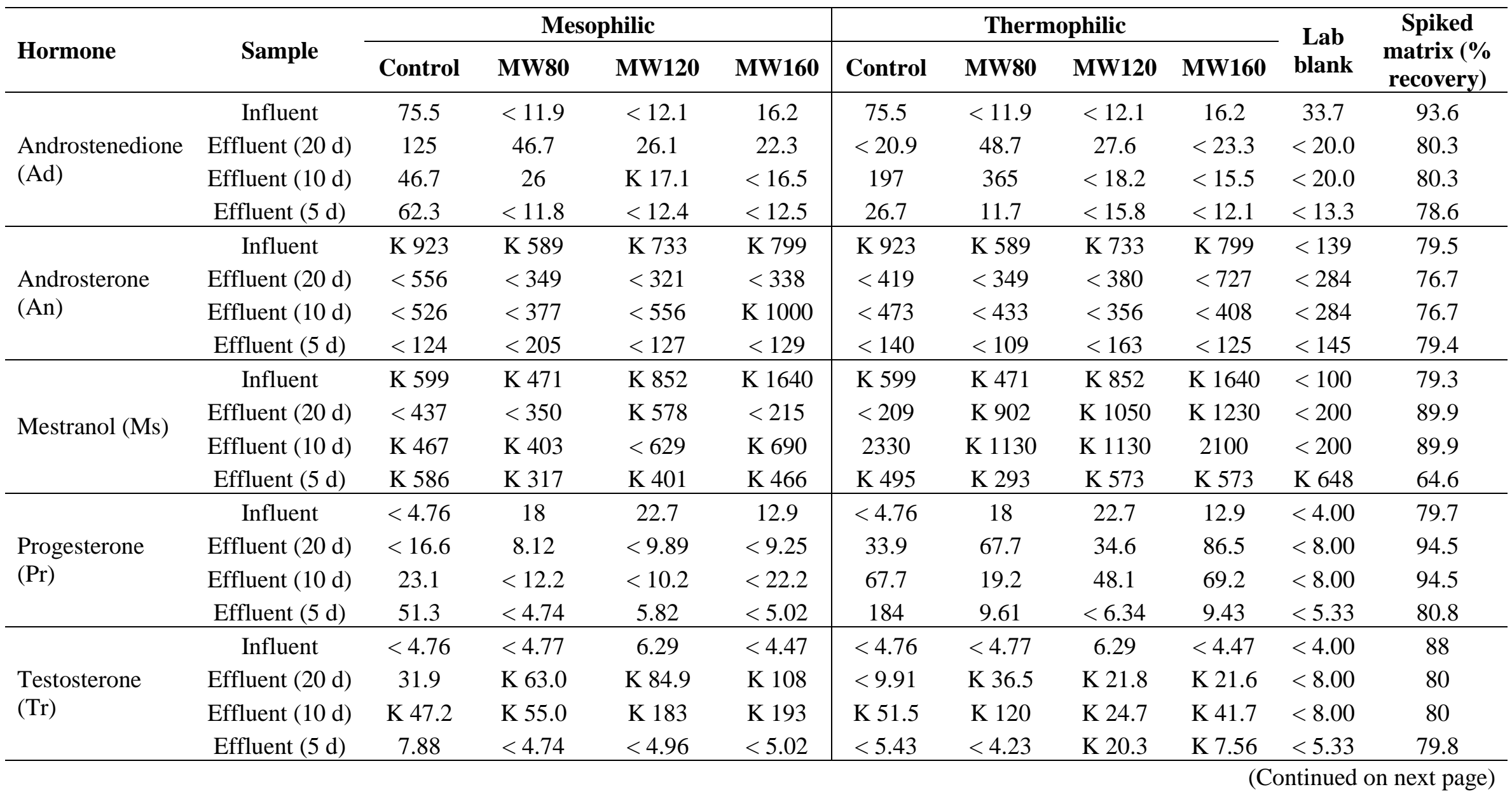


Table 3.4 Continued from previous page

\begin{tabular}{|c|c|c|c|c|c|c|c|c|c|c|c|}
\hline \multirow{2}{*}{ Hormone } & \multirow{2}{*}{ Sample } & \multicolumn{4}{|c|}{ Mesophilic } & \multicolumn{4}{|c|}{ Thermophilic } & \multirow{2}{*}{$\begin{array}{c}\text { Lab } \\
\text { blank }\end{array}$} & \multirow{2}{*}{$\begin{array}{c}\text { Spiked } \\
\text { matrix (\%) } \\
\text { recovery) }\end{array}$} \\
\hline & & Control & MW80 & MW120 & MW160 & Control & MW80 & MW120 & MW160 & & \\
\hline \multirow{4}{*}{$\begin{array}{l}17 \beta \text {-estradiol } \\
(\mathrm{E} 2)\end{array}$} & Influent & $<80.0$ & $<56.0$ & $<77.5$ & $<70.0$ & $<80.0$ & $<56.0$ & $<77.5$ & $<70.0$ & $<20.0$ & 96.4 \\
\hline & Effluent (20 d) & $<37.1$ & $<35.0$ & $<34.5$ & $<43.1$ & $<41.8$ & $<35.4$ & $<39.6$ & $<46.7$ & $<40.0$ & 70.7 \\
\hline & Effluent (10 d) & $<41.0$ & $<37.2$ & $<33.2$ & $<33.0$ & $<42.9$ & $<36.4$ & $<36.4$ & $<31.0$ & $<40.0$ & 70.7 \\
\hline & Effluent (5 d) & $<24.2$ & $<23.7$ & $<24.8$ & $<25.1$ & $<27.2$ & $<21.1$ & $<31.7$ & $<24.2$ & $<40.0$ & 81.6 \\
\hline \multirow{4}{*}{ Estrone (E1) } & Influent & $<23.8$ & $<23.8$ & $<24.3$ & $<22.4$ & $<23.8$ & $<23.8$ & $<24.3$ & $<22.4$ & $<20.0$ & 84.9 \\
\hline & Effluent (20 d) & $<37.1$ & $<35.0$ & $<34.5$ & $<43.1$ & $<41.8$ & $<35.4$ & $<39.6$ & $<46.7$ & $<40.0$ & 80 \\
\hline & Effluent (10 d) & $<41.0$ & $<37.2$ & $<33.2$ & $<33.0$ & $<42.9$ & $<36.4$ & $<36.4$ & $<31.0$ & $<40.0$ & 80 \\
\hline & Effluent (5 d) & $<24.2$ & $<23.7$ & $<24.8$ & $<25.1$ & $<27.2$ & $<21.1$ & $<31.7$ & $<24.2$ & $<40.0$ & 87.5 \\
\hline
\end{tabular}

${ }^{\mathrm{a}} \mathrm{K}$ : estimated maximum possible concentration, ' $<$ ': number following this symbol represents the reporting limit (RL), control: un-pretreated, MW: microwave (80,120 and 160 are the final pretreatment temperatures), lab blank: an aliquot of reagent water that is treated exactly as a sample including exposure to all glassware, equipment, solvents, reagents, internal standards, and surrogates that are used with samples, spiked matrix: matrix containing known quantity of analytes 


\subsubsection{Effects of microwave pretreatment on steroids in digester feed}

As expected, MW pretreatment resulted in a linear particulate COD solubilization with increased temperature as shown in Figure 3.6. However, there was no consistent pattern among different steroidal hormone concentrations with an increase in MW irradiation temperature in soluble (Figure 3.7a) or total phases (Figure 3.7b) of digester feeds. Compared to estrogenic (i.e. E1, E2, EE2), androgenic and progestogenic hormones have been shown to partition with aqueous phase mostly (Esperanza et al., 2007). This study indicated very high concentrations of Ad in the soluble phase of the control (not-pretreated) samples. However, MW pretreatment led to attenuation of these two hormones in both soluble and total phases of the digester influents with an increase in the MW temperature (Figure 3.7a). Similarly, E1 decreased in the soluble phase with an increase in the pretreatment temperature and was below the RL in the total phase.

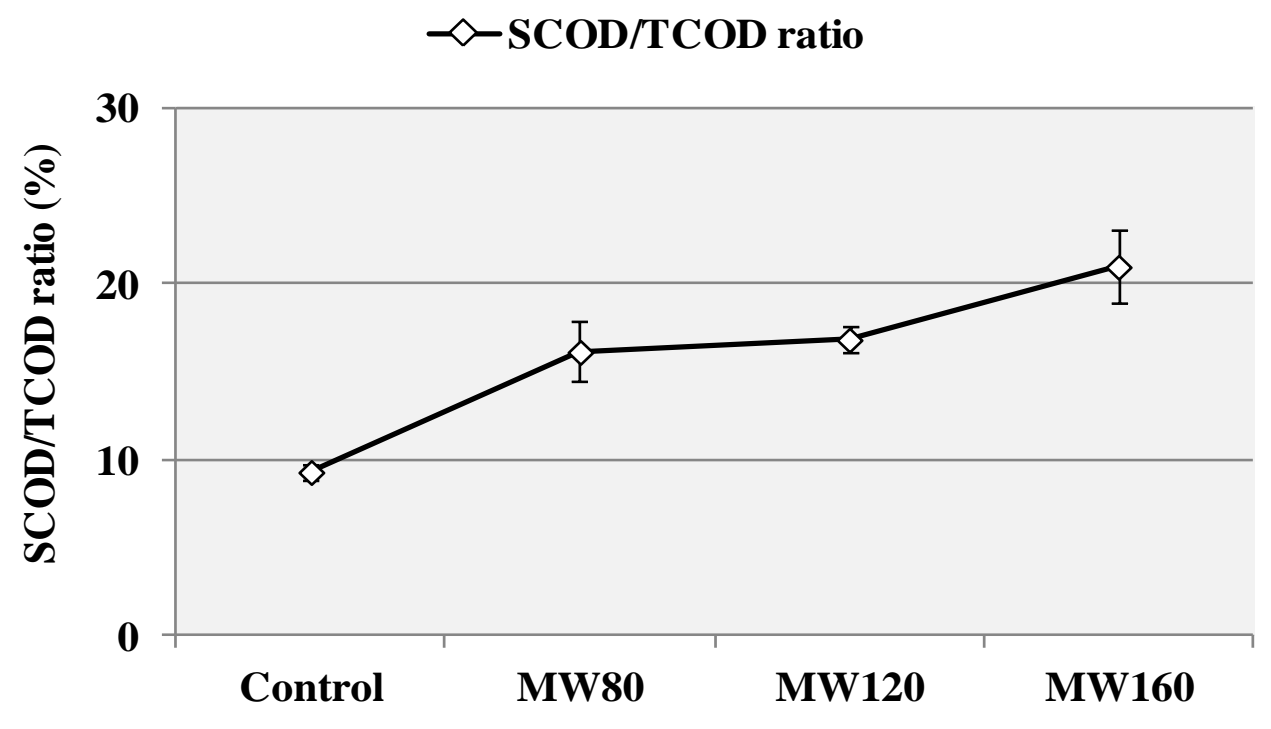

Figure 3.6 Effect of microwave (MW) pretreatment on waste sludge cake solubilization (SCOD: soluble chemical oxygen demand, TCOD: total chemical oxygen demand; 80, 120 and 160: ultimate pretreatment temperatures in ${ }^{\circ} \mathrm{C}$; data represent arithmetic mean of duplicates and error bars represent absolute difference between mean and duplicate measurements)

The elevated melting points of these three hormones $\left(155-256^{\circ} \mathrm{C}\right.$; Table 2.1$)$ suggest that it is unlikely that the attenuation of these compounds were due to evaporations from the soluble phase during MW irradiation of digester feed in a range of $80-160^{\circ} \mathrm{C}$. The attenuations could have been caused by abiotic transformation of the hormones. Autoxidation of cholesterol and plant sterols by heating is well documented in the literature (Osada et al., 1993; Baggio and 
Bragagnolo, 2006; Otaegui-Arrazola et al., 2010) and could explain the results obtained in the current study involving steroids with similar ring structures to sterols. This warrants further investigation to indentify the products of transformation. In the soluble phase of the digester feed, E2 was the only hormone showing some release with increasing temperature and was below the RL in the total phase. Based on these results, it can be postulated that both transformation (i.e. autoxidation, denaturation) and release of hormones from the complex polymeric floc structure occurred during the MW pretreatment. It is possible to postulate that for more hydrophobic hormones, such as E2, the release was higher. Furthermore, Pr was not detected in the soluble phase of the influent; however, it increased in the total phase. Based on the results in the literature, as the high MW pretreatment temperatures used could be inhibitory to any enzymatic activity in the digester feed (Daniel et al., 1996), transformation of one or more hormones into Pr was unlikely. However, this could be due to additional (to sonication described in section 3.3.2) hormone extraction step provided by the MW irradiation for the pretreated sludge samples. Literature shows that microwave assisted extraction has been used to extract hormones from solid samples (e.g., soil, sediment etc.) as an attractive alternative method to traditional extraction methods such as soxhlet extraction and sonication (Liu et al., 2004; Labadie and Budzinski, 2005; Hibberd et al., 2009). This could mean that the MW pretreated digester feed samples could be advantaged in terms of hormone extraction efficiency and subsequent detection sensitivity in the total phases due to hybrid (MW pretreatment of sludge followed by sonication as part of the analytical method for detection) extraction applied.

\subsubsection{Effects of microwave pretreatment on digester performance}

Except for the control digesters at the 5-day SRT, all control and pretreated digesters achieved steady state at all three SRTs, corresponding to volumetric OLRs of 1.74 to $6.96 \mathrm{~g} \mathrm{COD/L/d}$ (Figure 3.8). At the SRT of 5 days, both mesophilic and thermophilic controls stopped producing biogas after 20 days of operation with TVFA concentrations exceeding $1,818 \mathrm{mg} / \mathrm{L}$ at $\mathrm{pH}<5.64$ for mesophilic and $2,853 \mathrm{mg} / \mathrm{L}$ at $\mathrm{pH}<7.02$ for thermophilic controls while the pretreated digesters continued producing biogas. 
a)

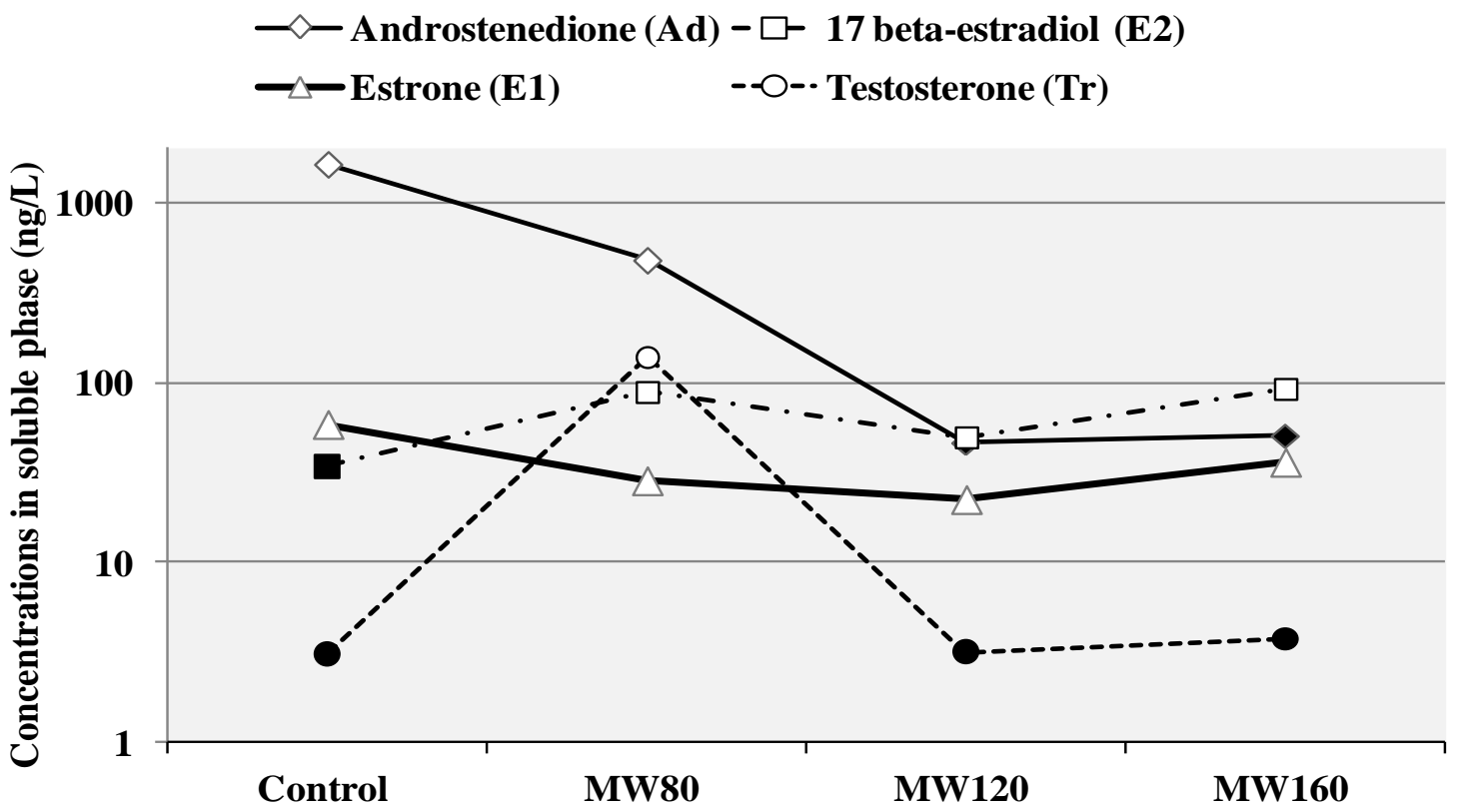

b)

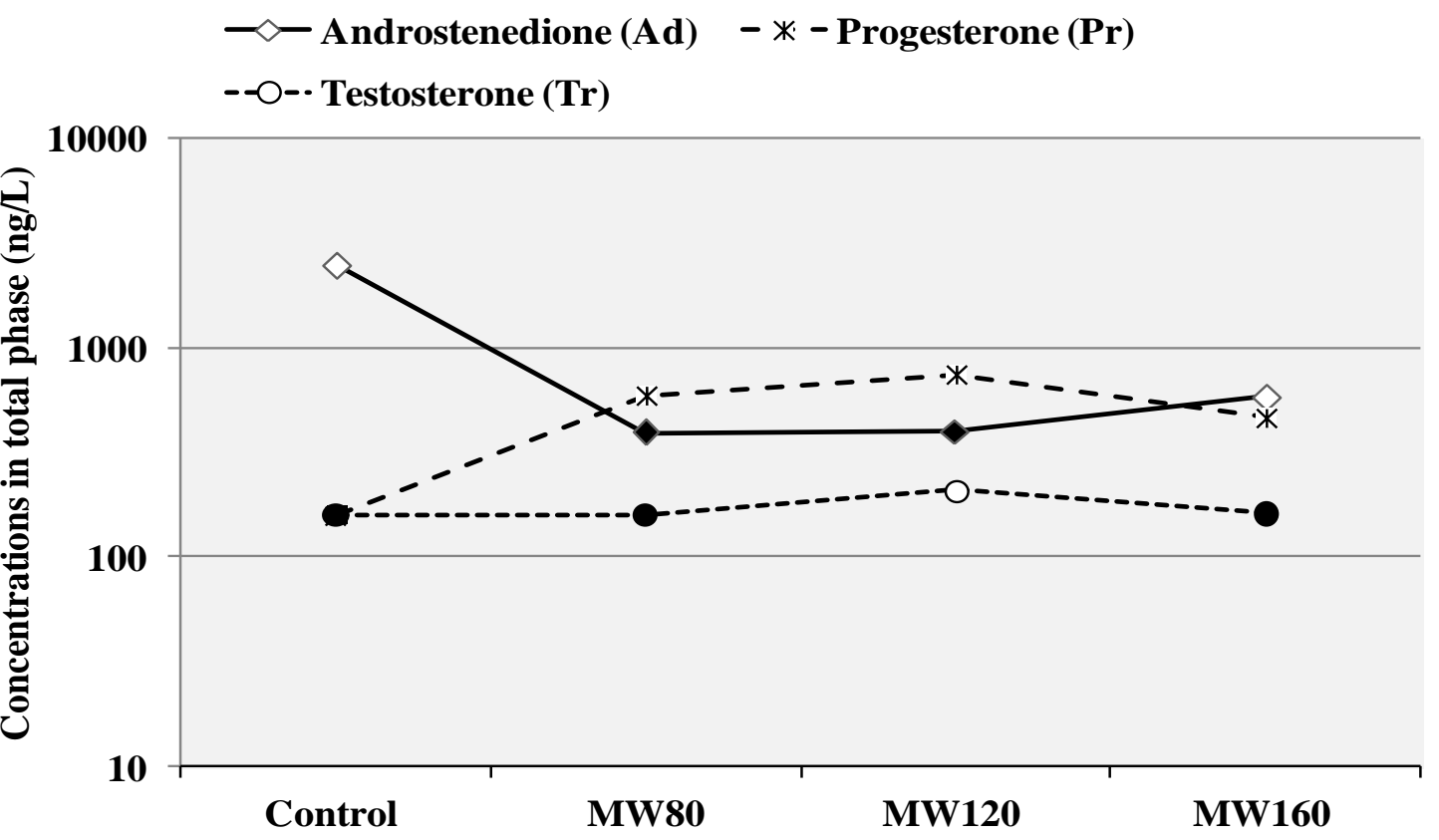

Figure 3.7 Effect of microwave (MW) on hormone concentrations in the a) soluble (supernatant) phase and b) total (sludge) phase of the influent (control: un-pretreated, 80, 120 and 160: ultimate MW pretreatment temperatures in ${ }^{\circ} \mathrm{C}$; single data point concentrations; black filled data points represents concentrations below reporting limit (RL) which varied as Tr: $3.08-3.71 \mathrm{ng} / \mathrm{L}$ and 157 - $160 \mathrm{ng} / \mathrm{L}$, Ad: 45.9 - $50 \mathrm{ng} / \mathrm{L}$ and 392 - $399 \mathrm{ng} / \mathrm{L}$, in soluble and total phase, respectively, $\operatorname{Pr}: 157 \mathrm{ng} / \mathrm{L}$ in total phase, E2: $34 \mathrm{ng} / \mathrm{L}$ in soluble phase) 


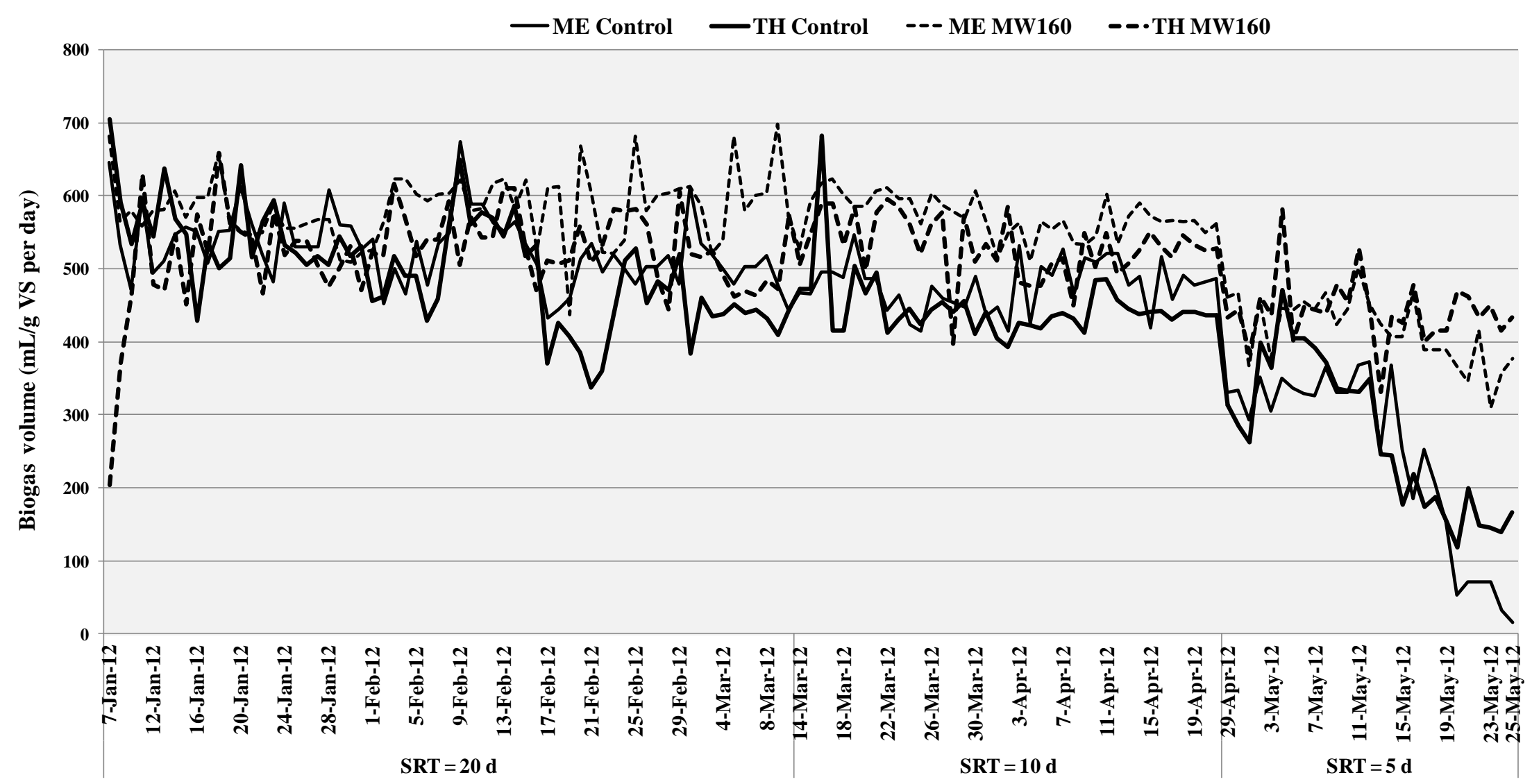

Figure 3.8 Daily biogas productions (normalized to volatile solids (VS) content of the feed) of control (fed with un-pretreated) and MW160 (fed with microwave pretreated sludge at $\left.160^{\circ} \mathrm{C}\right)$ thermophilic $(\mathrm{TH})$ and mesophilic $(\mathrm{ME})$ digesters at $\mathrm{STP}\left(1 \mathrm{~atm}, 0^{\circ} \mathrm{C}\right)$ during the 20, 10 and 5 days of sludge retention times (SRTs) 
Regarding the effect of pretreatments on digester performance, TCOD removal (Figure 3.9), VS removal (Figure 3.10) and daily methane productions (Figure 3.11) at standard temperature and pressures (STP; $\left.0^{\circ} \mathrm{C}, 1 \mathrm{~atm}\right)$ improved for the pretreated digesters at both mesophilic and thermophilic digester temperatures. The pretreatment effects were more prominent at the shortest SRT of 5 days, which was in agreement with the previous studies reported on mesophilic semicontinuous digestion of municipal sludge (WAS and WAS+PS) and after MW irradiation below boiling point $\left(<96^{\circ} \mathrm{C}\right)$ temperatures (Eskicioglu et al., 2007; Park, 2011). During the 5-day SRT, pretreated digesters showed TCOD removal improvements with respect to control, in the range of $54-97 \%$ and $88-120 \%$ for mesophilic and thermophilic digesters, respectively. The relative (to control) improvement for VS removal efficiencies was respectively in the range of $124-163 \%$ and $98-117 \%$ for mesophilic and thermophilic digesters, at the same SRT of 5 days. Similarly, pretreated digesters produced $101-121 \%$ and $57-81 \%$ higher methane, respectively for mesophilic and thermophilic digesters, over controls at SRT of 5 days. Biogas composition (\% of $\mathrm{CH}_{4}, \mathrm{~N}_{2}, \mathrm{O}_{2}, \mathrm{~N}_{2}$ ) at various SRTs as presented in Table 3.5 show that all of the digesters had $60 \%$ or higher methane content, except the controls at 5 days SRT.

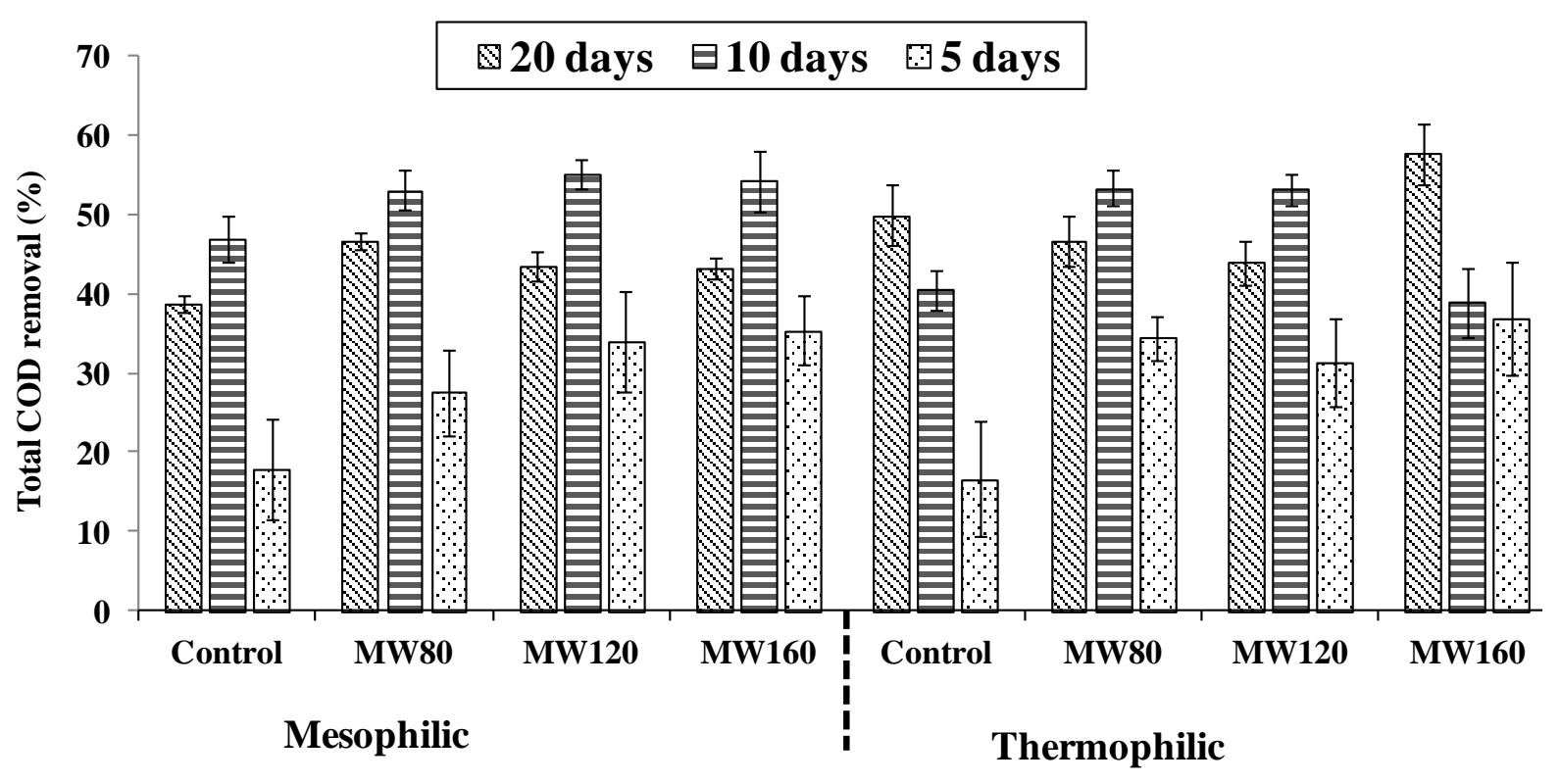

Figure 3.9 Total chemical oxygen demand (TCOD) removal efficiencies at sludge retention times (SRTs) of 20, 10 and 5 days (80, 120 and 160: ultimate microwave pretreatment temperatures in ${ }^{\circ} \mathrm{C}$; arithmetic means and standard deviations of 14 data points are shown) 


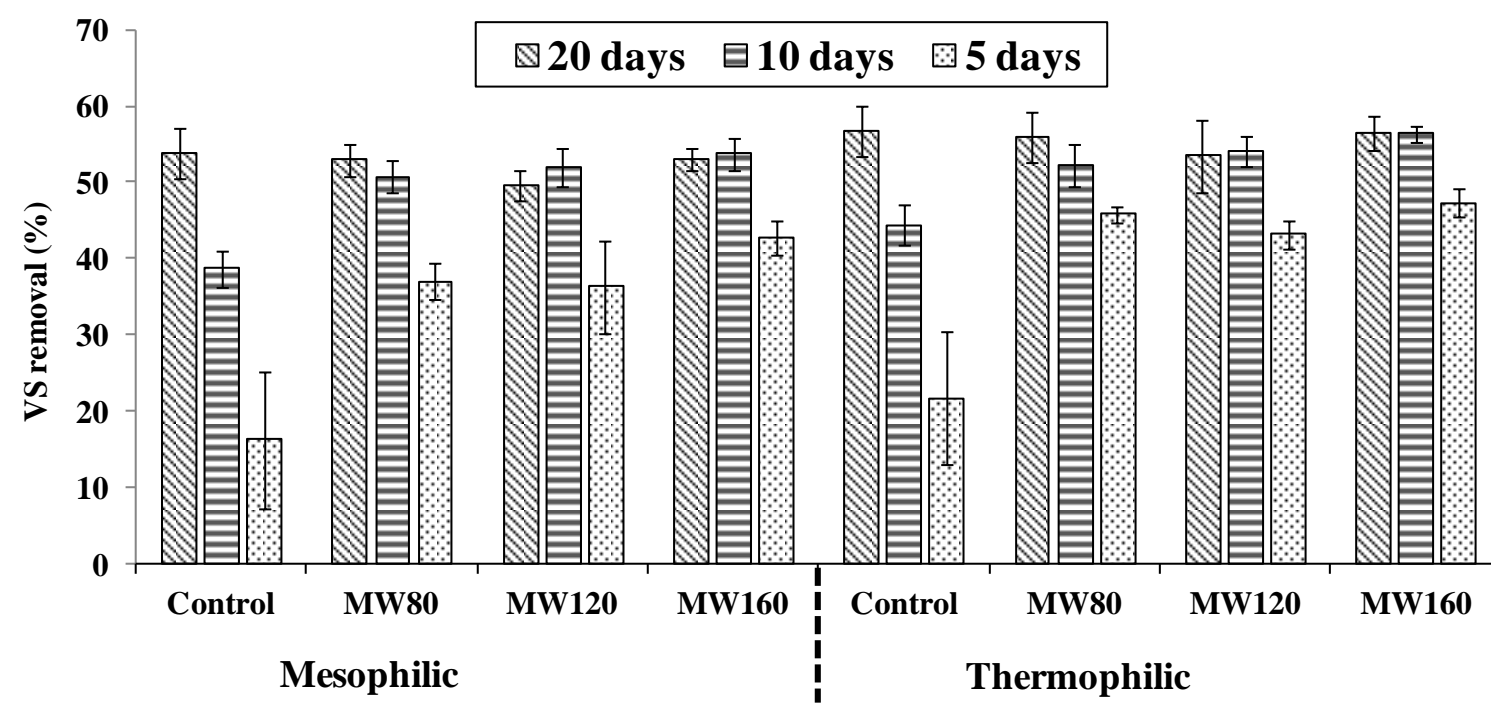

Figure 3.10 Volatile solids (VS) removal efficiencies at sludge retention times (SRTs) of 20, 10 and 5 days (80, 120 and 160: ultimate microwave pretreatment temperatures in ${ }^{\circ} \mathrm{C}$ unit; arithmetic mean and standard deviation of 14 data points are shown)

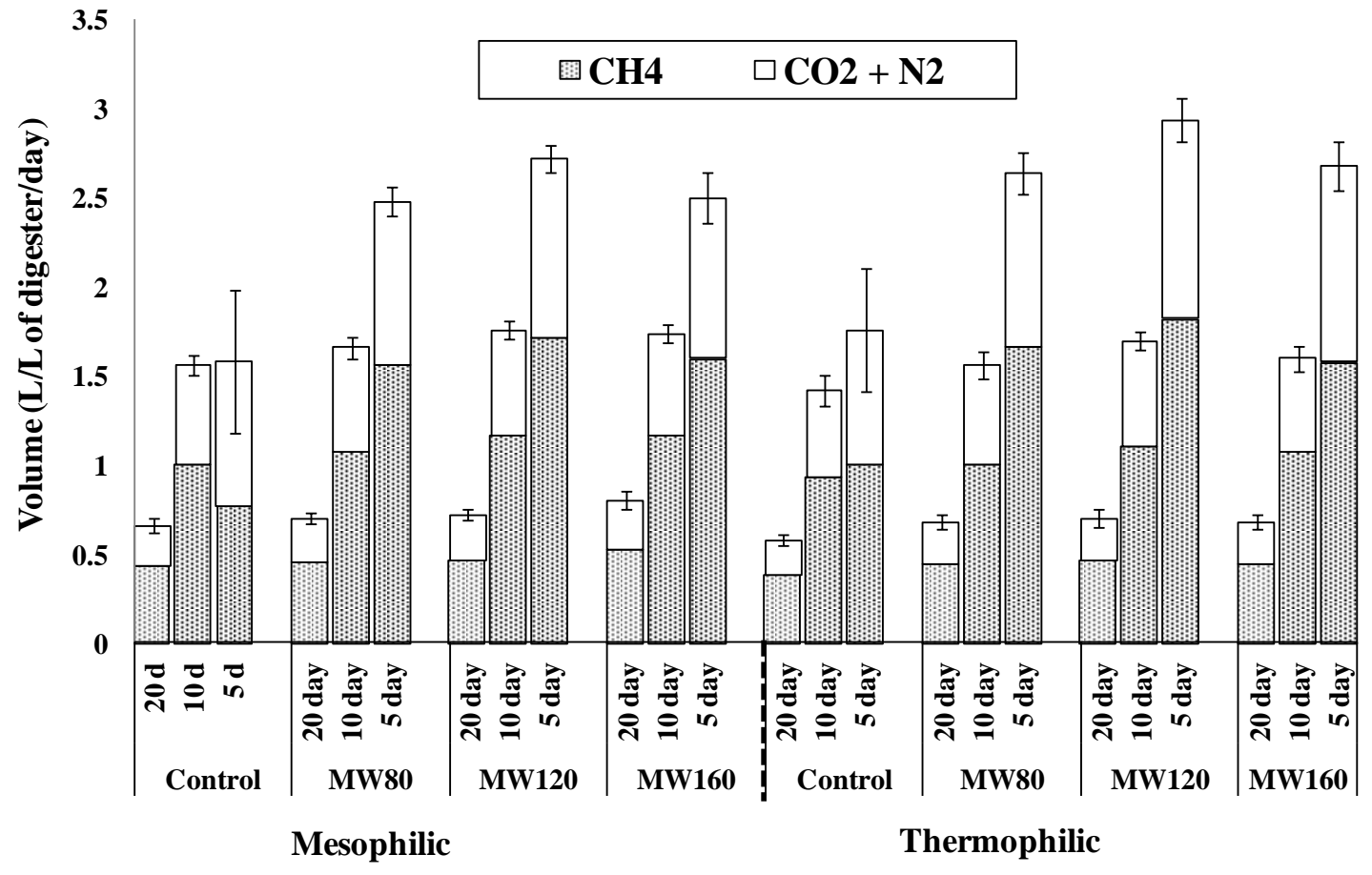

Figure 3.11 Average daily biogas $\left(\mathrm{CH}_{4}, \mathrm{CO}_{2}+\mathrm{N}_{2}\right.$, assuming $\mathrm{O}_{2}$ is negligible $)$ production rate at various sludge retention times (SRTs) at STP (80, 120 and 160: ultimate microwave pretreatment temperatures in ${ }^{\circ} \mathrm{C}$; STP: $0^{\circ} \mathrm{C}, 1 \mathrm{~atm}$; arithmatic mean and standard deviation of 60,36 and 26 data points for SRT of 20, 10 and 5 days, respectively) 
Table 3.5 Biogas composition (\%) at various sludge retention times (SRTs)

\begin{tabular}{|c|c|c|c|c|c|c|c|c|}
\hline & \multicolumn{4}{|c|}{ Mesophilic } & \multicolumn{4}{|c|}{ Thermophilic } \\
\hline & Control & MW80 & MW120 & MW160 & Control & MW80 & MW120 & MW160 \\
\hline \multicolumn{9}{|c|}{ SRT $=20$ days } \\
\hline \multirow{2}{*}{$\mathrm{CH}_{4}$} & 66 & 65 & 65 & 66 & 66 & 65 & 66 & 65 \\
\hline & $(2 \cdot 0,4)^{\mathrm{a}}$ & $(0,4)$ & $(1,4)$ & $(2,4)$ & $(2,4)$ & $(0,4)$ & $(1,4)$ & $(2,4)$ \\
\hline $\mathrm{CO}_{2}$ & 29 & 29 & 29 & 30 & 29 & 29 & 29 & 29 \\
\hline $\mathrm{N}_{2}$ & 4 & 5 & 5 & 3 & 4 & 5 & 4 & 5 \\
\hline $\mathrm{O}_{2}$ & 1 & 1 & 1 & 1 & 1 & 1 & 1 & 1 \\
\hline \multicolumn{9}{|c|}{ SRT $=10$ days } \\
\hline \multirow{2}{*}{$\mathrm{CH}_{4}$} & 64 & 65 & 66 & 67 & 66 & 64 & 65 & 67 \\
\hline & $(0.5,4)$ & $(2,4)$ & $(2,4)$ & $(2,4)$ & $(1,4)$ & $(3,4)$ & $(1,4)$ & $(2,4)$ \\
\hline $\mathrm{CO}_{2}$ & 32 & 32 & 31 & 30 & 30 & 31 & 31 & 30 \\
\hline $\mathrm{N}_{2}$ & 3 & 2 & 2 & 2 & 3 & 4 & 3 & 2 \\
\hline $\mathrm{O}_{2}$ & 1 & 1 & 1 & 1 & 1 & 1 & 1 & 1 \\
\hline \multicolumn{9}{|c|}{ SRT $=5$ days } \\
\hline \multirow{2}{*}{$\mathrm{CH}_{4}$} & 43 & 63 & 64 & 64 & 58 & 63 & 63 & 61 \\
\hline & $(13,9)$ & $(1,9)$ & $(1,9)$ & $(1,9)$ & $(4,9)$ & $(1,9)$ & $(1,9)$ & $(1,9)$ \\
\hline \multirow{2}{*}{$\mathrm{CO}_{2}$} & 48 & 33 & 33 & 33 & 34 & 33 & 32 & 32 \\
\hline & $(11,11)$ & $(1,6)$ & $(1,7)$ & $(1.5,5)$ & $(2.5,10)$ & $(1,5)$ & $(0.6,5)$ & $(0.2,3)$ \\
\hline \multirow{2}{*}{$\mathrm{N}_{2}$} & 8 & 3 & 2 & 2 & 6 & 4 & 4 & 6 \\
\hline & $(4,11)$ & $(1,6)$ & $(1,7)$ & $(1,5)$ & $(3,10)$ & $(0.5,5)$ & $(2,5)$ & $(2,3)$ \\
\hline \multirow{2}{*}{$\mathrm{O}_{2}$} & 1 & 1 & 1 & 1 & 2 & 1 & 1 & 1 \\
\hline & $(0.6,11)$ & $(0.2,6)$ & $(0.6,7)$ & $(1,5)$ & $(0.5,10)$ & $(0.1,5)$ & $(0.5,5)$ & $(0.1,3)$ \\
\hline
\end{tabular}

a (standard deviation, number of data points)

\subsubsection{Effects of pretreatment and anaerobic digester operating conditions on hormone concentrations}

The hormone concentrations before and after anaerobic digestion for different pretreatment temperatures (from both total and soluble phases) are displayed in Figures 3.12 to 3.14. Total phase concentrations of $\mathrm{Ad}$ and $\operatorname{Pr}$ were converted to $\mathrm{ng} / \mathrm{L}$ by multiplying with the concentrations in $\mathrm{ng} / \mathrm{g}$ by the TS (\%) content (Appendix B, Table B.4) of respective samples in order to make them comparable to soluble phase concentrations in $\mathrm{ng} / \mathrm{L}$. Matrix interferences were observed in the cases of $\mathrm{Tr}$, An and Ms and their detection in most of the samples did not meet quantification criteria specified in Table B. 1. Concentration profiles for these three hormones in soluble and total phases are presented in Appendix B (Figures B. 1 to B. 3). It 
should be noted that hormone concentration in total phase can change after digestion as a result of biodegradation, abiotic transformation. However, soluble phase concentrations are affected by sorption and desorption to sludge in addition to the aforementioned processes.

a)

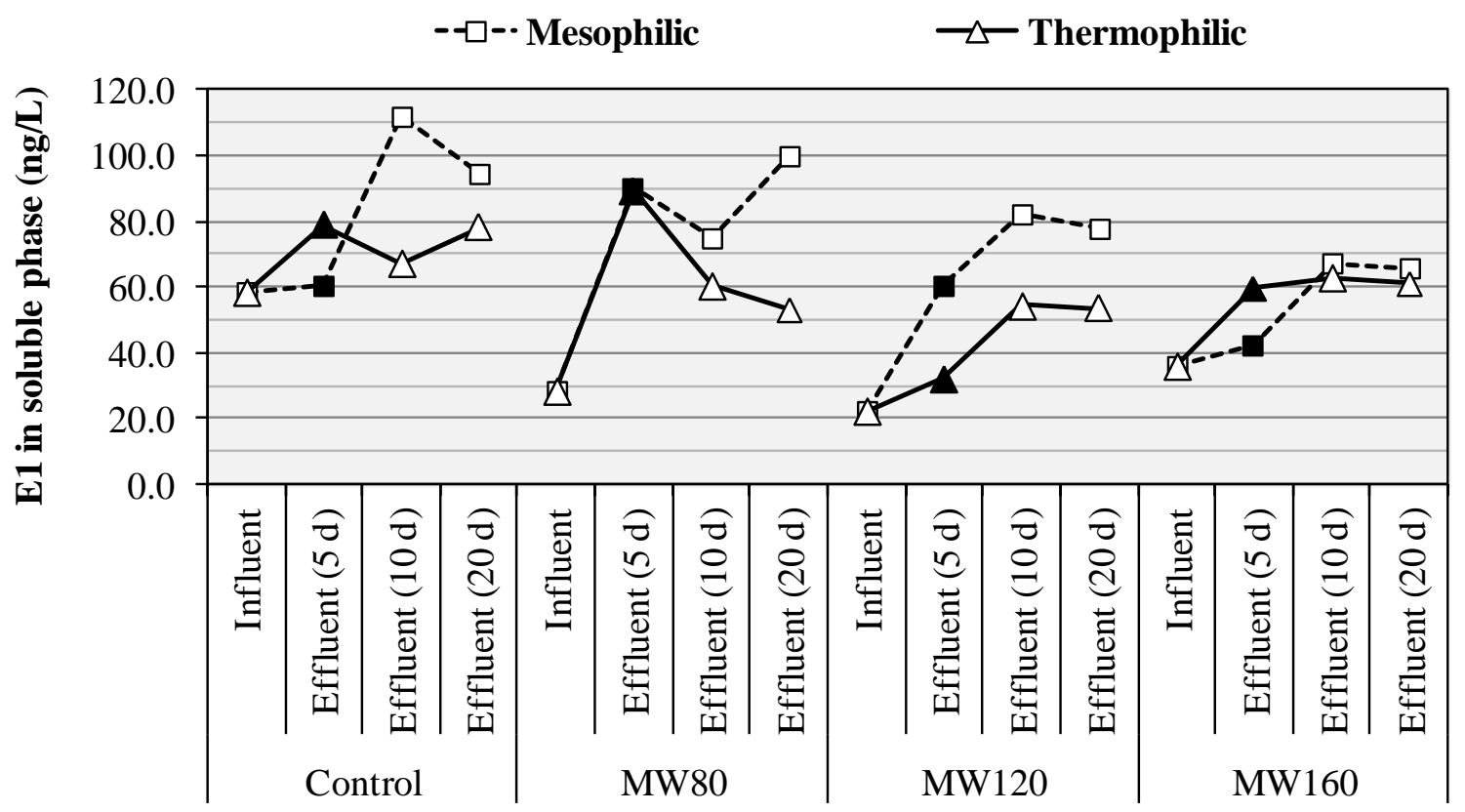

b)

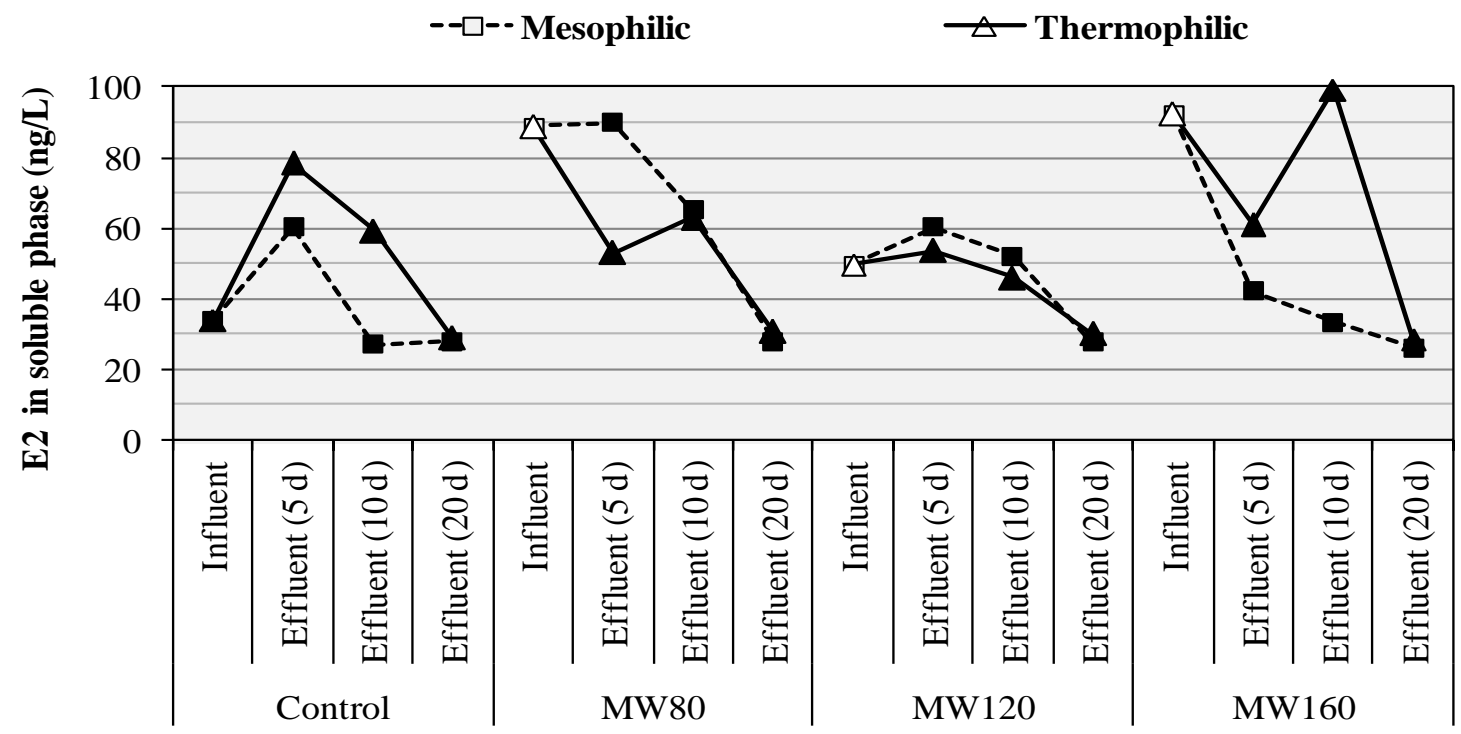

Figure 3.12 Concentrations of a) estrone (E1) and b) $17 \beta$-estradiol (E2) in soluble phases of the influent and effluents at various sludge retention times (SRTs) (control: un-pretreated; 80, 120 and 160 are ultimate microwave pretreatment temperatures in ${ }^{\circ} \mathrm{C}$ unit; black filled data points were below reporting limit (RL). RL varied as E1: 32 - 90 ng/L, E2: 26.2 - 90 ng/L) 
Despite the known inefficiency of conventional anaerobic digesters to biodegrade the hormones (Andersen et al., 2003; Esperanza et al., 2007; Holmes et al., 2010; Ifelebuegu, 2011), below RL concentrations of estrogenic hormones (i.e. E1, E2, E3 and EE2) reported in Table 3.4 made it difficult to estimate their removal from the total phase. Due to same reason, calculation of degradation coefficient was also not possible. However, the soluble phase concentrations indicated accumulation of E1 (Figure 3.11) and removal of E2 (Figure 3.12) in both controls and pretreated digesters. Previous studies indicated that, E1 is an intermediate compound of E2 degradation (Czajka and Londry, 2006; Furlong et al., 2010; Holmes et al., 2010; Zheng et al., 2012), which may be responsible for the observed accumulation of E1. Another possible reason could be cleaving of glucuronide and sulfate conjugates present in the primary sludge during anaerobic digestion (Furlong et al., 2010). Although, there is not much information that exists regarding the biodegradation and fate of androgenic and progesteronic hormones under anaerobic conditions (Esperanza et al., 2007), this study demonstrated an overall accumulation of Ad and Pr in most of the digesters (Figures 3.13 and 3.14). Despite the lower concentrations of Ad in the pretreated influents than the controls, the effluent concentrations revealed accumulation in both phases in most of the pretreated digesters. Also, the longest SRT (20 days) seemed to worsen the situation in case of presence of Ad (both thermophilic and mesophilic digesters) and $\operatorname{Pr}$ (thermophilic digesters). Possible explanation of such accumulation could be microbial assisted transformation of hormones. For example, Ad has been the starting compound in synthesis of androgenic and anabolic drugs for a long time and many microorganisms have been isolated from environment that are able to produce Ad by ring cleavage of plant sterols (Malaviya and Gomes, 2008). Such bioconversion of phytosterols had been reported to cause accumulation of androgens (e.g., androstenedione (Ad)) in anoxic river sediments receiving pulp and paper mill effluent (Jenkins et al., 2004). Recently, another study reported Ad to be a metabolite of Pr degradation using soil mold Penicillium aurantiogriseum (Eshrat and Aroona, 2011). However, the majority of these studies deal with aerobic microorganisms and unfortunately not much is known regarding biotransformation under anoxic or anaerobic conditions. It is possible that some other steroidal hormones, not monitored in this study, could have acted as precursors of the target hormones resulting in their accumulation. 
a)

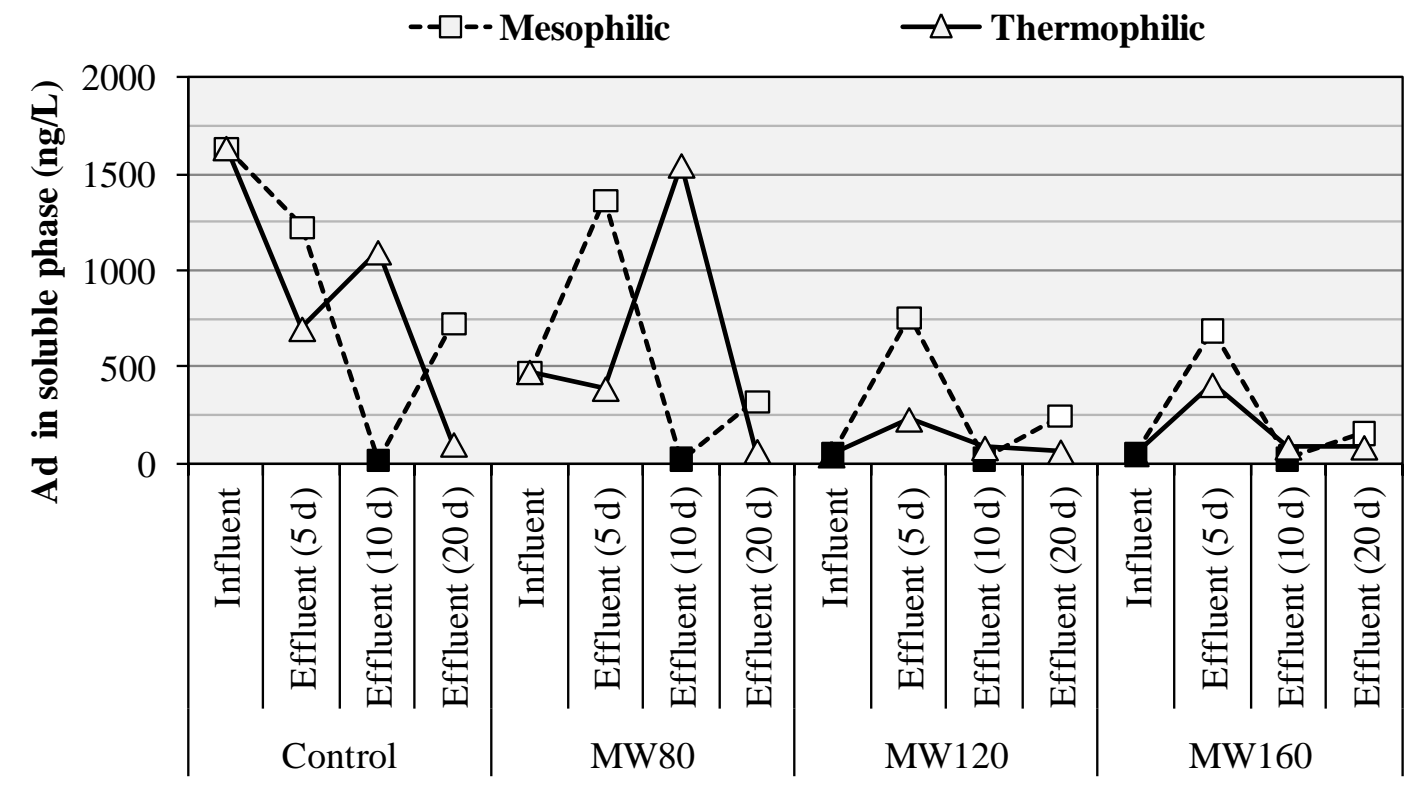

b)

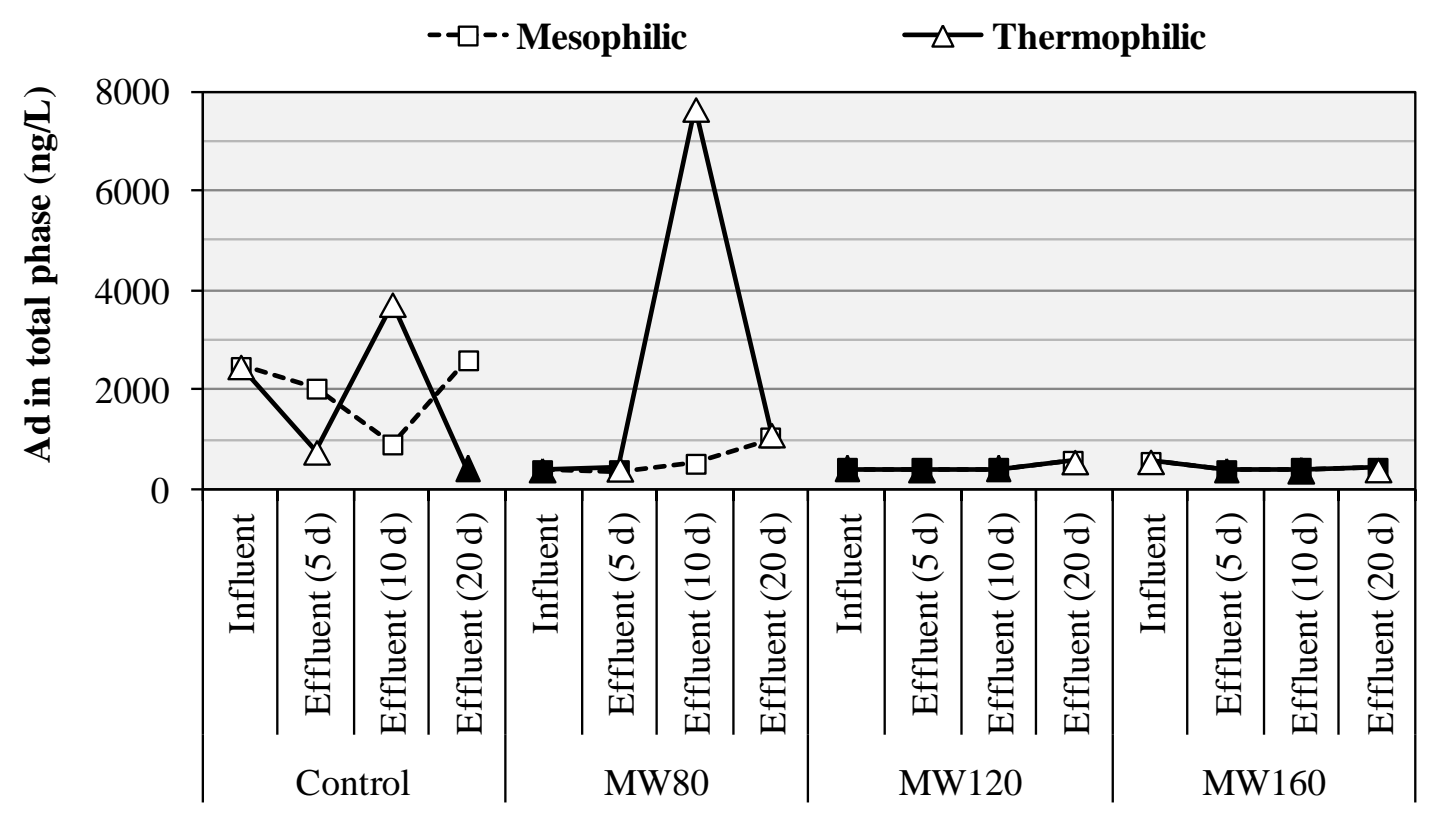

Figure 3.13 Concentrations of androstenedione (Ad) in a) soluble phase and b) total phase of the influent and effluents at various sludge retention times (SRTs) (control: un-pretreated; 80, 120 and 160 are ultimate microwave pretreatment temperatures in ${ }^{\circ} \mathrm{C}$ unit; black filled data points were below reporting limit (RL). RL varied as $18.2-50.3 \mathrm{ng} / \mathrm{L}$ and $362-412 \mathrm{ng} / \mathrm{L}$ in soluble and total phases, respectively) 
a)

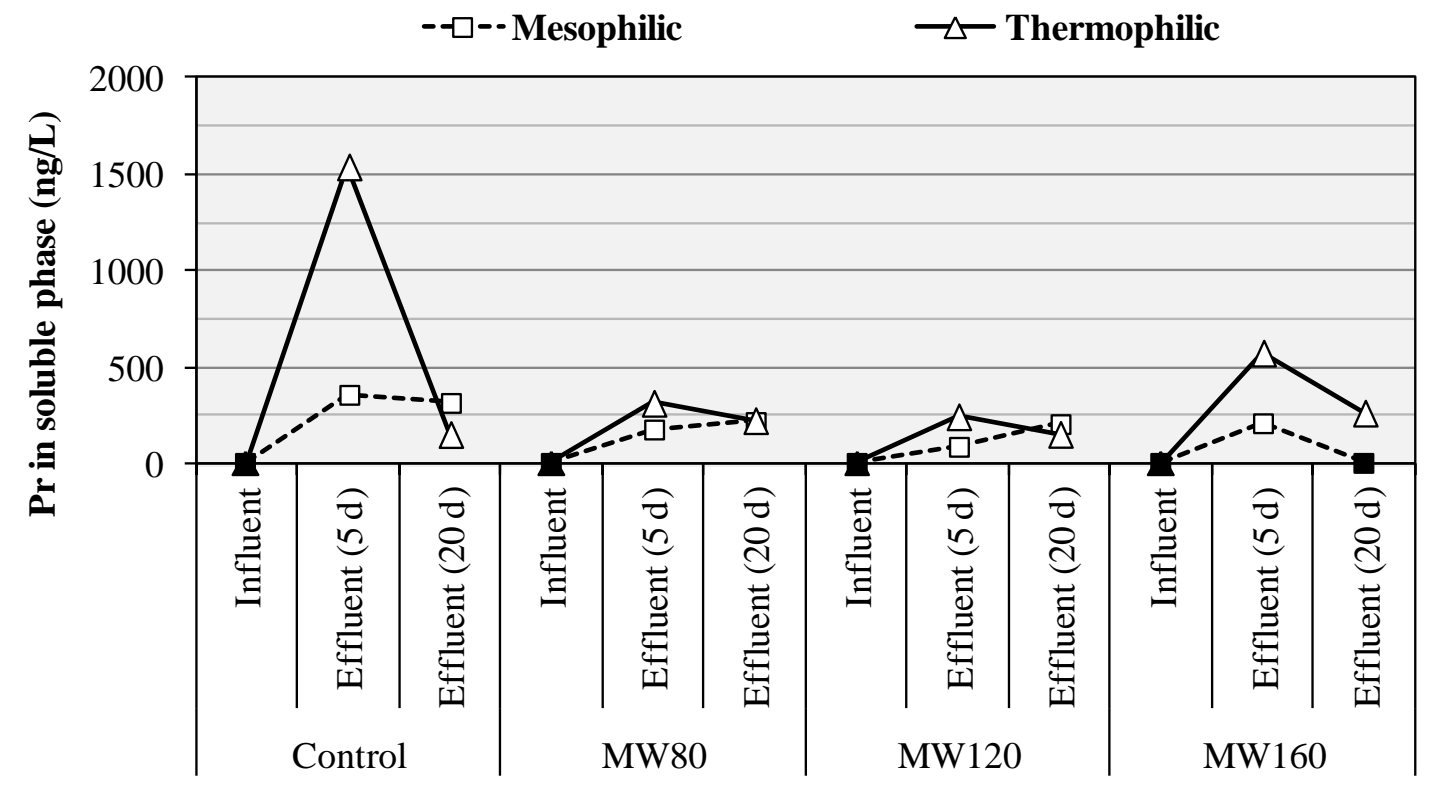

b)

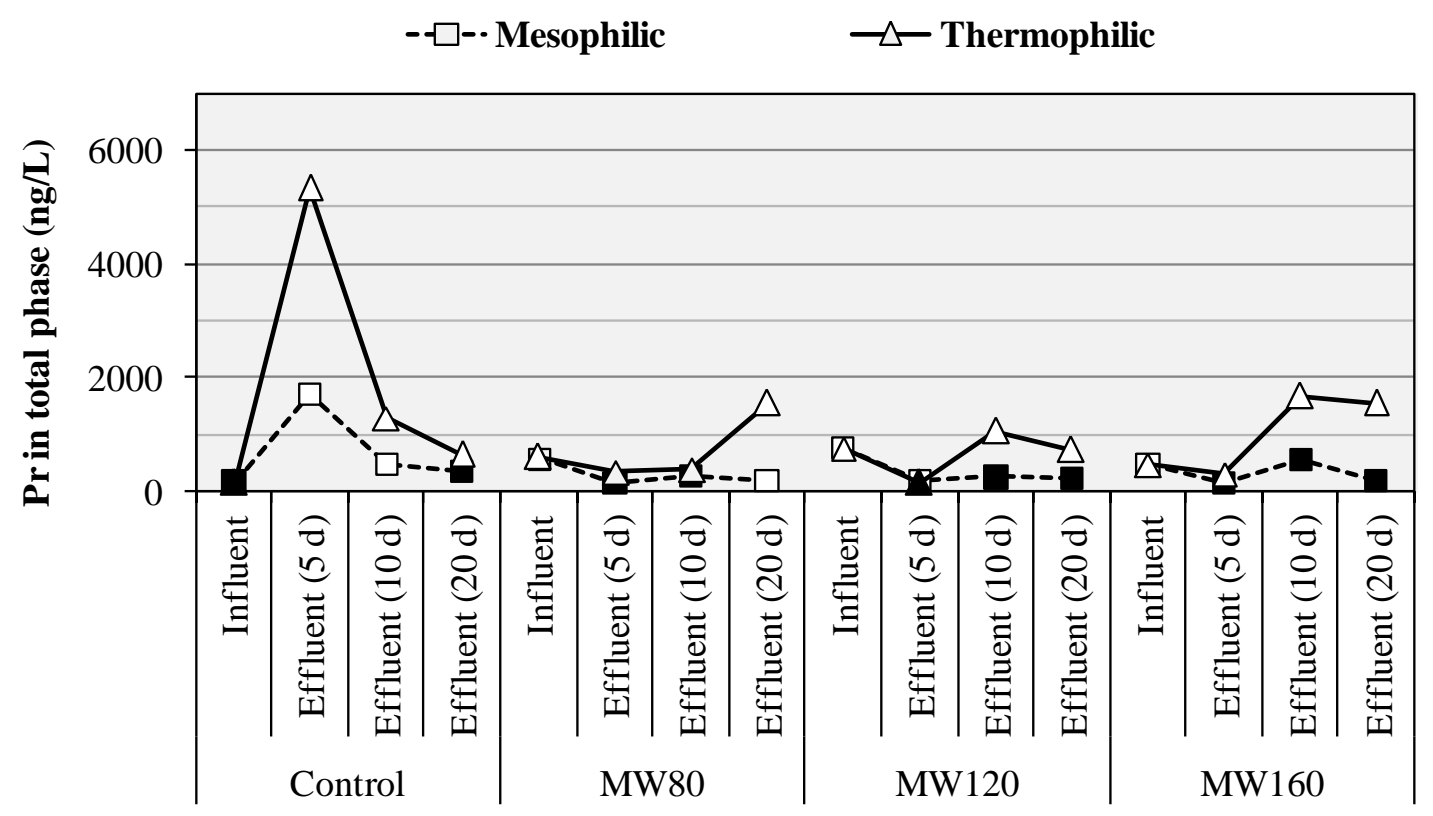

Figure 3.14 Concentrations of progesterone (Pr) in a) soluble phase and b) total phase of the influent and effluents at various sludge retention times (SRTs) (Pr was not quantifiable in soluble phase of the effluent of SRT 10 days; control: un-pretreated; 80, 120 and 160 are ultimate microwave pretreatment temperatures in ${ }^{\circ} \mathrm{C}$ unit; black filled data points were below reporting limit (RL). RL varied as $3.08-5.75 \mathrm{ng} / \mathrm{L}$ and $146-555 \mathrm{ng} / \mathrm{L}$ in soluble and total phases, respectively) 
Compared to control digesters, MW pretreated digesters, especially at elevated temperatures $\left(120,160^{\circ} \mathrm{C}\right)$, contained lower concentrations of $\mathrm{Ad}$, Pr and E1 in their effluents. This trend was more apparent in the total phases of effluents for both Ad (Figure 3.13b) and Pr (Figure 3.14b) and soluble phase of E1 (Figure 3.12a) under both mesophilic and thermophilic digester temperatures. These results were confirmed by statistical analyses. Multi-factor analysis of variance performed on hormone removal efficiency [calculated from eq. (3.1)] of $\operatorname{Pr}$ (total phase) suggested that MW pretreatment was a statistically significant factor $(\mathrm{P}<0.05)$ at $95 \%$ confidence level (Table 3.6). Similar statistical analysis of removal efficiency on Ad (soluble phase) revealed both SRT and pretreatment temperatures to be significant factors at the same (95\%) confidence level. For the estrogenic hormones, although removal of E1 from soluble phase was significantly $(\mathrm{P}<0.05)$ affected by digester operating and pretreatment temperatures; effect of SRT was found to be statistically insignificant. The statistical analysis for the hormones of Ad and E1 are provided in Tables C. 1 and C. 2 in Appendix C, along with the normality plots. On the other hand, removal of Pr (soluble phase) and Ad (total phase) were found to be not significantly affected by the studied factors.

Table 3.6 Analysis of Variance for removal efficiency of progesterone (Pr) from total phase ${ }^{a}$

\begin{tabular}{lccc}
\hline Factor & Unit & Levels & Values \\
\hline Digester (operating) temperature & ${ }^{\circ} \mathrm{C}$ & 2 & $35 \pm 2$ (mesophilic), $55 \pm 2$ (thermophilic) \\
Sludge retention time (SRT) & days & 3 & $20,10,5$ \\
Microwave temperature (MW) & ${ }^{\circ} \mathrm{C}$ & 4 & Control (un-pretreated), 80, 120, 160 \\
\hline
\end{tabular}

\begin{tabular}{lccccc}
\hline Source & DF & SS & MS & F & P \\
\hline Digester temperature & 1 & 688224 & 688224 & 3.59 & 0.107 \\
SRT & 2 & 789332 & 394666 & 2.06 & 0.209 \\
MW & 3 & 3989744 & 1329915 & 6.94 & 0.022 \\
Digester temperature $\times$ SRT & 2 & 198784 & 99392 & 0.52 & 0.620 \\
Digester temperature $\times$ MW & 3 & 917019 & 305673 & 1.59 & 0.286 \\
SRT $\times$ MW & 6 & 3649407 & 608235 & 3.17 & 0.093 \\
Error & 6 & 1150023 & 191671 & & \\
Total & 23 & 11382534 & & & \\
\hline
\end{tabular}

${ }^{a}$ DF: degrees of freedom; SS: sum of square; MS: mean of square; F: observed F value, P: probability value

In contrast to these findings, previously, it had been reported that thermal pretreatment of a mixture of WAS and PS (30:70, v/v) with an autoclave $\left(160^{\circ} \mathrm{C}, 60 \mathrm{~min}\right)$ followed by anaerobic digestion showed similar removal of estrogenic compounds (E1, E2 and EE2) relative to the control digesters for different SRTs (20 and 10 days for mesophilic, 10 and 6 days for 
thermophilic) (Carballa et al., 2006). However, in the above mentioned study only a single pretreatment temperature $\left(130^{\circ} \mathrm{C}\right.$ for $\left.60 \mathrm{~min}\right)$ was evaluated. Therefore, the current study, employing a wider range of pretreatment temperatures and three different digester SRTs suggested, for the first time, that pretreatment by MW can be a influencing factor in fate of steroidal hormones. In addition to overall lower concentrations of hormones (Ad, E1) detected in the digester effluents at elevated MW temperatures, thermophilic digesters consistently contained higher Pr in the effluents compared to those of mesophilic (Figure 3.14b).

The sum of concentrations of four hormones (E1, E2, Ad and Pr) in the supernatant (soluble) and sludge (total) phases of effluent and influent at the SRT of 20 days are presented in Figure 3.15. These hormones were considered since they were above RL in most of the samples. Also, when these hormones were not detected at RL in some of the samples, their concentrations were assumed to be equal to the RL. Concentration profiles in the soluble phase (Figure 3.15a) revealed that both mesophilic and thermophilic effluent supernatants showed higher concentrations at the elevated pretreatment temperatures $\left(120\right.$ and $\left.160^{\circ} \mathrm{C}\right)$ compared to influents. This may indicate that pretreatments may have facilitated the release of hormones from the particulate phase to soluble phase during both mesophilic and thermophilic digesters. Furthermore, compared to control digesters, MW pretreatment was able to lower the hormone loads in mesophilic digester centrates recycled back to the main WWTP. For example, at the SRT of 20 days, mesophilic supernatants contained 42\%, 52\%, 78\% less hormones in their digestate supernatants at MW pretreatment temperatures of 80,120 and $160^{\circ} \mathrm{C}$, compared to controls (Figure 3.15a). On the other hand, the thermophilic control contained more or less same concentrations of hormones in its digestate supernatant as the pretreated digesters. In fact, the thermophilic digester fed with pretreated sludge at $160^{\circ} \mathrm{C}$ showed $21 \%$ increase in total hormone concentrations compared to the control. Furthermore, in terms of the comparisons in the soluble phase, all of the thermophilic digesters, except MW 160, had smaller hormone concentrations compared to mesophilic digesters. However, the total phase concentration profiles (Figure 3.15b) suggested that thermophilic digesters actually accumulated more hormones with respect to both mesophilic digesters and influent. This in turn indicates that thermophilic anaerobic digesters may introduce higher amount of steroidal hormones to the environment in case of land application of dewatered digested sludge (biosolids). 
a)

$\nabla$ Influent (ME \& TH) $\square$ Effluent(ME) $\quad$ Effluent (TH)

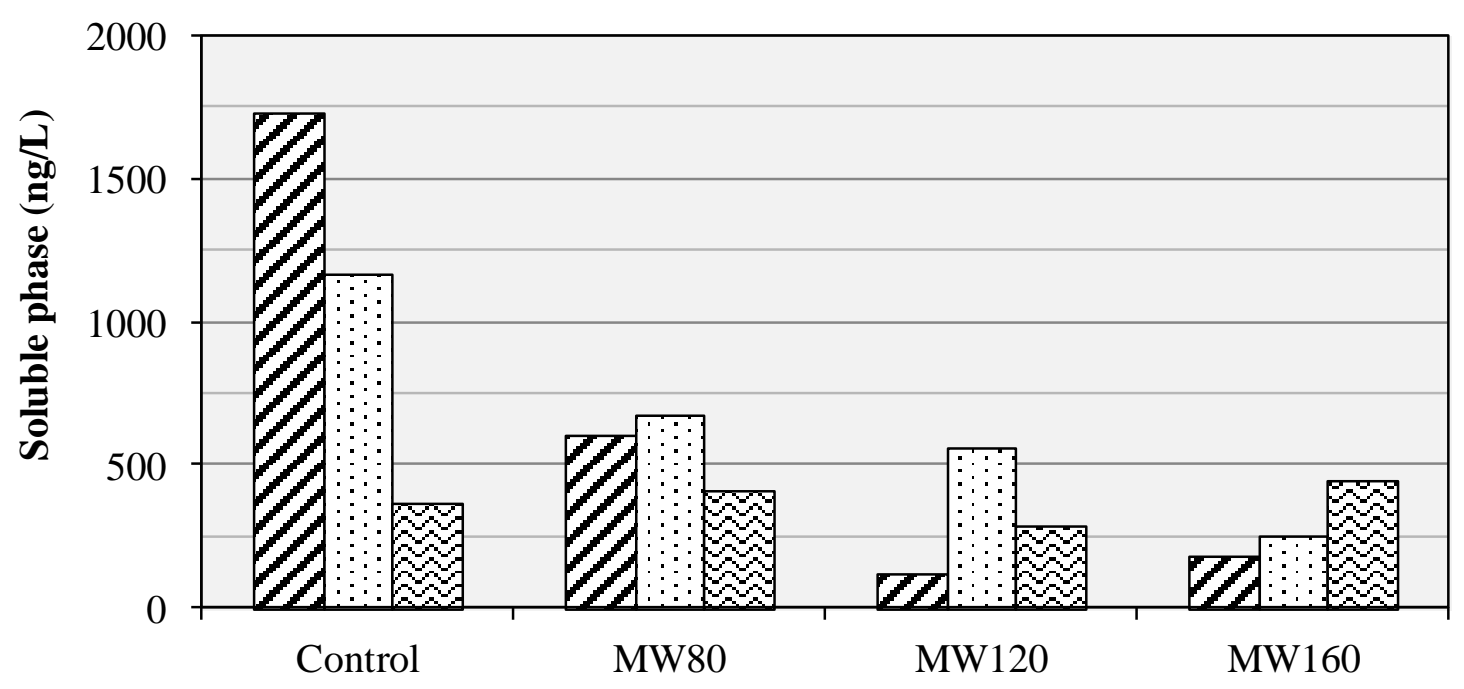

b)

\section{$\square$ Influent (ME \& TH) $\square$ Effluent(ME) $\quad$ Effluent (TH)}

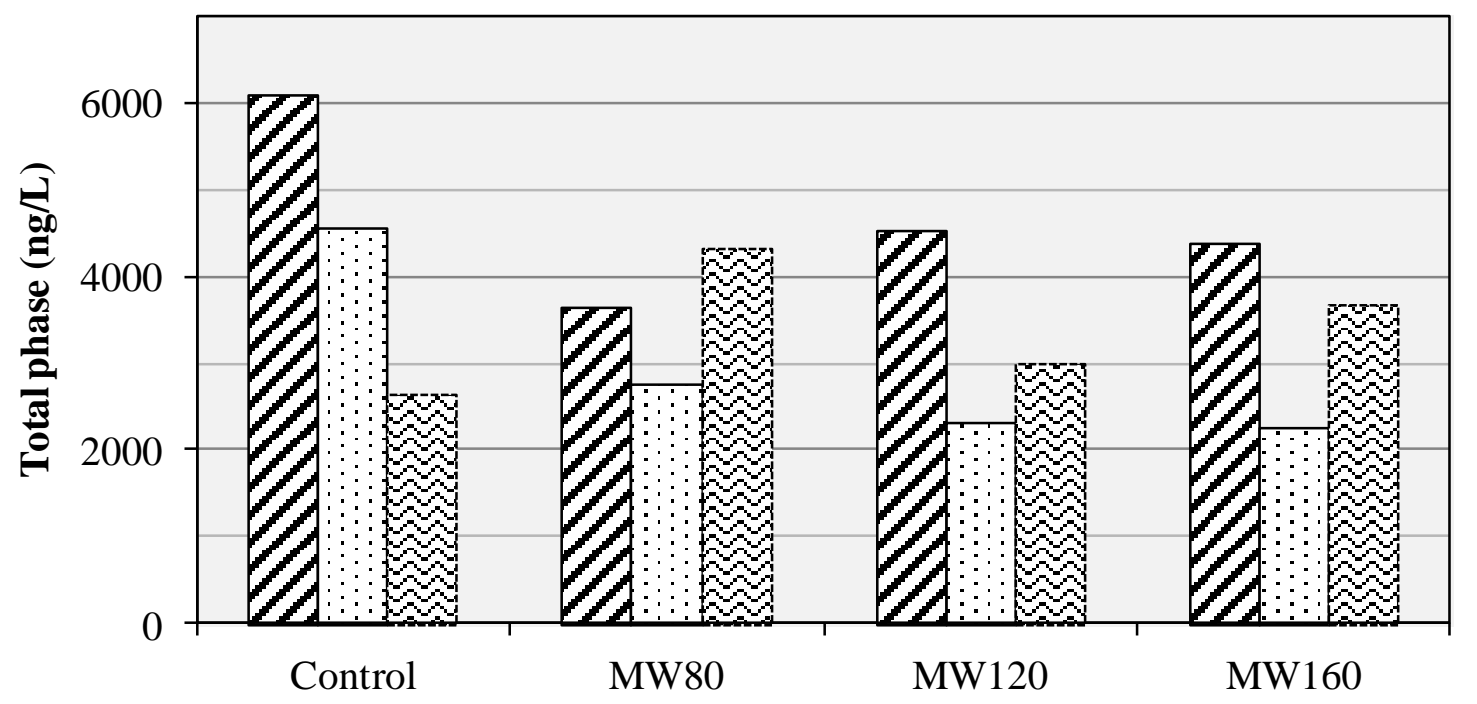

Figure 3.15 Total hormone concentrations ( $\Sigma$ of estrone (E1), 17ß-estradiol (E2), androstenedione (Ad) and progesterone (Pr)) in the a) soluble phase (supernatant) and b) total phase (sludge) of the influent and effluent at 20 days SRT (80, 120 and 160: ultimate microwave pretreatment temperatures in ${ }^{\circ} \mathrm{C}$ unit)

The concentrations of estrogenic $(\mathrm{E} 1+\mathrm{E} 2)$, androgenic (Ad) and progestogenic (Pr) hormones ranged between 30 and $140 \mathrm{ng} / \mathrm{L}, 66.4$ and $732 \mathrm{ng} / \mathrm{L}$ and < 5.5 and $317 \mathrm{ng} / \mathrm{L}$, respectively, in the soluble phase of control and pretreated digester effluents in the same SRT (20 
days). These concentrations are comparable to the concentrations of hormones in the wastewater entering the WWTP (Chang et al., 2011; Liu et al., 2012a).

\subsection{Summary}

In summary, transformation and fate 16 steroidal hormones were studied during anaerobic digestion of control (unpretreated) and MW pretreated municipal sludge cake using semicontinuous bench-scale digesters. Only five of the 16 hormones were detected in the total and/or soluble phases of digester influents. Among these five, only E2 fell below the detection limit and the rest were detected in the effluents. MW pretreatment at three different temperatures (i.e. 80, 120 and $160^{\circ} \mathrm{C}$ ) showed release of comparatively more hydrophobic hormones (i.e. E2) in the soluble phase and attenuation of some other hormones (i.e. E1, Ad, Tr). Low biodegradation efficiency of steroidal hormones in anaerobic digesters resulted in accumulation of Ad and E1 in both soluble and total phases. However, compared to aforementioned hormones, Pr showed some removal from total phase of the mesophilic digesters. The simultaneous accumulation and removal can be attributed to microbial biotransformation of the steroidal hormones; however, this needs further investigation. At 20 days SRT, thermophilic digesters contained overall less concentration of steroidal hormones in the effluent supernatants. However, mesophilic digesters seemed to perform better in terms of total attenuation of hormones at the same SRT (20 days) and would likely to have lower concentrations in the dewatered effluents. MW pretreatment also showed increased organic removal and methane production rate, especially at shorter SRTs (5 days). 


\section{Chapter 4 Conclusions and perspectives}

\subsection{Conclusions}

This study investigated fate of 16 natural and synthetic hormones during advanced anaerobic digestion of municipal sludge cake using MW pretreatment prior to digestion. The factors studied here included pretreatment temperature $\left(80,120\right.$ and $\left.160^{\circ} \mathrm{C}\right)$, SRT $(20,10$ and 5 days) and operating temperature (mesophilic, $35 \pm 2{ }^{\circ} \mathrm{C}$; thermophilic, $35 \pm 2{ }^{\circ} \mathrm{C}$ ). To determine the potential effect of MW hydrolysis, hormones were quantified in sludge (total) and supernatant (soluble) phase of the digester influent and effluent streams. Following the collection and analysis of data obtained from eight semi-continuously fed lab-scale digesters, the following conclusions were drawn:

- Seven (E1, E2, Ad, Pr, Tr, An and Ms) out of 16 hormones were above RL in one or more of the influent and/or effluent streams. For three of these hormones (Tr, An and Ms), despite the peaks being detected in mass spectrometry, most of the sample showed presence matrix interference.

- The most potent estrogens, i.e., E1, E2, E3 and EE2, were below the RL in the sludge phase of all the influent samples; while both E1 and E2 were detected in the range of 22.4 - $92.4 \mathrm{ng} / \mathrm{L}$. Concentrations of $\operatorname{Tr}(<4.76-6.29 \mathrm{ng} / \mathrm{g})$ and $\operatorname{Pr}(<4.76-22.7 \mathrm{ng} / \mathrm{g})$ were comparable to previously reported concentrations of hormones in dewatered sludge. However, while concentration of Ad $(<11.9-75.5 \mathrm{ng} / \mathrm{g})$ was slightly higher than the previous studies $(6.7-12 \mathrm{ng} / \mathrm{g})$.

- Microwave pretreatment of the digester feed (influent) led to attenuation of Ad and $\mathrm{Tr}$ in both soluble and total phases with an increase in the MW temperature. Similar trend was observed with E1 in the soluble phase. Furthermore, more hydrophobic hormones, such as E2, showed release to soluble phase from total phase. These suggest that both transformation (i.e. autoxidation, denaturation) and release of hormones from the complex polymeric floc structure occurred during the MW pretreatment.

- Pretreated digesters performed better in terms of TCOD removal, VS removal and biogas production rate. This improvement was especially prominent during the shortest SRT 
(highest organic loading rate) of operation (5 days). In fact, both mesophilic and thermophilic control (fed with unpretreated sludge) digesters stopped producing biogas after 20 days of operation as a result of VFA accumulation, while the pretreated digesters continued producing biogas.

- Despite the attenuation of E2, most potent natural estrogen, anaerobic digestion showed overall increase in most of the hormones (E1, Ad, Pr) in effluent relative to influent concentrations. This supports the previous finding that these micropollutants often exhibit resistance to anaerobic degradation.

- Although, below RL concentrations of E1, E2 in the sludge phase made it difficult to speculate their degradation, soluble phase concentrations of the influent and effluent stream from all the digesters revealed accumulation of E1 and attenuation of E2. Therefore, it is possible that E1 was an intermediate compound of E2 degradation, as suggested by previous literature.

- Statistical analysis revealed MW pretreatment temperature was in fact a significant factor $(\mathrm{P} \leq 0.05)$ in removal of Pr from sludge phase. Similarly, removal of Ad and E1 from soluble phase of digester effluent were significantly $(\mathrm{P} \leq 0.05)$ different at studied pretreatment temperatures. Furthermore, SRT and operating temperatures influenced removal of Ad and E1 from soluble phase, respectively.

- Total hormone concentration $(\mathrm{E} 1+\mathrm{E} 2+\mathrm{Ad}+\mathrm{Pr})$ in the supernatant (soluble phase) of mesophilic digesters linearly decreased (relative to control) with increasing MW temperature at 20 days SRT. This indicates that pretreated digester has the potential to introduce smaller amount of target compounds to the WWTP with the recycled supernatant of the digestate in the mesophilic temperature range. In contrast, at same SRT, thermophilic control performed in the same range as pretreated thermophilic digesters. In fact, effluent supernatant of the thermophilic digester fed with pretreated sludge at $160^{\circ} \mathrm{C}$, had slightly higher total hormone concentration relative to control.

- Despite thermophilic digesters showing lower hormone concentrations $(\mathrm{E} 1+\mathrm{E} 2+\mathrm{Ad}+$ Pr) in supernatants relative to mesophilic at 20 days SRT, total phase concentrations suggested more accumulation in thermophilic digesters. This may result in higher 
steroidal hormone concentrations in dewatered digested sludge, eventually ending up in the agricultural land with biosolids.

\subsection{Thesis contributions}

For the first time, this study investigated the fate of steroidal hormones in sewage sludge during anaerobic digestion coupled with MW pretreatment. Although, initial hypothesis was that pretreatment would release hormones from sludge floc to soluble phase of the sludge, the results indicated both release and transformation of hormones occurred during pretreatment. Overall hormone concentrations decreased in the influents of digesters following MW pretreatment. This has never been reported before. In addition, this research also affirms the previous findings that anaerobic digestion was mostly inefficient in degrading steroidal hormone concentrations. However, in contrast to previous studies, various factors (e.g., pretreatment temperatures, digestion temperatures, SRTs) were found to be significantly affecting fate of these compounds. This suggests that, it is possible to optimize the digestion system in terms of steroidal hormone removal.

\subsection{Perspectives}

The conclusions presented here can be verified and expanded based on the following recommended research:

- Microwave pretreated digester feeds showed reduction of some hormone concentrations. Exact mechanism of this attenuation is yet to be studied.

- Anaerobic digesters showed high accumulation of some hormones, suggesting possibility of microbial assisted conversion of one hormone to another. Although, a number of reports showed microorganisms isolated from environment are able to perform such transformation, these are mostly under aerobic condition. Degradation of steroidal hormones under anaerobic conditions needs further studies.

- Estrogenic and androgenic potency of the hormones varies over a wide range. Instead of quantifying each hormone separately, another approach could be to use bioassays. This would enable us to study effect of pretreatment on the total endocrine disruption potency of the influent and effluent streams. 
- Since this study shows MW pretreatment has the potential to attenuate most of the hormones in the influent, other emerging pretreatment techniques such as mechanical, chemical etc. should be incorporated into future studies. 


\section{References}

Ackman, R. G., 1972. Porous polymer bead packings and formic acid vapor in the GLC of volatile free fatty acids. Journal of Chromatographic Science 10(9), 560-565.

Adams, N. R., 1998. Clover phyto-oestrogens in sheep in western australia. Pure and Applied Chemistry 70(9), 1855-1862.

Adlercreutz, H., Hockerstedt, K., Bannwart, C., Bloigu, S., Hdmalainen, E., Fotsis, T. and Ollus, A., 1987. Effect of dietary-components, including lignans and phytoestrogens, on enterohepatic circulation and liver-metabolism of estrogens and on sex-hormone binding globulin (SHBG). Journal of Steroid Biochemistry and Molecular Biology 27(4-6), 11351144.

Adlercreutz, H. and Martin, F., 1980. Biliary excretion and intestinal metabolism of progesterone and estrogens in man. Journal of Steroid Biochemistry 13(2), 231-244.

Agency, U.S. Environmental Protection, 2011. http://www.epa.gov/scipoly/oscpendo/index.htm.

Ahmed, S. R., 2000. The immune system as a potential target for environmental estrogens (endocrine disrupters): A new emerging field. Toxicology 150(1-3), 191-206.

Andersen, H. R., Hansen, M., Kjølholt, J., Stuer-Lauridsen, F., Ternes, T. and Halling-Sørensen, B., 2005. Assessment of the importance of sorption for steroid estrogens removal during activated sludge treatment. Chemosphere 61(1), 139-146.

Andersen, H., Siegrist, H., Halling-Sorensen, B. and Ternes, T. A., 2003. Fate of estrogens in a municipal sewage treatment plant. Environmental Science \& Technology 37(18), 40214026.

Apedaile, E., 2001. A perspective on biosolids management. The Canadian Journal of Infectious Diseases 12(4).

APHA, 2005 Standard methods for the examination of water and wastewater, Washington DC, USA.

AXYS, 2012. Method summary of axys method MLA-072 rev. 03 ver 02 (proprietary). 
Baggio, S. R. and Bragagnolo, N., 2006. The effect of heat treatment on the cholesterol oxides, cholesterol, total lipid and fatty acid contents of processed meat products. Food Chemistry 95(4), 611-619.

Barnabe, S., Brar, S. K., Tyagi, R. D., Beauchesne, I. and Surampalli, R. Y., 2009. Pre-treatment and bioconversion of wastewater sludge to value-added products-fate of endocrine disrupting compounds. Science of the Total Environment 407(5), 1471-1488.

Baronti, C., Curini, R., D'Ascenzo, G., Di Corcia, A., Gentili, A. and Samperi, R., 2000. Monitoring natural and synthetic estrogens at activated sludge sewage treatment plants and in a receiving river water. Environmental Science \& Technology 34(24), 5059-5066.

Beszedes, S., Laszlo, Z., Szabo, G. and Hodur, C., 2011. Effects of microwave pretreatments on the anaerobic digestion of food industrial sewage sludge. Environmental Progress \& Sustainable Energy 30(3), 486-492.

Botheju, D. and Bakke, R., 2011. Oxygen effects in anaerobic digestion-a review. The Open Waste management Journal 4, 19.

Braga, O., Smythe, G. A., SchÃfer, A. I. and Feitz, A. J., 2005. Fate of steroid estrogens in australian inland and coastal wastewater treatment plants. Environmental Science \& Technology 39(9), 3351-3358.

Briciu, R. D., Kot-Wasik, A. and Namiesnik, J., 2009. Analytical challenges and recent advances in the determination of estrogens in water environments. Journal of Chromatographic Science 47(2), 127-139.

Brown, G. S., 2006. The effects of estrogen on the growth and tuberization of potato plants (Solanum tuberosum cv. 'iwa') grown in liquid tissue culture media, University of Canterbury.

Buchberger, W. W., 2007. Novel analytical procedures for screening of drug residues in water, waste water, sediment and sludge. Analytica Chimica Acta 593(2), 129-139.

Burkholder, J., Libra, B., Weyer, P., Heathcote, S., Kolpin, D., Thorne, P. S. and Wichman, M., 2007. Impacts of waste from concentrated animal feeding operations on water quality. Environmental Health Perspectives 115(2), 308-312. 
Caliman, F. A. and Gavrilescu, M., 2009. Pharmaceuticals, personal care products and endocrine disrupting agents in the environment - A review Clean-Soil Air Water 37(4-5), 277-303.

Camel, V., 2001. Recent extraction techniques for solid matrices-supercritical fluid extraction, pressurized fluid extraction and microwave-assisted extraction: Their potential and pitfalls. Analyst 126(7), 1182-1193.

Canada, Office of the Auditor General of, 2011. http://www.oagbvg.gc.ca/internet/English/pet_310_e_35780.html.

Carballa, M., Manterola, G., Larrea, L., Ternes, T., Omil, F. and Lema, J. M., 2007. Influence of ozone pre-treatment on sludge anaerobic digestion: Removal of pharmaceutical and personal care products. Chemosphere 67(7), 1444-1452.

Carballa, M., Omil, F., Alder, A. C. and Lema, J. M., 2006. Comparison between the conventional anaerobic digestion of sewage sludge and its combination with a chemical or thermal pre-treatment concerning the removal of pharmaceuticals and personal care products. Water Science and Technology 53(8), 109-117.

Carballa, M., Omil, F., Lema, J. M., Llompart, M., Garcia-Jares, C., Rodriguez, I., Gomez, M. and Ternes, T., 2004. Behavior of pharmaceuticals, cosmetics and hormones in a sewage treatment plant. Water Research 38(12), 2918-2926.

Carballa, M., Omil, F. and Lema, J.M., 2009. Influence of different pretreatments on anaerobically digested sludge characteristics: Suitability for final disposal. Water, Air, \& Soil Pollution 199(1), 311-321.

Carballa, Marta, Fink, Guido, Omil, Francisco, Lema, Juan M. and Ternes, Thomas, 2008. Determination of the solid-water distribution coefficient $\left(\mathrm{k}_{\mathrm{d}}\right)$ for pharmaceuticals, estrogens and musk fragrances in digested sludge. Water Research 42(1-2), 287-295.

Cargouet, M., Perdiz, D., Mouatassim-Souali, A., Tamisier-Karolak, S. and Levi, Y., 2004. Assessment of river contamination by estrogenic compounds in Paris area (France). Science of the Total Environment 324(1-3), 55-66.

Chang, C. J., Tyagi, V. K. and Lo, S. L., 2011. Effects of microwave and alkali induced pretreatment on sludge solubilization and subsequent aerobic digestion. Bioresource Technology 102(17), 7633-7640. 
Chang, H. S., Choo, K. H., Lee, B. and Choi, S. J., 2009. The methods of identification, analysis, and removal of endocrine disrupting compounds (EDCs) in water. Journal of Hazardous Materials 172(1), 1-12.

Chimchirian, R. F., Suri, R. P. S. and Fu, H., 2007. Free synthetic and natural estrogen hormones in influent and effluent of three municipal wastewater treatment plants. Water Environment Research 79(9), 969-974.

Chiu, T. Y., Koh, Y. K. K., Paterakis, N., Boobis, A. R., Cartmell, E., Richards, K. H., Lester, J. N. and Scrimshaw, M. D., 2009. The significance of sample mass in the analysis of steroid estrogens in sewage sludges and the derivation of partition coefficients in wastewaters. Journal of Chromatography 1216(24), 4923-4926.

Citulski, J. A. and Farahbakhsh, K., 2010. Fate of endocrine-active compounds during municipal biosolids treatment: A review. Environmental Science \& Technology 44(22), 8367-8376.

Clara, M., Kreuzinger, N., Strenn, B., Gans, O. and Kroiss, H., 2005. The solids retention time a suitable design parameter to evaluate the capacity of wastewater treatment plants to remove micropollutants. Water Research 39(1), 97-106.

Clara, M., Strenn, B., Saracevic, E. and Kreuzinger, N., 2004. Adsorption of bisphenol-a, 17 beta-estradiole and 17 alpha-ethinylestradiole to sewage sludge. Chemosphere 56(9), 843-851.

Clouzot, L., Marrot, B., Doumenq, P. and Roche, N., 2008. 17 alpha-ethinylestradiol: An endocrine disrupter of great concern. Analytical methods and removal processes applied to water purification. A review. Environmental Progress 27(3), 383-396.

Coe, T. S., Soffker, M. K., Filby, A. L., Hodgson, D. and Tyler, C. R., 2010. Impacts of early life exposure to estrogen on subsequent breeding behavior and reproductive success in zebrafish. Environmental Science \& Technology 44(16), 6481-6487.

Considine, D.M. and Considine, G.D., 1984. Van nostrand reinhold encyclopedia of chemistry. Van Nostrand Reinhold.

Czajka, C. P. and Londry, K. L., 2006. Anaerobic biotransformation of estrogens. Science of the Total Environment 367(2-3), 932-941. 
D'Ascenzo, G., Di Corcia, A., Gentili, A., Mancini, R., Mastropasqua, R., Nazzari, M. and Samperi, R., 2003. Fate of natural estrogen conjugates in municipal sewage transport and treatment facilities. Science of the Total Environment 302(1-3), 199-209.

Daniel, R. M., Dines, M. and Petach, H. H., 1996. The denaturation and degradation of stable enzymes at high temperatures. Biochemical Journal 317, 1-11.

De Gusseme, B., Pycke, B., Hennebel, T., Marcoen, A., Vlaeminck, S. E., Noppe, H., Boon, N. and Verstraete, W., 2009. Biological removal of 17 alpha-ethinylestradiol by a nitrifier enrichment culture in a membrane bioreactor. Water Research 43(9), 2493-2503.

de Mes, T., Zeeman, G. and Lettinga, G., 2005. Occurrence and fate of estrone, 17b-estradiol and 17a-ethynylestradiol in stps for domestic wastewater. Reviews in Environmental Science and Biotechnology 4(4), 275.

Delbes, G., Levacher, C. and Habert, R., 2006. Estrogen effects on fetal and neonatal testicular development. Reproduction 132(4), 527-538.

Development, Organization for Economic Co-operation and, 2002. http://www.oecd.org/document/58/0,3343,en_2649_34377_2348794_1_1_1_1,00.html.

Donova, MV, 2007. Transformation of steroids by actinobacteria: A review. Applied Biochemistry and Microbiology 43(1), 1-14.

Drewes, J. E., Hemming, J., Ladenburger, S. J., Schauer, J. and Sonzogni, W., 2005. An assessment of endocrine disrupting activity changes during wastewater treatment through the use of bioassays and chemical measurements. Water Environment Research 77(1), $12-23$.

Droste, R.L., 1997. Theory and practice of water and wastewater treatment. Wiley New York.

Eshrat, G.F. and Aroona, C., 2011. Biotransformation of progesterone by Penicillium aurantiogriseum. Research Journal of Microbiology 6(1), 98-104.

Eskicioglu, C., Droste, R.L. and Kennedy, K.J., 2007. Performance of anaerobic waste activated sludge digesters after microwave pretreatment. Water Environment Research 79(11), 2265-2273. 
Eskicioglu, C., Kennedy, K. J. and Droste, R. L., 2009. Enhanced disinfection and methane production from sewage sludge by microwave irradiation. Desalination 248(1-3), 279285.

Esperanza, M., Suidan, M. T., Marfil-Vega, R., Gonzalez, C., Sorial, G. A., McCauley, P. and Brenner, R., 2007. Fate of sex hormones in two pilot-scale municipal wastewater treatment plants: Conventional treatment. Chemosphere 66(8), 1535-1544.

Estrada-Arriaga, E. B. and Mijaylova, N. P., 2010. A comparison of biodegradation kinetic models applied to estrogen removal with nitrifying activated sludge. Water Science and Technology 62(9), 2183-2189.

Fan, Z. L., Wu, S. M., Chang, H. and Hu, J. Y., 2011. Behaviors of glucocorticoids, androgens and progestogens in a municipal sewage treatment plant: Comparison to estrogens. Environmental Science \& Technology 45(7), 2725-2733.

Fang, H., Tong, W. D., Branham, W. S., Moland, C. L., Dial, S. L., Hong, H. X., Xie, Q., Perkins, R., Owens, W. and Sheehan, D. M., 2003. Study of 202 natural, synthetic, and environmental chemicals for binding to the androgen receptor. Chemical Research in Toxicology 16(10), 1338-1358.

Fernandez, M., Noguerol, T. N., Lacorte, S., Buchanan, I. and Piña, B., 2009. Toxicity identification fractionation of environmental estrogens in waste water and sludge using gas and liquid chromatography coupled to mass spectrometry and recombinant yeast assay. Analytical and Bioanalytical Chemistry 393(3), 957-968.

Fernandez, M. P., Ikonomou, M. G. and Buchanan, I., 2007. An assessment of estrogenic organic contaminants in canadian wastewaters. Science of the Total Environment 373(1), 250269.

Fisch, H. and Goluboff, E. T., 1996. Geographic variations in sperm counts: A potential cause of bias in studies of semen quality. Fertility and Sterility 65(5), 1044-1046.

Folmar, L. C., Hemmer, M. J., Denslow, N. D., Kroll, K., Chen, J., Cheek, A., Richman, H., Meredith, H. and Grau, E. G., 2002. A comparison of the estrogenic potencies of estradiol, ethynylestradiol, diethylstilbestrol, nonylphenol and methoxychlor in vivo and in vitro. Aquatic Toxicology 60(1-2), 101-110. 
Forrez, Ilse, Carballa, Marta, Boon, Nico and Verstraete, Willy, 2009. Biological removal of 17 $\alpha$-ethinylestradiol (EE2) in an aerated nitrifying fixed bed reactor during ammonium starvation. Journal of Chemical Technology \& Biotechnology 84(1), 119-125.

Froehner, S., Piccioni, W., Machado, K. S. and Aisse, M. M., 2011. Removal capacity of caffeine, hormones, and bisphenol by aerobic and anaerobic sewage treatment. Water Air and Soil Pollution 216(1-4), 463-471.

Fujii, K., Kikuchi, S., Satomi, M., Ushio-Sata, N. and Morita, N., 2002. Degradation of 17ßestradiol by a gram-negative bacterium isolated from activated sludge in a sewage treatment plant in tokyo, japan. Applied and Environmental Microbiology 68(4), 20572060.

Furlong, E. T., Gray, J. L., Quanrud, D. M., Teske, S. S., Esposito, K., Marine, J., Ela, W. P., Stinson, B., Kolpin, D. W. and Phillips, P. J., 2010. Fate of estrogenic compounds during municipal sludge stabilization and dewatering.

Gaulke, L. S., Strand, S. E., Kalhorn, T. F. and Stensel, H. D., 2008. 17 alpha-ethinylestradiol transformation via abiotic nitration in the presence of ammonia oxidizing bacteria. Environmental Science \& Technology 42(20), 7622-7627.

Ge, H., Jensen, P. D. and Batstone, D. J., 2010. Pre-treatment mechanisms during thermophilicmesophilic temperature phased anaerobic digestion of primary sludge. Water Research 44(1), 123-130.

Gomes, R. L., Avcioglu, E., Scrimshaw, M. D. and Lester, J. N., 2004. Steroid estrogen determination in sediment and sewage sludge: A critique of sample preparation and chromatographic/mass spectrometry considerations, incorporating a case study in method development. Trac-Trends in Analytical Chemistry 23(10-11), 737-744.

Gomes, R. L., Birkett, J. W., Scrimshaw, M. D. and Lester, J. N., 2005. Simultaneous determination of natural and synthetic steroid estrogens and their conjugates in aqueous matrices by liquid chromatography/mass spectrometry. International Journal of Environmental Analytical Chemistry 85(1), 1-14. 
Hansen, P. D., Dizer, H., Hock, B., Marx, A., Sherry, J., McMaster, M. and Blaise, C., 1998. Vitellogenin - a biomarker for endocrine disruptors. Trac-Trends in Analytical Chemistry 17(7), 448-451.

Hashimoto, T., Onda, K., Nakamura, Y., Tada, K., Miya, A. and Murakami, T., 2007. Comparison of natural estrogen removal efficiency in the conventional activated sludge process and the oxidation ditch process. Water Research 41(10), 2117-2126.

Hecker, M. and Hollert, H., 2011. Endocrine disruptor screening: Regulatory perspectives and needs. Environmental Sciences Europe 23(15), 14.

Hibberd, A., Maskaoui, K., Zhang, Z. and Zhou, J. L., 2009. An improved method for the simultaneous analysis of phenolic and steroidal estrogens in water and sediment. Talanta 77(4), 1315-1321.

Holbrook, R. D., Novak, J. T., Grizzard, T. J. and Love, N. G., 2002. Estrogen receptor agonist fate during wastewater and biosolids treatment processes: A mass balance analysis. Environmental Science \& Technology 36(21), 4533-4539.

Holmes, M., Kumar, A., Shareef, A., Doan, H., Stuetz, R. and Kookana, R., 2010. Fate of indicator endocrine disrupting chemicals in sewage during treatment and polishing for non-potable reuse. Water Science and Technology 62(6), 1416-1423.

IARC, 2007. Combined estrogen-progestogen contraceptives and combined estrogenprogestogen menopausal therapy, Organization.

Ifelebuegu, A. O., 2011. The fate and behavior of selected endocrine disrupting chemicals in full scale wastewater and sludge treatment unit processes. International Journal of Environmental Science and Technology 8(2), 245-254.

Irwin, L. K., Gray, S. and Oberdorster, E., 2001. Vitellogenin induction in painted turtle, chrysemys picta, as a biomarker of exposure to environmental levels of estradiol. Aquatic Toxicology 55(1-2), 49-60.

Ivashechkin, P., Corvini, P. F. X. and Dohmann, M., 2004. Behaviour of endocrine disrupting chemicals during the treatment of municipal sewage sludge. Water Science and Technology 50(5), 133-140. 
Janeczko, A. and Skoczowski, A., 2005. Mammalian sex hormones in plants. Folia Histochemica Et Cytobiologica 43(2), 71-79.

Jenkins, M. B., Endale, D. M., Schomberg, H. H., Hartel, P. G. and Cabrera, M. L., 2009. 17ßestradiol and testosterone in drainage and runoff from poultry litter applications to tilled and no-till crop land under irrigation. Journal of Environmental Management 90(8), 2659-2664.

Jenkins, R. L., Wilson, E. M., Angus, R. A., Howell, W. M., Kirk, M., Moore, R., Nance, M. and Brown, A., 2004. Production of androgens by microbial transformation of progesterone in vitro: A model for androgen production in rivers receiving paper mill effluent. Environmental Health Perspectives 112(15), 1508-1511.

Jenkins, R.L., Wilson, E.M., Angus, R.A., Howell, W.M. and Kirk, M., 2003. Androstenedione and progesterone in the sediment of a river receiving paper mill effluent. Toxicological Sciences 73(1), 53-59.

Jiang, J. Q., Yin, Q., Zhou, J. L. and Pearce, P., 2005. Occurrence and treatment trials of endocrine disrupting chemicals (EDCs) in wastewaters. Chemosphere 61(4), 544-550.

Jobling, S., Nolan, M., Tyler, C. R., Brighty, G. and Sumpter, J. P., 1998. Widespread sexual disruption in wild fish. Environmental Science \& Technology 32(17), 2498-2506.

Jobling, S., Williams, R., Johnson, A. , Taylor, A., Gross-Sorokin, M., Nolan, M., Tyler, C. R., van Aerle, R., Santos, E. and Brighty, G., 2006. Predicted exposures to steroid estrogens in uk rivers correlate with widespread sexual disruption in wild fish populations. Environmental Health Perspectives 114, 32-39.

Johnson, A. C., Belfroid, A. and Di Corcia, A., 2000. Estimating steroid oestrogen inputs into activated sludge treatment works and observations on their removal from the effluent. Science of the Total Environment 256(2-3), 163-173.

Johnson, A. C. and Williams, R. J., 2004. A model to estimate influent and effluent concentrations of estradiol, estrone, and ethinylestradiol at sewage treatment works. Environmental Science and Technology 38(13), 3649-3658. 
Johnson, A. C., Williams, R. J. and Matthiessen, P., 2006. The potential steroid hormone contribution of farm animals to freshwaters, the united kingdom as a case study. Science of the Total Environment 362(1-3), 166-178.

Jolly, M. and Gillard, J., 2009. The economics of advanced digestion, Leeds, UK.

Jones-Lepp, T. and Stevens, Rick, 2007. Pharmaceuticals and personal care products in biosolids/sewage sludge: The interface between analytical chemistry and regulation. Analytical and Bioanalytical Chemistry 387(4), 1173-1183.

Joss, A., Andersen, H., Ternes, T., Richle, P. R. and Siegrist, H., 2004. Removal of estrogens in municipal wastewater treatment under aerobic and anaerobic conditions: Consequences for plant optimization. Environmental Science and Technology 38(11), 3047-3055.

Khanal, S. K., Xie, B., Thompson, M. L., Sung, S., Ong, S. K. and Van Leeuwen, J., 2006. Fate, transport, and biodegradation of natural estrogens in the environment and engineered systems. Environmental Science \& Technology 40(21), 6537-6546.

Khunjar, W. O., Mackintosh, S. A., Skotnicka-Pitak, J., Baik, S., Aga, D. S. and Love, N. G., 2011. Elucidating the relative roles of ammonia oxidizing and heterotrophic bacteria during the biotransformation of 17 alpha-ethinylestradiol and trimethoprim. Environmental Science \& Technology 45(8), 3605-3612.

Kidd, K. A., Blanchfield, P. J., Mills, K. H., Palace, V. P., Evans, R. E., Lazorchak, J. M. and Flick, R. W., 2007. Collapse of a fish population after exposure to a synthetic estrogen. Proceedings of the National Academy of Sciences of the United States of America 104(21), 8897-8901.

Kim, D. J. and Youn, Y., 2011. Characteristics of sludge hydrolysis by ultrasound and thermal pretreatment at low temperature. Korean Journal of Chemical Engineering 28(9), 18761881.

Kim, J. K., Alley, D., Hu, P., Karlamangla, A., Seeman, T. and Crimmins, E. M., 2007. Changes in postmenopausal hormone therapy use since 1988 - commentary. Womens Health Issues 17(6), 338-341. 
Kjaer, J., Olsen, P., Bach, K. , Barlebo, H.C. , Ingerslev, F. , Hansen, M. and Sorensen, B.H., 2007. Leaching of estrogenic hormones from manure-treated structured soils. Environmental Science and Technology 41(11), 3911--3917.

Koh, Y. K. K., Chiu, T. Y., Boobis, A., Cartmell, E., Scrimshaw, M. D. and Lester, J. N., 2008. Treatment and removal strategies for estrogens from wastewater. Environmental Technology 29(3), 245-267.

Koh, Y. K. K., Chiu, T. Y., Boobis, A. R., Scrimshaw, M. D., Bagnall, J. P., Soares, A., Pollard, S., Cartmell, E. and Lester, J. N., 2009. Influence of operating parameters on the biodegradation of steroid estrogens and nonylphenolic compounds during biological wastewater treatment processes. Environmental Science \& Technology 43(17), 66466654.

Komori, K., Tanaka, H., Okayasu, Y., Yasojima, M. and Sato, C., 2004. Analysis and occurrence of estrogen in wastewater in japan. Water Science and Technology 50(5), 93-100.

Kozlowska-Tylingo, K., Namieśnik, J., and Górecki, T., 2010. Determination of estrogenic endocrine disruptors in environmental samples - a review of chromatographic methods. Critical Reviews in Analytical Chemistry 40(3), 194-201.

Kreuzinger, N., Clara, M., Strenn, B. and Kroiss, H., 2004. Relevance of the sludge retention time (srt) as design criteria for wastewater treatment plants for the removal of endocrine disruptors and pharmaceuticals from wastewater. Water Science and Technology 50(5), 149-156.

Labadie, P. and Budzinski, H., 2005. Determination of steroidal hormone profiles along the Jalle d'eysines River (near Bordeaux, France). Environmental Science \& Technology 39(14), 5113-5120.

Lange, I. G., Daxenberger, A., Schiffer, B., Witters, H., Ibarreta, D. and Meyer, H. H. D., 2002. Sex hormones originating from different livestock production systems: Fate and potential disrupting activity in the environment. Analytica Chimica Acta 473(1-2), 27-37.

Layton, A. C., Gregory, B. W., Seward, J. R., Schultz, T. W. and Sayler, G. S., 2000. Mineralization of steroidal hormones by biosolids in wastewater treatment systems in tennessee USA. Environmental Science \& Technology 34(18), 3925-3931. 
Lee, H. B. and Liu, D., 2002. Degradation of 17 beta-estradiol and its metabolites by sewage bacteria. Water Air and Soil Pollution 134(1-4), 353-368.

Legler, J., Dennekamp, M., Vethaak, A. D., Brouwer, A., Koeman, J. H., van der Burg, B. and Murk, A. J., 2002a. Detection of estrogenic activity in sediment-associated compounds using in vitro reporter gene assays. Science of the Total Environment 293(1-3), 69-83.

Legler, J., Jonas, A., Lahr, J., Vethaak, A. D., Brouwer, A. and Murk, A. J., 2002b. Biological measurement of estrogenic activity in urine and bile conjugates with the in vitro er-calux reporter gene assay. Environmental Toxicology and Chemistry 21(3), 473-479.

Legler, J., van den Brink, C. E., Brouwer, A., Murk, A. J., van der Saag, P. T., Vethaak, A. D. and van der Burg, P., 1999. Development of a stably transfected estrogen receptormediated luciferase reporter gene assay in the human T47D breast cancer cell line. Toxicological Sciences 48(1), 55-66.

Li, F. S., Yuasa, A., Obara, A. and Mathews, A. P., 2005. Aerobic batch degradation of 17-beta estradiol (E2) by activated sludge: Effects of spiking E2 concentrations, MLVSS, and temperatures. Water Research 39(10), 2065-2075.

Li, Y. M., Zeng, Q. L. and Yang, S. J., 2011. Removal and fate of estrogens in an anaerobicanoxic-oxic activated sludge system. Water Science and Technology 63(1), 51-56.

Lin, Y. Q., Wang, D. H., Wu, S. Q. and Wang, C. M., 2009. Alkali pretreatment enhances biogas production in the anaerobic digestion of pulp and paper sludge. Journal of Hazardous Materials 170(1), 366-373.

Liu, R., Zhou, J. L. and Wilding, A., 2004. Microwave-assisted extraction followed by gas chromatography-mass spectrometry for the determination of endocrine disrupting chemicals in river sediments. Journal of Chromatography A 1038(1-2), 19-26.

Liu, S., Ying, G. G., Zhao, J. L., Chen, F., Yang, B., Zhou, L. J. and Lai, H. J., 2011. Trace analysis of 28 steroids in surface water, wastewater and sludge samples by rapid resolution liquid chromatography-electrospray ionization tandem mass spectrometry. Journal of Chromatography A 1218(10), 1367-1378.

Liu, S., Ying, G. G., Zhao, J. L., Zhou, L. J., Yang, B., Chen, Z. F. and Lai, H. J., 2012a. Occurrence and fate of androgens, estrogens, glucocorticoids and progestagens in two 
different types of municipal wastewater treatment plants. Journal of Environmental Monitoring 14(2), 482-491.

Liu, S., Ying, G. G., Zhou, L. J., Zhang, R. Q., Chen, Z. F. and Lai, H. J., 2012b. Steroids in a typical swine farm and their release into the environment. Water Research 46(12), 37543768.

Liu, Z. H., Kanjo, Y. and Mizutani, S., 2009a. Removal mechanisms for endocrine disrupting compounds (edcs) in wastewater treatment - physical means, biodegradation, and chemical advanced oxidation: A review. Science of the Total Environment 407(2), 731748.

Liu, Z. H., Kanjo, Y. and Mizutani, S., 2009b. Urinary excretion rates of natural estrogens and androgens from humans, and their occurrence and fate in the environment: A review. Science of the Total Environment 407(18), 4975-4985.

Lopez, J., 2010. Endocrine- disrupting chemical pollution: Why the epa should regulate these chemicals under the clean water act. Sustainable Development Law and Policy X(3), 1922.

Lundgren, M. S. and Novak, P. J., 2009. Quantification of phytoestrogens in industrial waste streams. Environmental Toxicology and Chemistry 28(11), 2318-2323.

Mackay, D. and Shiu, W. Y., 1981. A critical-review of henrys law constants for chemicals of environmental interest. Journal of Physical and Chemical Reference Data 10(4), 11751199.

Malaviya, A. and Gomes, J., 2008. Androstenedione production by biotransformation of phytosterols. Bioresource Technology 99(15), 6725-6737.

Martin, A. R., Delgado, J. N. and Remers, W. A. (eds) (1998) Wilson and gisvold's textbook of organic medicinal and pharmaceutical chemistry, Lipincott-Raven, Philadelphia.

Matejicek, D., Houserova, P. and Kuban, V., 2007. Combined isolation and purification procedures prior to the high-performance liquid chromatographic-ion-trap tandem mass spectrometric determination of estrogens and their conjugates in river sediments. Journal of Chromatography 1171(1-2), 80-89. 
McAdam, E. J., Bagnall, J. P., Koh, Y. K. K., Chiu, T. Y., Pollard, S., Scrimshaw, M. D., Lester, J. N. and Cartmell, E., 2010. Removal of steroid estrogens in carbonaceous and nitrifying activated sludge processes. Chemosphere 81(1), 1-6.

McLachlan, J. A., Simpson, E. and Martin, M., 2006. Endocrine disrupters and female reproductive health. Best Practice \& Research Clinical Endocrinology \& Metabolism 20(1), 63-75.

Mudhoo, A. and Sharma, S.K., 2011. Microwave irradiation technology in waste sludge and wastewater treatment research. Critical Reviews in Environmental Science and Technology 41(11), 999-1066.

Muller, J. A., 2000. Pretreatment processes for the recycling and reuse of sewage sludge. Water Science and Technology 42(9), 167-174.

Muller, M., Combalbert, S., Delgenes, N., Bergheaud, V., Rocher, V., Benoit, P., Delgens, J. P., Patureau, D. and Hernandez-Raquet, G., 2010. Occurrence of estrogens in sewage sludge and their fate during plant-scale anaerobic digestion. Chemosphere 81(1), 65-71.

Muller, M., Rabenoelina, F., Balaguer, P., Patureau, D., Lemenach, K., Budzinski, H., Barcelo, D., De Alda, M. L., Kuster, M., Delgenes, J. P. and Hernandez-Raquet, G., 2008. Chemical and biological analysis of endocrine-disrupting hormones and estrogenic activity in an advanced sewage treatment plant. Environmental Toxicology and Chemistry 27(8), 1649-1658.

Nieto, A., Borrull, F., Pocurull, E. and Marce, R. M., 2008. Determination of natural and synthetic estrogens and their conjugates in sewage sludge by pressurized liquid extraction and liquid chromatography-tandem mass spectrometry Journal of Chromatography A 1213(2), 224-230.

Onyeche, T., 2006 Sewage sludge as source of energy, pp. 29-31, Moscow, Russia.

Osada, K., Kodama, T., Yamada, K. and Sugano, M., 1993. Oxidation of cholesterol by heating. Journal of Agricultural and Food Chemistry 41(8), 1198-1202.

Otaegui-Arrazola, A., Menéndez-Carreño, M., Ansorena, D. and Astiasarán, I., 2010. Oxysterols: A world to explore. Food and Chemical Toxicology 48(12), 3289-3303. 
Panter, G. H., Thompson, R. S. and Sumpter, J. P., 1998. Adverse reproductive effects in male fathead minnows (Pimephales promelas) exposed to environmentally relevant concentrations of the natural oestrogens, oestradiol and oestrone. Aquatic Toxicology 42(4), 243-253.

Park, W.J., 2011. Effects of microwave pretreatment on mesophilic anaerobic digestion for mixture of primary and secondary sludges compared with thermal pretreatment. Environmental Engineering Research 16(2), 103-109.

Pilli, S., Bhunia, P., Yan, S., LeBlanc, R. J., Tyagi, R. D. and Surampalli, R. Y., 2011. Ultrasonic pretreatment of sludge: A review. Ultrasonics Sonochemistry 18(1), 1-18.

Pino-Jelcic, S. A., Hong, S. M. and Park, J. K., 2006. Enhanced anaerobic biodegradability and inactivation of fecal coliforms and salmonella spp. In wastewater sludge by using microwaves. Water Environment Research 78(2), 209-216.

Pollock, M. S., Dube, M. G. and Schryer, R., 2010. Investigating the link between pulp mill effluent and endocrine disruption: Attempts to explain the presence of intersex fish in the Wabigoon River, Ontario, Canada. Environmental Toxicology and Chemistry 29(4), 952965.

Purdom, C. E., Hardiman, P. A., Bye, V. V. J., Eno, N. C., Tyler, C. R. and Sumpter, J. P., 1994. Estrogenic effects of effluents from sewage treatment works. Chemistry and Ecology 8(4), 275-285.

Reddy, S., Iden, C. R. and Brownawell, B. J., 2005. Analysis of steroid conjugates in sewage influent and effluent by liquid chromatography-tandem mass spectrometry. Analytical Chemistry 77(21), 7032-7038.

Ren, Y. X., Nakano, K., Nomura, M., Chiba, N. and Nishimura, O., 2007. Effects of bacterial activity on estrogen removal in nitrifying activated sludge. Water Research 41(14), 30893096.

Richardson, S. D., 2008. Environmental mass spectrometry: Emerging contaminants and current issues. Analytical Chemistry 80(12), 4373-4402. 
Routledge, E. J. and Sumpter, J. P., 1996. Estrogenic activity of surfactants and some of their degradation products assessed using a recombinant yeast screen. Environmental Toxicology and Chemistry 15(3), 241-248.

Safe, S. H., 2000. Endocrine disruptors and human health - is there a problem? An update. Environmental Health Perspectives 108(6), 487-493.

Saha, M., Eskicioglu, C. and Marin, J., 2011. Microwave, ultrasonic and chemo-mechanical pretreatments for enhancing methane potential of pulp mill wastewater treatment sludge. Bioresource Technology 102(17), 7815-7826.

Salgado, R., Noronha, J. P., Oehmen, A., Carvalho, G. and Reis, M. A. M., 2010. Analysis of 65 pharmaceuticals and personal care products in 5 wastewater treatment plants in portugal using a simplified analytical methodology. Water Science and Technology 62(12), 28622871.

Salsabil, M. R., Laurent, J., Casellas, M. and Dagot, C., 2010. Techno-economic evaluation of thermal treatment, ozonation and sonication for the reduction of wastewater biomass volume before aerobic or anaerobic digestion. Journal of Hazardous Materials 174(1-3), 323-333.

Segura, Pedro A., Tremblay, Patrice, Picard, Pierre, Gagnon, Christian and Sauvé, Sébastien, 2010. High-throughput quantitation of seven sulfonamide residues in dairy milk using laser diode thermal desorption-negative mode atmospheric pressure chemical ionization tandem mass spectrometry. Journal of Agricultural and Food Chemistry 58(3), 14421446.

Servos, M. R., Bennie, D. T., Burnison, B. K., Jurkovic, A., McInnis, R., Neheli, T., Schnell, A., Seto, P., Smyth, S. A. and Ternes, T. A., 2005. Distribution of estrogens, 17 betaestradiol and estrone, in canadian municipal wastewater treatment plants. Science of the Total Environment 336(1-3), 155-170.

Shackleton, C. H. L., 1986. Profiling steroid-hormones and urinary steroids. Journal of Chromatography 379, 91-156. 
Shi, J., Fujisawa, S., Nakai, S. and Hosomi, M., 2004. Biodegradation of natural and synthetic estrogens by nitrifying activated sludge and ammonia-oxidizing bacterium nitrosomonas europaea Water Research 38(9), 2323-2330.

Skiadas, I.V., Gavala, H.N., Lu, J. and Ahring, B.K., 2005. Thermal pre-treatment of primary and secondary sludge at $70^{\circ} \mathrm{c}$ prior to anaerobic digestion. Water Science and Technology 52(1-2), 161-166.

Skotnicka-Pitak, J., Khunjar, W. O., Love, N. G. and Aga, D. S., 2009. Characterization of metabolites formed during the biotransformation of 17 alpha-ethinylestradiol by nitrosomonas europaea in batch and continuous flow bioreactors. Environmental Science \& Technology 43(10), 3549-3555.

Stevens-Garmon, J., Drewes, J.E., Khan, S.J., McDonald, J.A. and Dickenson, E.R.V., 2011. Sorption of emerging trace organic compounds onto wastewater sludge solids. Water Research 45(11), 3417-3426.

Svenson, A., Allard, A. S. and Ek, M., 2003. Removal of estrogenicity in swedish municipal sewage treatment plants. Water Research 37(18), 4433-4443.

Tan, B. L. L., Hawker, D.W., Mueller, J. F., Leusch, F. D. L., Tremblay, L. A. and Chapman, H. F., 2007. Comprehensive study of endocrine disrupting compounds using grab and passive sampling at selected wastewater treatment plants in south east Queensland, Australia. Environment International 33(5), 654-669.

Tchobanoglous, G. , Burton, F. L. and Stensel, H. D., 2002. Wstewater engineering: Treatment and reuse. Mcgraw Hill, New York, USA.

Ternes, T. A., Andersen, H., Gilberg, D. and Bonerz, M., 2002. Determination of estrogens in sludge and sediments by liquid extraction and GC/MS/MS. Analytical Chemistry 74(14), 3498-3504.

Ternes, T. A., Kreckel, P. and Mueller, J., 1999a. Behaviour and occurrence of estrogens in municipal sewage treatment plants - ii. Aerobic batch experiments with activated sludge. Science of the Total Environment 225(1-2), 91-99.

Ternes, T. A., Stumpf, M., Mueller, J., Haberer, K., Wilken, R. D. and Servos, M., 1999b. Behavior and occurrence of estrogens in municipal sewage treatment plants - i. 
Investigations in Germany, Canada and Brazil. Science of the Total Environment 228(1), $87-87$.

Teske, S. S. and Arnold, R. G., 2008. Removal of natural and xeno-estrogens during conventional wastewater treatment. Reviews in Environmental Science and Biotechnology 7(2), 107-124.

Tyagi, V. K. and Lo, S. L., 2011. Application of physico-chemical pretreatment methods to enhance the sludge disintegration and subsequent anaerobic digestion: An up to date review. Reviews in Environmental Science and Bio-Technology 10(3), 215-242.

Tyler, C. R., Spary, C., Gibson, R., Santos, E. M., Shears, J. and Hill, E. M., 2005. Accounting for differences in estrogenic responses in rainbow trout (Oncorhynchus mykiss : Salmonidae) and roach (Rutilus rutilus : Cyprinidae) exposed to effluents from wastewater treatment works. Environmental Science \& Technology 39(8), 2599-2607.

Tyler, C. R., Filby, A. L., Bickley, L. K., Cumming, R. I., Gibson, R., Labadie, P., Katsu, Y., Liney, K. E., Shears, J. A., Silva-Castro, V., Urushitani, H., Lange, A., Winter, M. J., Iguchi, T. and Hill, E. M., 2009. Environmental health impacts of equine estrogens derived from hormone replacement therapy. Environmental Science \& Technology 43(10), 3897-3904.

Vader, J. S., van Ginkel, C. G., Sperling, Fmgm, de Jong, J., de Boer, W., de Graaf, J. S., van der Most, M. and Stokman, P. G. W., 2000. Degradation of ethinyl estradiol by nitrifying activated sludge. Chemosphere 41(8), 1239-1243.

Van Huyssteen, J. J., 1967. Gas chromatographic separation of anaerobic digester gases using porous polymers. Water Research 1(3), 237-242.

Vethaak, A. D., Lahr, J., Schrap, S. M., Belfroid, A. C., Rijs, G. B. J., Gerritsen, A., de Boer, J., Bulder, A. S., Grinwis, G. C. M., Kuiper, R. V., Legler, J., Murk, T. A. J., Peijnenburg, W., Verhaar, H. J. M. and de Voogt, P., 2005. An integrated assessment of estrogenic contamination and biological effects in the aquatic environment of the netherlands. Chemosphere 59(4), 511-524. 
Viglino, Liza, Prevost, Michele and Sauve, Sebastien, 2011. High throughput analysis of solidbound endocrine disruptors by LDTD-APCI-MS/MS. Journal of Environmental Monitoring 13(3), 583-590.

Villagrasa, M., Guillamón, M., Eljarrat, E. and Barceló, D., 2007. Matrix effect in liquid chromatography-electrospray ionization mass spectrometry analysis of benzoxazinoid derivatives in plant material. Journal of Chromatography 1157(1-2), 108-114.

Weigel, S., Berger, U., Jensen, E., Kallenborn, R., Thoresen, H. and Huhnerfuss, H., 2004. Determination of selected pharmaceuticals and caffeine in sewage and seawater from tromso/norway with emphasis on ibuprofen and its metabolites. Chemosphere 56(6), 583592.

Wett, B., Phothilangka, P. and Eladawy, A., 2010. Systematic comparison of mechanical and thermal sludge disintegration technologies. Waste Management 30(6), 1057-1062.

Wise, A., O'Brien, K. and Woodruff, T., 2011. Are oral contraceptives a significant contributor to the estrogenicity of drinking water? Environmental Science \& Technology 45(1), 5160.

Wood, N., Tran, H. and Master, E., 2009. Pretreatment of pulp mill secondary sludge for highrate anaerobic conversion to biogas. Bioresource Technology 100(23), 5729-5735.

Yang, Y. Y., Gray, J. L., Furlong, E. T., Davis, J. G., ReVello, R. C. and Borch, T., 2012. Steroid hormone runoff from agricultural test plots applied with municipal biosolids. Environmental Science \& Technology 46(5), 2746-2754.

Yang, Y. Y., Pereyra, L. P., Young, R. B., Reardon, K. F. and Borch, T., 2011. Testosteronemineralizing culture enriched from swine manure: Characterization of degradation pathways and microbial community composition. Environmental Science \& Technology 45(16), 6879-6886.

Yi, T. and Harper, W. F., 2007. The link between nitrification and biotransformation of 17 alphaethinylestradiol. Environmental Science \& Technology 41(12), 4311-4316.

Ying, G. G., Kookana, R. S. and Kumar, A., 2008. Fate of estrogens and xenoestrogens in four sewage treatment plants with different technologies rid a-2670-2008. Environmental Toxicology and Chemistry 27(1), 87-94. 
Yoshimoto, T., Nagai, F., Fujimoto, J., Watanabe, K., Mizukoshi, H., Makino, T., Kimura, K., Saino, H., Sawada, H. and Omura, H., 2004. Degradation of estrogens by Rhodococcus zopfii and Rhodococcus equi isolates from activated sludge in wastewater treatment plants. Applied and Environmental Microbiology 70(9), 5283-5289.

Yu, Q., Lei, H. Y., Li, Z., Li, H. L., Chen, K., Zhang, X. H. and Liang, R. L., 2010. Physical and chemical properties of waste-activated sludge after microwave treatment. Water Research 44(9), 2841-2849.

Yu, Q., Lei, H., Yu, G., Feng, X., Li, Z. and Wu, Z., 2009. Influence of microwave irradiation on sludge dewaterability. Chemical Engineering Journal 155(1), 88-93.

Zeng, Q. , Li, Y. and Gu, G., 2009a. Nitrate-dependent degradation of 17 alpha-ethinylestradiol by acclimated activated sludge under anaerobic conditions. Journal of Chemical Technology and Biotechnology 84(12), 1841-1847.

Zeng, Q., Li, Y., Gu, G., Zhao, J., Zhang, C. and Luan, J., 2009b. Sorption and biodegradation of 17 beta-estradiol by acclimated aerobic activated sludge and isolation of the bacterial strain. Environmental Engineering Science 26(4), 783-790.

Zhang, Z., Feng, Y., Gao, P., Wang, C. and Ren, N., 2011. Occurrence and removal efficiencies of eight edcs and estrogenicity in a STP. Journal of Environmental Monitoring 13(5), 1366-1373.

Zheng, W., Li, X., Yates, S. R. and Bradford, S. A., 2012. Anaerobic transformation kinetics and mechanism of steroid estrogenic hormones in dairy lagoon water. Environmental Science \& Technology 46(10), 5471-5478. 


\section{Appendices}

\section{Appendix A: Calibration charts}

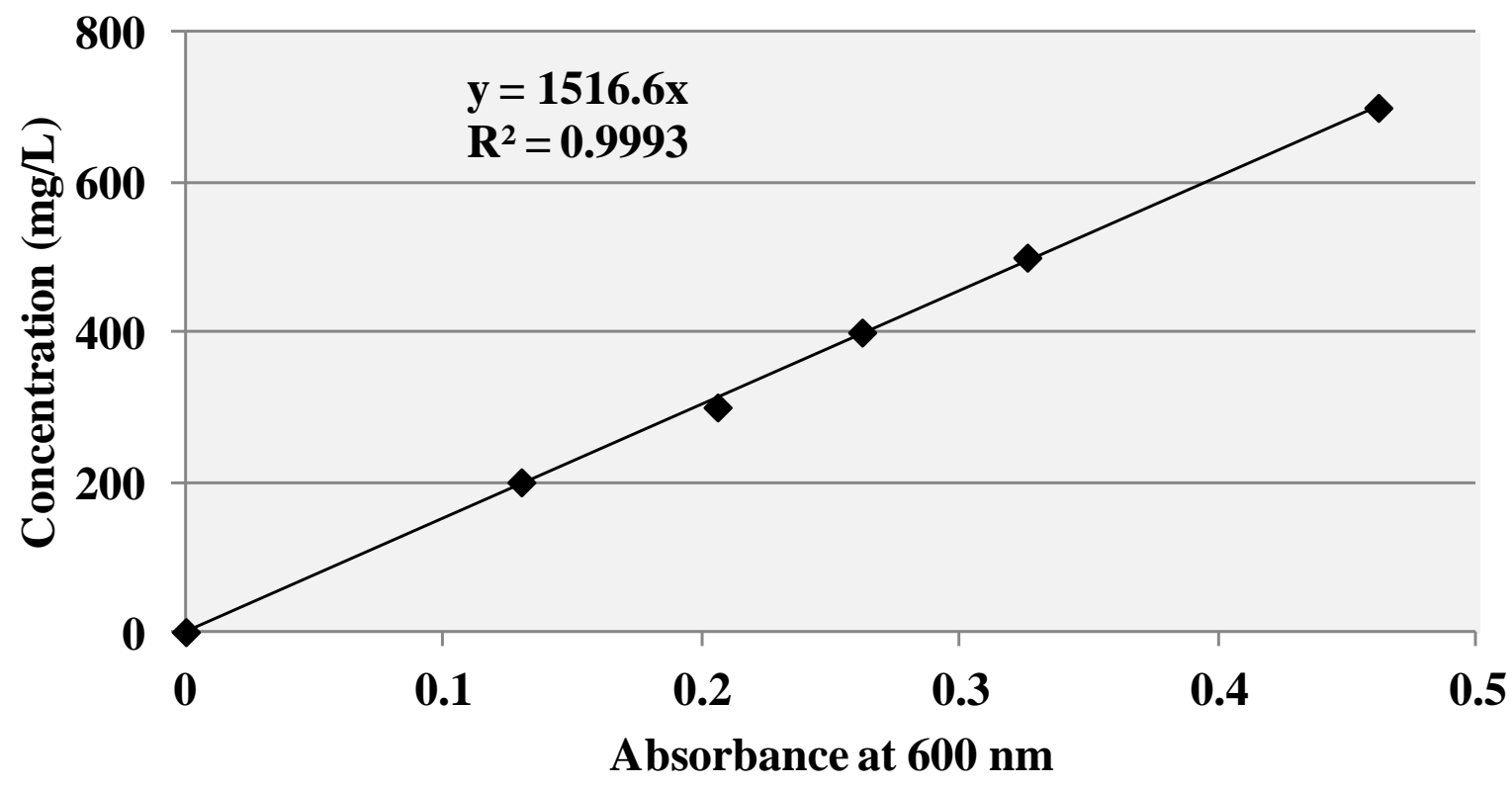

Figure A.1 Calibration curve for COD determination

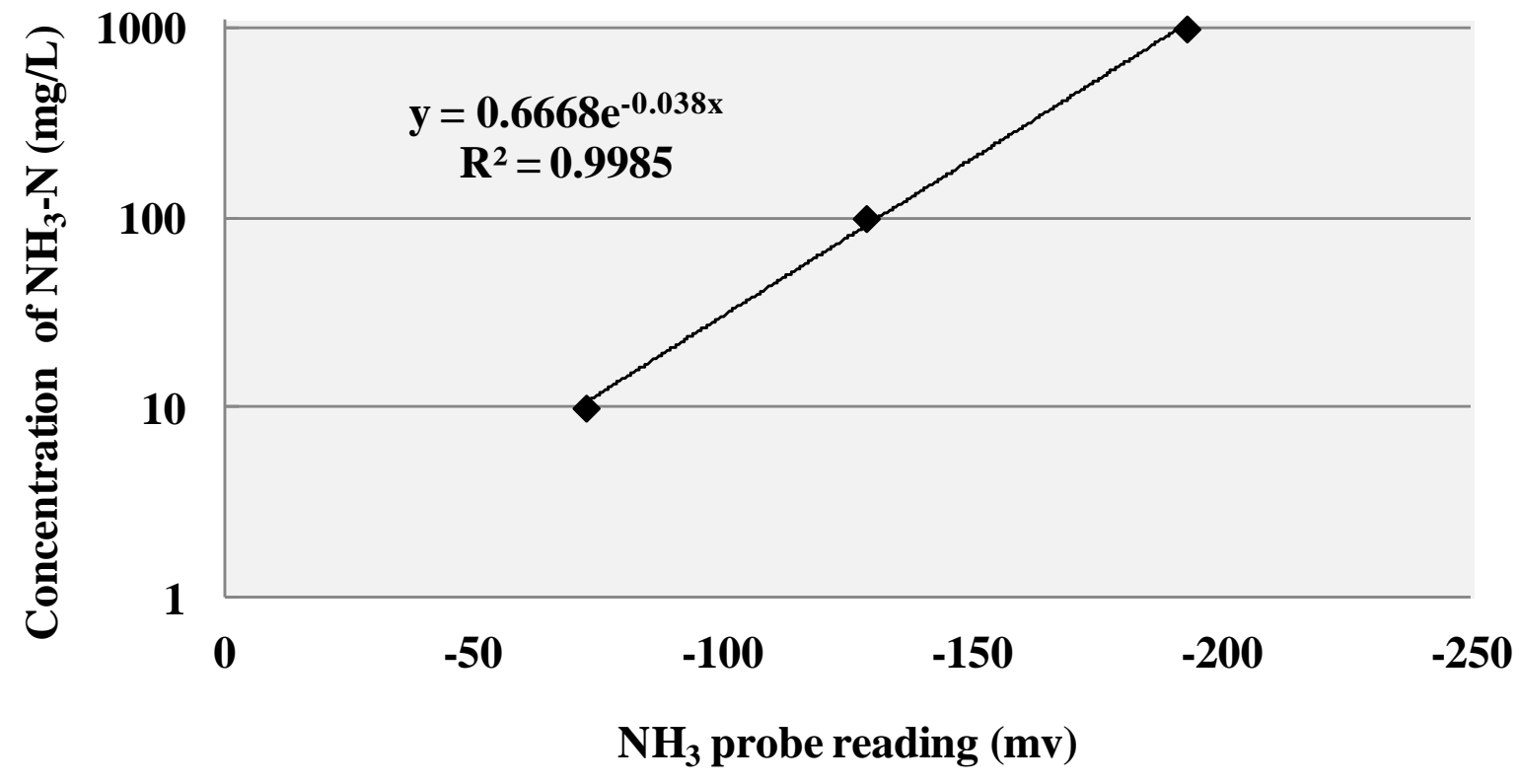

Figure A.2 Calibration curve for $\mathrm{NH}_{3}-\mathrm{N}$ determination 


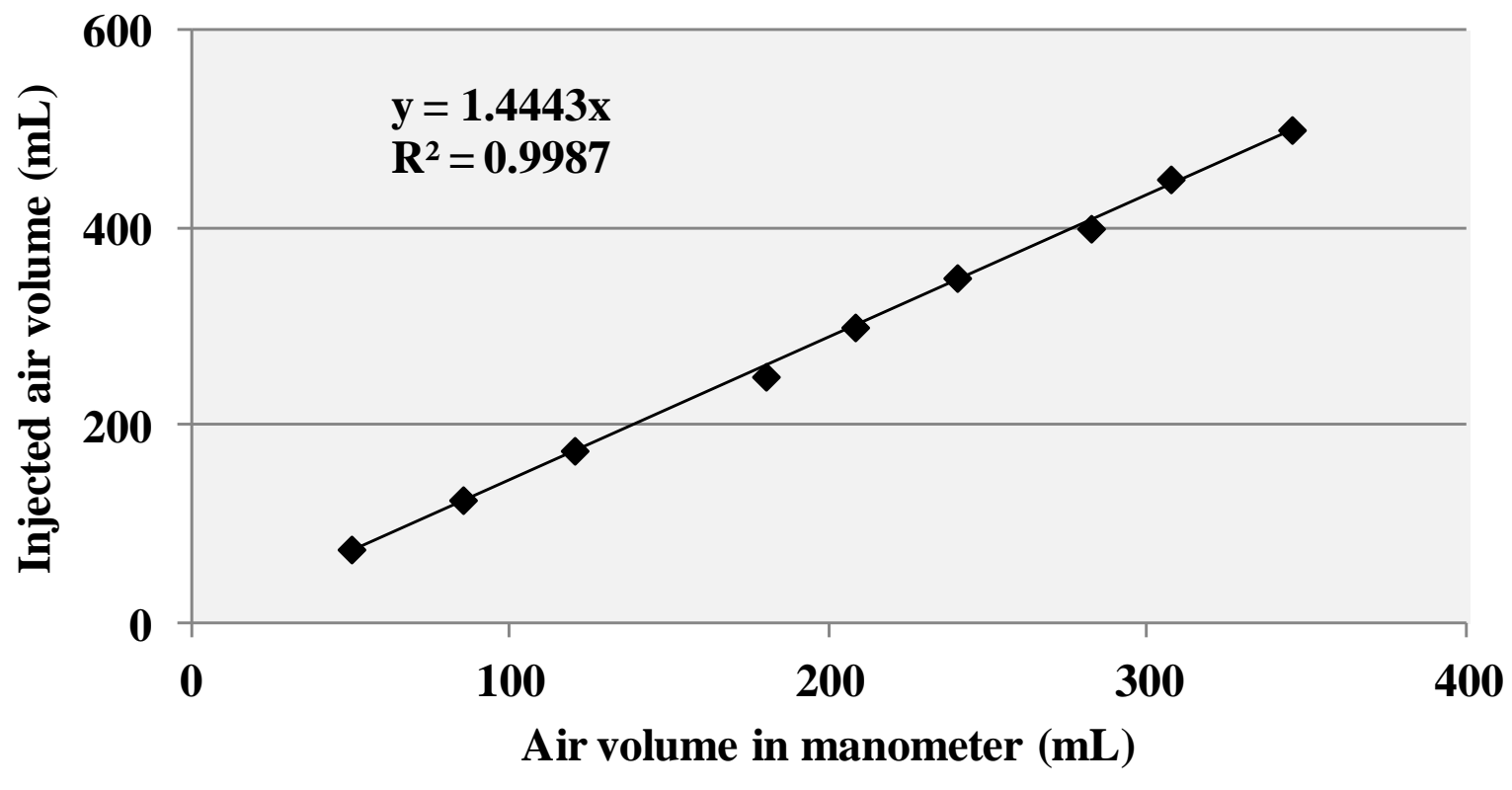

Figure A.3 Calibration curve for biogas measurement via manometer at $\operatorname{STP}\left(0^{\circ} \mathrm{C}, 1 \mathrm{~atm}\right)$ 


\section{Appendix B: Analytical detection of hormones}

Table B.1 Quality control acceptance criteria*

\begin{tabular}{|c|c|c|c|c|c|}
\hline \multirow{2}{*}{ Analytes } & \multicolumn{2}{|c|}{ IPR (\%) } & \multirow{2}{*}{$\begin{array}{c}\text { OPR } \\
\text { recovery } \\
(\%)\end{array}$} & \multirow{2}{*}{$\begin{array}{c}\text { Sample recovery } \\
(\%)\end{array}$} & \multirow{2}{*}{$\begin{array}{c}\text { Blank } \\
\text { level } \\
\text { (ng) }\end{array}$} \\
\hline & Recovery & RSD & & & \\
\hline Mestranol & $50-125$ & 30 & $45-130$ & - & $\leq 40$ \\
\hline Estrone & $30-140$ & 40 & $25-150$ & - & $\leq 4$ \\
\hline $17 \alpha$-Dihydroequilin & $35-160$ & 50 & $30-170$ & - & $\leq 4$ \\
\hline $17 \alpha$-Ethinylestradiol & $70-125$ & 30 & $70-130$ & - & $\leq 20$ \\
\hline $17 \alpha$-Estradiol & $50-125$ & 30 & $45-130$ & - & $\leq 4$ \\
\hline 17ß-Estradiol & $25-150$ & 40 & $20-160$ & - & $\leq 4$ \\
\hline Norethindrone & $75-125$ & 30 & $70-130$ & - & $\leq 4$ \\
\hline Equilin & $35-135$ & 30 & $30-140$ & - & $\leq 8$ \\
\hline Norgestrel & $70-125$ & 30 & $65-130$ & - & $\leq 4$ \\
\hline Testosterone & $75-125$ & 30 & $70-130$ & - & $\leq 0.8$ \\
\hline Progesterone & $75-125$ & 30 & $70-130$ & - & $\leq 0.8$ \\
\hline Androstenedione & $75-125$ & 30 & $70-130$ & - & $\leq 2$ \\
\hline Estriol & $75-130$ & 30 & $70-135$ & - & $\leq 48$ \\
\hline Allyl Trenbolone & $45-125$ & 30 & $40-130$ & - & $\leq 0.8$ \\
\hline Androsterone & $65-125$ & 30 & $65-130$ & - & $\leq 20$ \\
\hline Equilenin & $45-210$ & 50 & $40-220$ & - & $\leq 0.8$ \\
\hline \multicolumn{6}{|l|}{ Surrogate Standard } \\
\hline d4-17ß-Estradiol & $25-180$ & 40 & $20-190$ & $20-190^{\mathrm{a}}$ & - \\
\hline d6-Norethindrone & $75-130$ & 30 & $70-130$ & $70-130^{\mathrm{a}}$ & - \\
\hline d4-17 $\alpha$-Ethinylestradiol & $50-190$ & 30 & $40-200$ & $40-200^{\mathrm{a}}$ & - \\
\hline d9-Progesterone & $75-130$ & 30 & $70-130$ & $70-130^{\mathrm{a}}$ & - \\
\hline d6-Norgestrel & $75-130$ & 30 & $70-135$ & $70-135^{a}$ & - \\
\hline
\end{tabular}

*IPR: initial precision recovery, OPR: Ongoing precision recovery, RSD: relative standard deviation

${ }^{\mathrm{a}}$ Recoveries outside limits may be accepted based on application and professional judgment 
Table B.2 Reporting limit (RL) of steroidal hormones in supernatant (ng/L) of influent and effluents at different SRT's*

\begin{tabular}{|c|c|c|c|c|c|c|c|c|c|c|c|}
\hline \multirow[b]{2}{*}{ Hormones } & \multirow[b]{2}{*}{ Sample } & \multicolumn{4}{|c|}{ Mesophilic } & \multicolumn{4}{|c|}{ Thermophilic } & \multirow{2}{*}{$\begin{array}{c}\text { Lab } \\
\text { blank }\end{array}$} & \multirow{2}{*}{$\begin{array}{l}\text { Spiked matrix } \\
\text { (\% recovery) }\end{array}$} \\
\hline & & Control & MW80 & MW120 & MW160 & Control & MW80 & MW120 & MW160 & & \\
\hline \multirow{4}{*}{$\begin{array}{l}\text { Allyl } \\
\text { Trenbolone }\end{array}$} & Influent & $<9.18$ & $<12.4$ & $<39.9$ & $<22.1$ & $<9.18$ & $<12.4$ & $<39.9$ & $<22.1$ & $<3.28$ & 32.7 \\
\hline & Effluent (20 d) & $<17.9$ & $<24.1$ & $<16.5$ & $<27.0$ & $<20.6$ & $<15.1$ & $<20.4$ & $<15.8$ & $<5.47$ & 80.7 \\
\hline & Effluent (10 d) & $<5.55$ & $<5.59$ & $<7.06$ & $<8.68$ & $<13.6$ & $<7.62$ & $<13.3$ & $<18.0$ & $<8.47$ & 122 \\
\hline & Effluent (5d) & $<23.2$ & $<33.6$ & $<24.0$ & 42.3 & $<32.7$ & $<40.8$ & $<35.6$ & $<50.6$ & $<0.820$ & 42.5 \\
\hline \multirow{4}{*}{ Estriol (E3) } & Influent & $<123$ & $<125$ & $<126$ & $<149$ & $<123$ & $<125$ & $<126$ & $<149$ & $<128$ & 105 \\
\hline & Effluent (20 d) & $<112$ & $<112$ & $<110$ & $<105$ & $<114$ & $<122$ & $<121$ & $<114$ & $<107$ & 114 \\
\hline & Effluent (10 d) & $<4120$ & $<554$ & $<4070$ & $<5890$ & $<5440$ & $<5840$ & $<7260$ & $<5030$ & $<737$ & 267 \\
\hline & Effluent $(5 \mathrm{~d})$ & $<984$ & $<4890$ & $<4420$ & $<8250$ & $<8750$ & $<5290$ & $<5460$ & $<8560$ & $<16.0$ & 82.4 \\
\hline \multirow{4}{*}{ Norgestrel } & Influent & $<230$ & $<68.8$ & $<196$ & $<266$ & $<230$ & $<68.8$ & $<196$ & $<266$ & $<16.0$ & 74 \\
\hline & Effluent (20 d) & $<95.8$ & $<81.8$ & $<90.3$ & $<92.3$ & $<140$ & $<79.4$ & $<83.7$ & $<115$ & $<26.7$ & 89.2 \\
\hline & Effluent (10 d) & $<27.1$ & $<57.7$ & $<50.1$ & $<52.4$ & $<50.6$ & $<51.7$ & $<66.0$ & $<83.5$ & $<69.8$ & 131 \\
\hline & Effluent (5d) & $<60.2$ & $<90.0$ & $<60.2$ & $<42.1$ & $<78.7$ & $<80.1$ & $<53.6$ & $<408$ & $<4.00$ & 87.1 \\
\hline \multirow{4}{*}{$\begin{array}{l}17 \alpha- \\
\text { dihydroequilin }\end{array}$} & Influent & $<50.3$ & $<29.8$ & $<30.0$ & $<26.7$ & $<50.3$ & $<29.8$ & $<30.0$ & $<26.7$ & $<16.0$ & 72.3 \\
\hline & Effluent (20 d) & $<31.2$ & $<39.5$ & $<34.1$ & $<53.1$ & $<60.9$ & $<124$ & $<149$ & $<57.0$ & $<26.7$ & 100 \\
\hline & Effluent (10 d) & $<27.1$ & $<27.3$ & $<27.3$ & $<25.7$ & $<29.3$ & $<29.3$ & $<26.4$ & $<25.1$ & $<40.0$ & 96.2 \\
\hline & Effluent (5d) & $<60.2$ & $<90.0$ & $<60.2$ & $<42.1$ & $<78.7$ & $<53.1$ & $<53.6$ & $<61.1$ & $<40.0$ & 84.2 \\
\hline \multirow{4}{*}{ Equilenin } & Influent & $<3.31$ & $<3.12$ & $<3.16$ & $<3.71$ & $<3.31$ & $<3.12$ & $<3.16$ & $<3.71$ & $<3.20$ & 87.9 \\
\hline & Effluent (20 d) & $<5.59$ & $<5.60$ & $<5.50$ & $<5.25$ & $<5.69$ & $<6.11$ & $<6.04$ & $<5.69$ & $<5.33$ & 70.8 \\
\hline & Effluent (10 d) & $<5.41$ & $<5.45$ & $<5.45$ & $<5.13$ & $<5.86$ & $<5.86$ & $<5.28$ & $<7.55$ & $<8.00$ & 81.1 \\
\hline & Effluent (5d) & $<12.0$ & $<18.0$ & $<12.0$ & $<8.41$ & $<15.7$ & $<10.6$ & $<10.7$ & $<12.2$ & $<8.00$ & 98.9 \\
\hline \multirow{4}{*}{ Equilin } & Influent & $<30.8$ & $<31.2$ & $<31.6$ & $<37.1$ & $<30.8$ & $<31.2$ & $<31.6$ & $<37.1$ & $<32.0$ & 81 \\
\hline & Effluent (20 d) & $<55.9$ & $<56.0$ & $<55.0$ & $<52.5$ & $<56.9$ & $<61.1$ & $<60.4$ & $<56.9$ & $<53.3$ & 83 \\
\hline & Effluent (10 d) & $<54.1$ & $<54.5$ & $<54.5$ & $<51.3$ & $<58.6$ & $<58.6$ & $<52.8$ & $<50.2$ & $<80.0$ & 83.7 \\
\hline & Effluent (5d) & $<120$ & $<180$ & $<120$ & $<84.1$ & $<157$ & $<106$ & $<107$ & $<122$ & $<80.0$ & 83.7 \\
\hline
\end{tabular}


Table B.2 Continued from previous page

\begin{tabular}{|c|c|c|c|c|c|c|c|c|c|c|c|}
\hline \multirow[b]{2}{*}{ Hormones } & \multirow[b]{2}{*}{ Sample } & \multicolumn{4}{|c|}{ Mesophilic } & \multicolumn{4}{|c|}{ Thermophilic } & \multirow{2}{*}{$\begin{array}{c}\text { Lab } \\
\text { blank }\end{array}$} & \multirow{2}{*}{$\begin{array}{c}\text { Spiked matrix } \\
\text { (\% recovery) }\end{array}$} \\
\hline & & Control & MW80 & MW120 & MW160 & Control & MW80 & MW120 & MW160 & & \\
\hline \multirow{4}{*}{$17 \alpha$-estradiol } & Influent & $<15.4$ & $<15.6$ & $<15.8$ & $<18.6$ & $<15.4$ & $<15.6$ & $<15.8$ & $<18.6$ & $<16.0$ & 92.4 \\
\hline & Effluent (20 d) & $<27.9$ & $<28.0$ & $<27.5$ & $<26.2$ & $<28.4$ & $<30.6$ & $<30.2$ & $<50.0$ & $<26.7$ & 88 \\
\hline & Effluent (10 d) & $<27.1$ & $<27.3$ & $<27.3$ & $<25.7$ & $<29.3$ & $<29.3$ & $<26.4$ & $<25.1$ & $<40.0$ & 86.5 \\
\hline & Effluent $(5 \mathrm{~d})$ & $<60.2$ & $<90.0$ & $<60.2$ & $<42.1$ & $<78.7$ & $<53.1$ & $<53.6$ & $<61.1$ & $<40.0$ & 81.1 \\
\hline \multirow{4}{*}{$\begin{array}{l}17 \alpha- \\
\text { ethinylestradiol } \\
(E E 2)\end{array}$} & Influent & $<29.9$ & $<19.5$ & $<19.8$ & $<23.2$ & $<29.9$ & $<19.5$ & $<19.8$ & $<23.2$ & $<20.0$ & 84.4 \\
\hline & Effluent (20 d) & $<34.9$ & $<35.0$ & $<34.4$ & $<32.8$ & $<35.5$ & $<38.2$ & $<37.8$ & $<35.6$ & $<33.3$ & 99.9 \\
\hline & Effluent (10 d) & $<33.8$ & $<34.1$ & $<34.1$ & $<32.1$ & $<36.6$ & $<36.7$ & $<33.0$ & $<31.4$ & $<50.0$ & 84.5 \\
\hline & Effluent (5 d) & $<75.2$ & $<112$ & $<75.3$ & $<52.6$ & $<98.3$ & $<66.3$ & $<67.0$ & $<76.4$ & $<50.0$ & 79.3 \\
\hline \multirow{4}{*}{$\begin{array}{l}\text { Norethindrone } \\
(\mathrm{Nr})\end{array}$} & Influent & $<44.2$ & $<44.8$ & $<92.4$ & $<108$ & $<44.2$ & $<44.8$ & $<92.4$ & $<108$ & $<16.0$ & 68.3 \\
\hline & Effluent (20 d) & $<63.4$ & $<67.5$ & $<65.7$ & $<65.5$ & $<75.3$ & $<91.0$ & $<77.5$ & $<81.3$ & $<26.7$ & 95.1 \\
\hline & Effluent (10 d) & $<33.6$ & $<32.3$ & $<53.3$ & $<59.2$ & $<51.5$ & $<69.5$ & $<58.2$ & $<53.8$ & 88.7 & 141 \\
\hline & Effluent (5 d) & 124 & $<90.0$ & $<78.4$ & $<131$ & $<131$ & $<53.1$ & $<94.3$ & $<169$ & $<4.00$ & 81.4 \\
\hline
\end{tabular}

$*<$ : number following this symbol represents the reporting limit (RL), control: un-pretreated, MW: microwave (80,120 and 160 are the final pretreatment temperatures), lab blank: an aliquot of reagent water that is treated exactly as a sample including exposure to all glassware, equipment, solvents, reagents, internal standards, and surrogates that are used with samples, spiked matrix: matrix containing known quantity of analytes 
Table B.3 Reporting limit (RL) of steroidal hormones in total phase (ng/g of dry weight) of influent and effluents at different SRT's*

\begin{tabular}{|c|c|c|c|c|c|c|c|c|c|c|c|}
\hline \multirow{2}{*}{ Hormones } & \multirow{2}{*}{ Sample } & \multicolumn{4}{|c|}{ Mesophilic } & \multicolumn{4}{|c|}{ Thermophilic } & \multirow{2}{*}{$\begin{array}{c}\text { Lab } \\
\text { blank }\end{array}$} & \multirow{2}{*}{$\begin{array}{l}\text { Spiked matrix } \\
\text { (\% recovery) }\end{array}$} \\
\hline & & Control & MW80 & MW120 & MW160 & Control & MW80 & MW120 & MW160 & & \\
\hline \multirow{4}{*}{$\begin{array}{l}\text { Allyl } \\
\text { trenbolone }\end{array}$} & Influent & $<6.87$ & $<4.89$ & $<5.20$ & $<4.87$ & $<6.87$ & $<4.89$ & $<5.20$ & $<4.87$ & $<4.10$ & 53.3 \\
\hline & Effluent (20 d) & $<8.05$ & $<7.18$ & $<7.07$ & $<8.83$ & $<9.35$ & $<9.62$ & $<8.91$ & $<14.0$ & $<8.20$ & 63.2 \\
\hline & Effluent (10 d) & $<11.0$ & $<9.01$ & $<7.96$ & $<9.44$ & $<11.9$ & $<8.53$ & $<9.40$ & $<8.27$ & $<8.20$ & 63.2 \\
\hline & Effluent (5d) & $<4.96$ & $<4.85$ & $<5.08$ & $<5.14$ & $<5.57$ & $<4.33$ & $<6.50$ & $<5.73$ & $<5.47$ & 49.3 \\
\hline \multirow{4}{*}{$\begin{array}{l}\text { Estriol } \\
\text { (E3) }\end{array}$} & Influent & $<1010$ & $<917$ & $<833$ & $<1610$ & $<1010$ & $<917$ & $<833$ & $<1610$ & $<268$ & 132 \\
\hline & Effluent (20 d) & $<148$ & $<487$ & $<138$ & $<172$ & $<626$ & $<141$ & $<158$ & $<187$ & $<160$ & 76 \\
\hline & Effluent (10 d) & $<513$ & $<149$ & $<394$ & $<615$ & $<171$ & $<146$ & $<145$ & $<124$ & $<160$ & 76 \\
\hline & Effluent (5d) & $<96.9$ & $<94.7$ & $<99.2$ & $<100$ & $<109$ & $<84.5$ & $<127$ & $<97.0$ & $<107$ & 85.2 \\
\hline \multirow{4}{*}{ Norgestrel } & Influent & $<36.5$ & $<40.9$ & $<46.1$ & $<42.4$ & $<36.5$ & $<40.9$ & $<46.1$ & $<42.4$ & $<20.0$ & 71.2 \\
\hline & Effluent (20 d) & $<37.1$ & $<35.0$ & $<34.5$ & $<43.1$ & $<41.8$ & $<35.4$ & $<39.6$ & $<46.7$ & $<40.0$ & 98.7 \\
\hline & Effluent (10 d) & $<41.0$ & $<37.2$ & $<33.2$ & $<33.0$ & $<42.9$ & $<36.4$ & $<36.4$ & $<31.0$ & $<40.0$ & 98.7 \\
\hline & Effluent (5d) & $<24.2$ & $<23.7$ & $<24.8$ & $<25.1$ & $<71.2$ & $<21.1$ & $<31.7$ & $<24.2$ & $<26.7$ & 89.1 \\
\hline \multirow{4}{*}{ Equilenin } & Influent & $<4.76$ & $<4.77$ & $<4.86$ & $<4.47$ & $<4.76$ & $<4.77$ & $<4.86$ & $<4.47$ & $<4.00$ & 87.8 \\
\hline & Effluent (20 d) & $<7.42$ & $<7.01$ & $<6.90$ & $<8.61$ & $<8.36$ & $<7.07$ & $<7.91$ & $<9.33$ & $<8.00$ & 124 \\
\hline & Effluent (10 d) & $<8.21$ & $<7.44$ & $<6.64$ & $<6.61$ & $<8.57$ & $<7.28$ & $<7.27$ & $<6.21$ & $<8.00$ & 124 \\
\hline & Effluent (5 d) & $<4.84$ & $<4.74$ & $<4.96$ & $<5.02$ & $<5.43$ & $<4.23$ & $<6.34$ & $<4.85$ & $<8.00$ & 114 \\
\hline \multirow{4}{*}{$\begin{array}{l}17 \alpha- \\
\text { dihydroequilin }\end{array}$} & Influent & $<91.4$ & $<52.7$ & $<48.1$ & $<39.2$ & $<91.4$ & $<52.7$ & $<48.1$ & $<39.2$ & $<20.0$ & 82.3 \\
\hline & Effluent (20 d) & $<37.1$ & $<35.0$ & $<34.5$ & $<43.1$ & $<41.8$ & $<35.4$ & $<39.6$ & $<46.7$ & $<40.0$ & 71.7 \\
\hline & Effluent (10 d) & $<41.0$ & $<37.2$ & $<33.2$ & $<33.0$ & $<42.9$ & $<36.4$ & $<36.4$ & $<31.0$ & $<40.0$ & 71.7 \\
\hline & Effluent $(5 \mathrm{~d})$ & $<24.2$ & $<23.7$ & $<24.8$ & $<25.1$ & $<27.2$ & $<21.1$ & $<31.7$ & $<24.2$ & $<40.0$ & 75.8 \\
\hline \multirow{4}{*}{ Equilin } & Influent & $<59.0$ & $<51.7$ & $<48.6$ & $<49.1$ & $<59.0$ & $<51.7$ & $<48.6$ & $<49.1$ & $<40.0$ & 69.6 \\
\hline & Effluent (20 d) & $<74.2$ & $<70.1$ & $<69.0$ & $<86.1$ & $<83.6$ & $<70.7$ & $<79.1$ & $<93.3$ & $<80.0$ & 73.1 \\
\hline & Effluent (10 d) & $<82.1$ & $<74.4$ & $<66.4$ & $<66.1$ & $<85.7$ & $<72.8$ & $<72.7$ & $<62.1$ & $<80.0$ & 73.1 \\
\hline & Effluent (5 d) & $<48.4$ & $<47.4$ & $<49.6$ & $<50.2$ & $<54.3$ & $<42.3$ & $<63.4$ & $<48.5$ & $<80.0$ & 84.1 \\
\hline
\end{tabular}


Table B.3 Continued from previous page

\begin{tabular}{|c|c|c|c|c|c|c|c|c|c|c|c|}
\hline \multirow[b]{2}{*}{ Hormones } & \multirow[b]{2}{*}{ Sample } & \multicolumn{4}{|c|}{ Mesophilic } & \multicolumn{4}{|c|}{ Thermophilic } & \multirow{2}{*}{$\begin{array}{c}\text { Lab } \\
\text { blank }\end{array}$} & \multirow{2}{*}{$\begin{array}{c}\text { Spiked matrix } \\
\text { (\% recovery) }\end{array}$} \\
\hline & & Control & MW80 & MW120 & MW160 & Control & MW80 & MW120 & MW160 & & \\
\hline \multirow{4}{*}{$\begin{array}{l}17 \alpha- \\
\text { ethinylestradiol } \\
(\mathrm{EE} 2)\end{array}$} & Influent & $<29.7$ & $<29.8$ & $<30.4$ & $<27.9$ & $<29.7$ & $<29.8$ & $<30.4$ & $<27.9$ & $<25.0$ & 97.3 \\
\hline & Effluent (20 d) & $<46.4$ & $<43.8$ & $<43.1$ & $<73.9$ & $<52.2$ & $<44.2$ & $<72.3$ & $<58.3$ & $<50.0$ & 87.6 \\
\hline & Effluent (10 d) & $<51.3$ & $<46.5$ & $<41.5$ & $<41.3$ & $<53.6$ & $<45.5$ & $<45.5$ & $<38.8$ & $<50.0$ & 87.6 \\
\hline & Effluent (5 d) & $<30.3$ & $<29.6$ & $<31.0$ & $<31.3$ & $<33.9$ & $<26.4$ & $<39.6$ & $<30.3$ & $<50.0$ & 89.1 \\
\hline \multirow{4}{*}{$17 \alpha$-estradiol } & Influent & $<23.8$ & $<23.8$ & $<24.3$ & $<22.4$ & $<23.8$ & $<23.8$ & $<24.3$ & $<22.4$ & $<20.0$ & 98.8 \\
\hline & Effluent (20 d) & $<37.1$ & $<35.0$ & $<34.5$ & $<43.1$ & $<41.8$ & $<35.4$ & $<39.6$ & $<46.7$ & $<40.0$ & 82.1 \\
\hline & Effluent (10 d) & $<41.0$ & $<37.2$ & $<33.2$ & $<33.0$ & $<42.9$ & $<36.4$ & $<36.4$ & $<31.0$ & $<40.0$ & 82.1 \\
\hline & Effluent (5 d) & $<24.2$ & $<23.7$ & $<24.8$ & $<25.1$ & $<27.2$ & $<21.1$ & $<31.7$ & $<24.2$ & $<40.0$ & 91 \\
\hline \multirow{4}{*}{$\begin{array}{l}\text { Norethindrone } \\
(\mathrm{Nr})\end{array}$} & Influent & $<23.8$ & $<23.8$ & $<24.3$ & $<22.4$ & $<23.8$ & $<23.8$ & $<24.3$ & $<22.4$ & $<20.0$ & 73.9 \\
\hline & Effluent (20 d) & $<37.1$ & $<35.0$ & $<34.5$ & $<43.1$ & $<41.8$ & $<35.4$ & $<39.6$ & $<46.7$ & $<40.0$ & 90.7 \\
\hline & Effluent (10 d) & $<41.0$ & $<37.2$ & $<33.2$ & $<33.0$ & $<42.9$ & $<36.4$ & $<36.4$ & $<31.0$ & $<40.0$ & 90.7 \\
\hline & Effluent (5 d) & $<24.2$ & $<23.7$ & $<24.8$ & $<25.1$ & $<27.2$ & $<21.1$ & $<31.7$ & $<24.2$ & $<26.7$ & 85.1 \\
\hline
\end{tabular}

$*<$ : number following this symbol represents the reporting limit (RL), control: un-pretreated, MW: microwave (80,120 and 160 are the final pretreatment temperatures), lab blank: an aliquot of reagent water that is treated exactly as a sample including exposure to all glassware, equipment, solvents, reagents, internal standards, and surrogates that are used with samples, spiked matrix: matrix containing known quantity of analytes

Table B.4 Total solids (TS) concentrations (\%,w/w) of the influent and effluent samples analyzed for hormones

\begin{tabular}{|c|c|c|c|c|c|c|c|c|}
\hline \multirow{2}{*}{ Sample } & \multicolumn{4}{|c|}{ Mesophilic } & \multicolumn{4}{|c|}{ Thermophilic } \\
\hline & Control & MW80 & MW120 & MW160 & Control & MW80 & MW120 & MW160 \\
\hline Influent & 3.3 & 3.3 & 3.3 & 3.6 & 3.3 & 3.3 & 3.3 & 3.6 \\
\hline Effluent (20 d) & 2.1 & 2.2 & 2.2 & 1.9 & 1.9 & 2.3 & 2.1 & 1.8 \\
\hline Effluent (10 d) & 2 & 2.1 & 2.4 & 2.5 & 1.9 & 2.1 & 2.2 & 2.4 \\
\hline Effluent $(5 \mathrm{~d})$ & 3.3 & 3.1 & 3.2 & 3 & 2.9 & 3.7 & 2.4 & 3.2 \\
\hline
\end{tabular}


a)

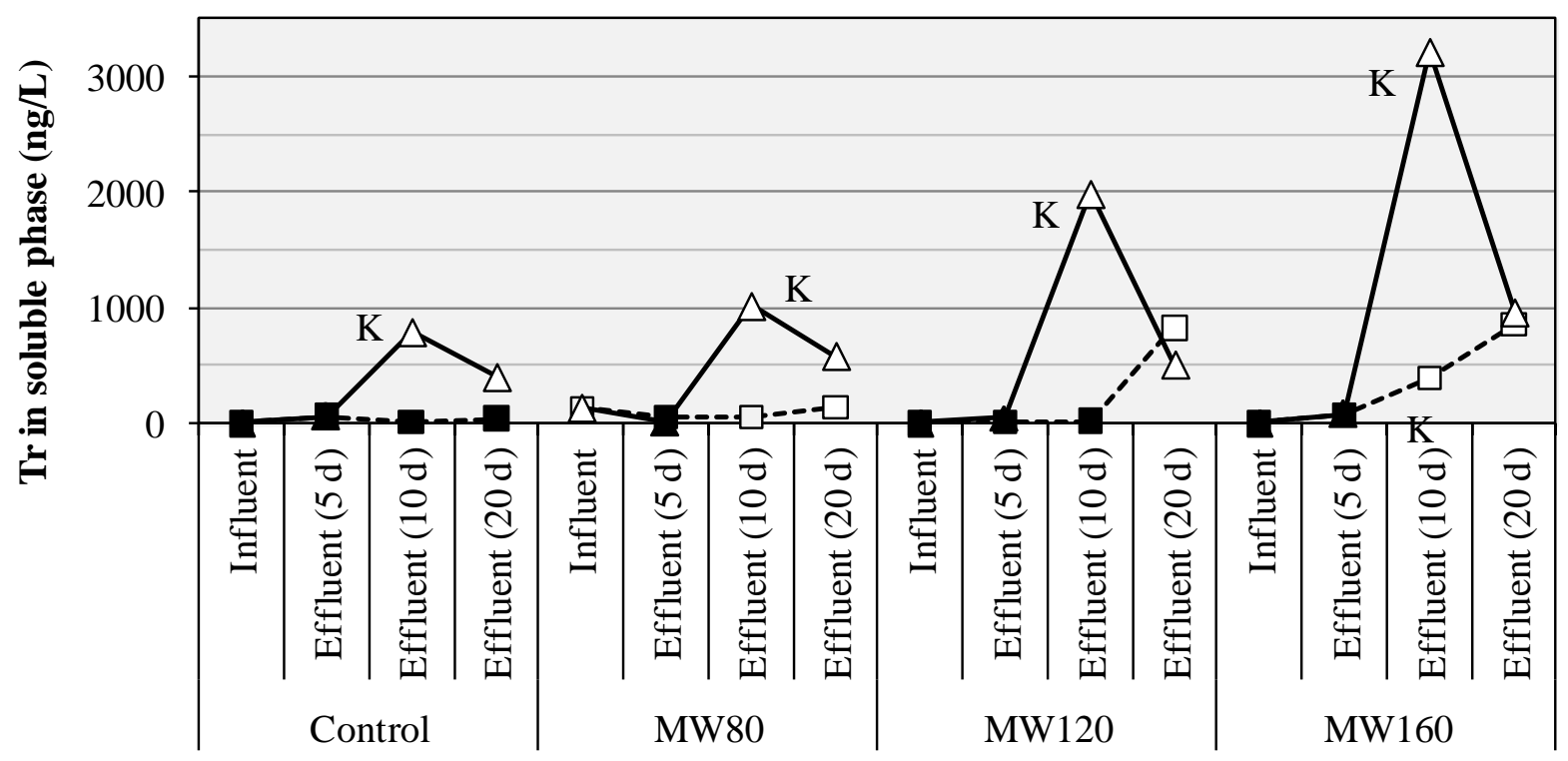

b)

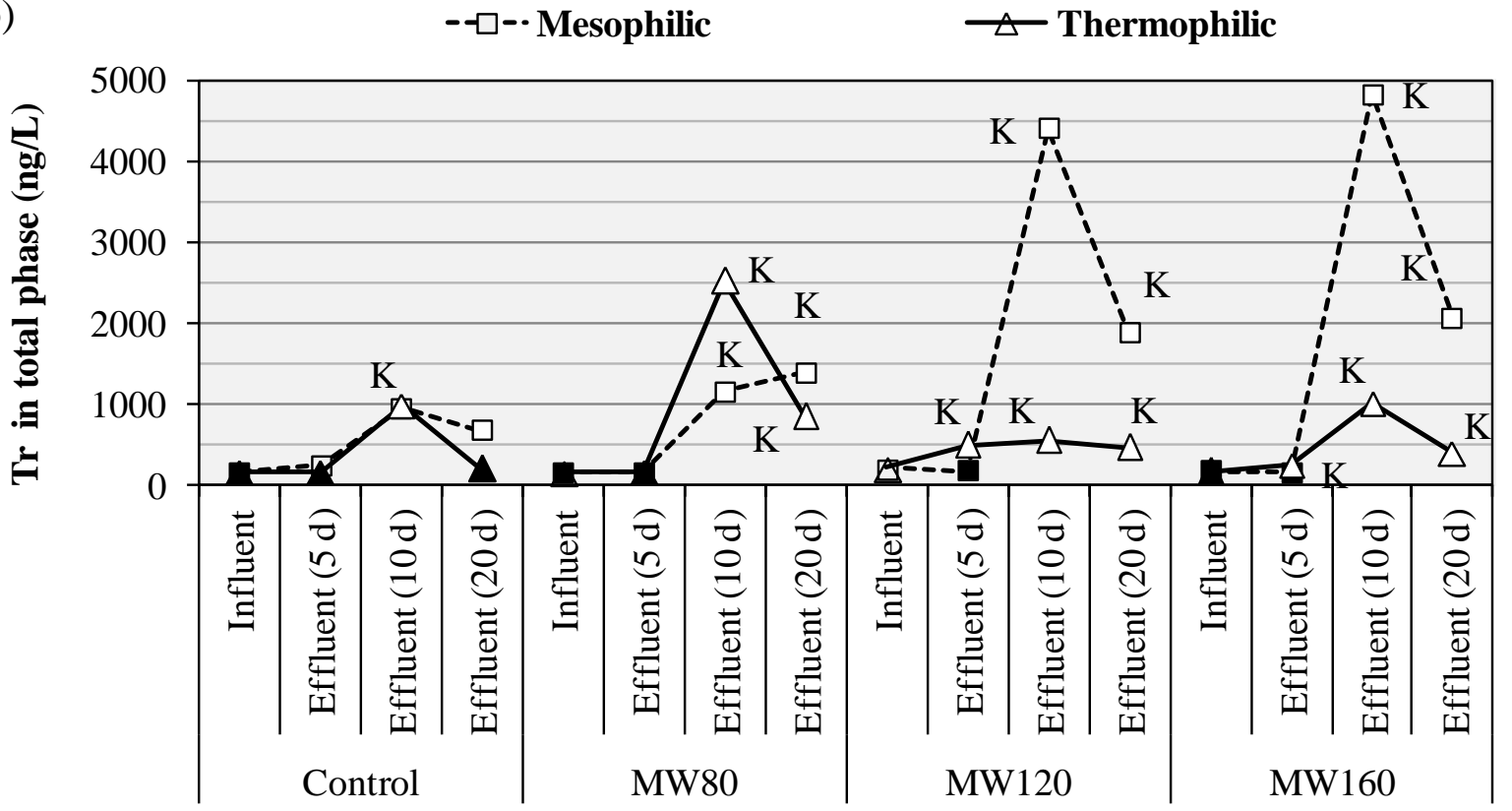

Figure B.1 Concentrations of testosterone (Tr) in a) soluble phase and b) total phase of the influent and effluents at different sludge retention times (SRTs) (80,120 and 160 are ultimate pretreatment temperatures in ${ }^{\circ} \mathrm{C}$ unit; black filled data points were below reporting limit (RL); $\mathrm{RL}$ varied as $3.08-82.9 \mathrm{ng} / \mathrm{L}$ in soluble phases; $\mathrm{K}$ flagged data points represent estimated maximum concentration) 
a)

$--\square-$-Mesophilic $\quad \longrightarrow-$ Thermophilic

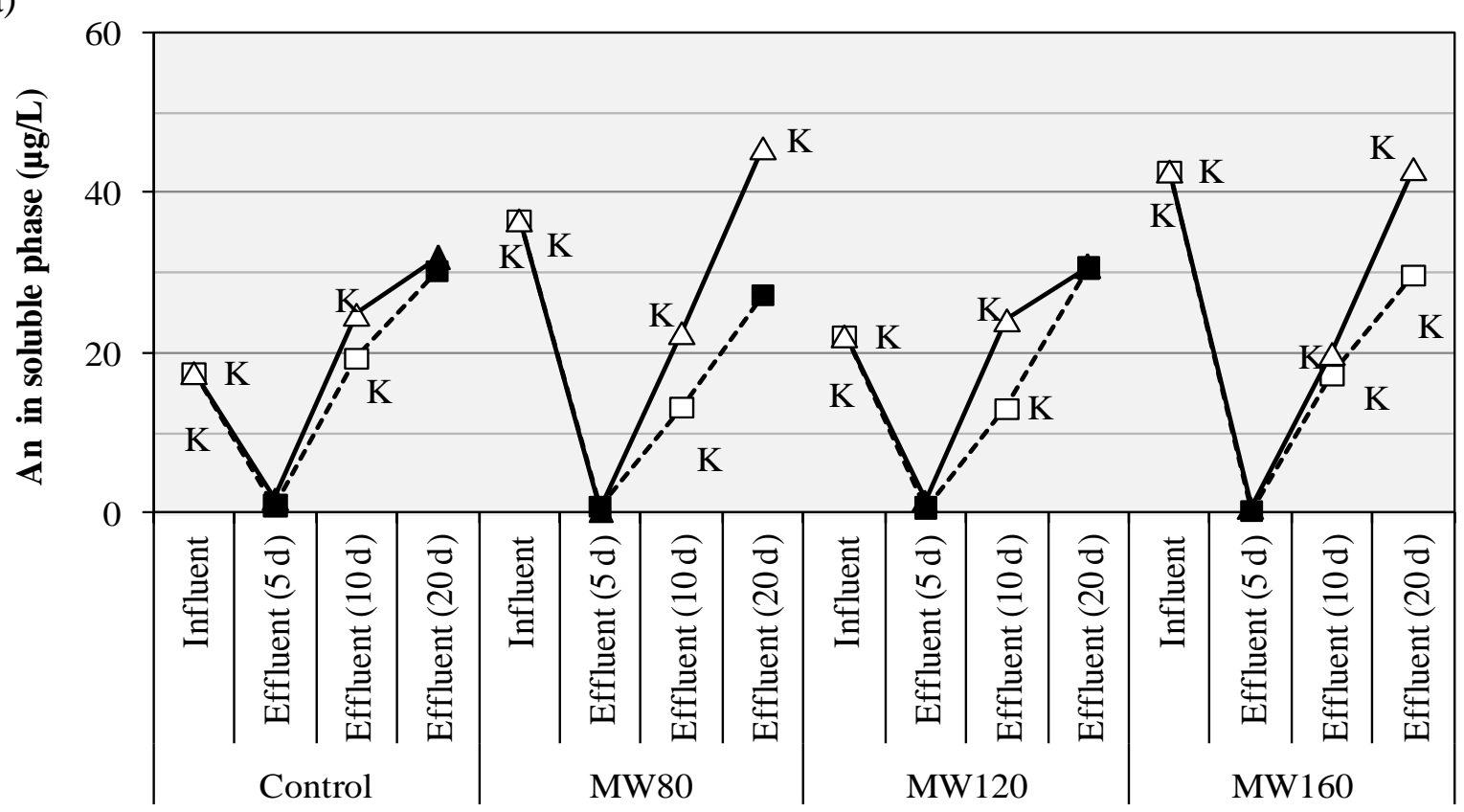

b)

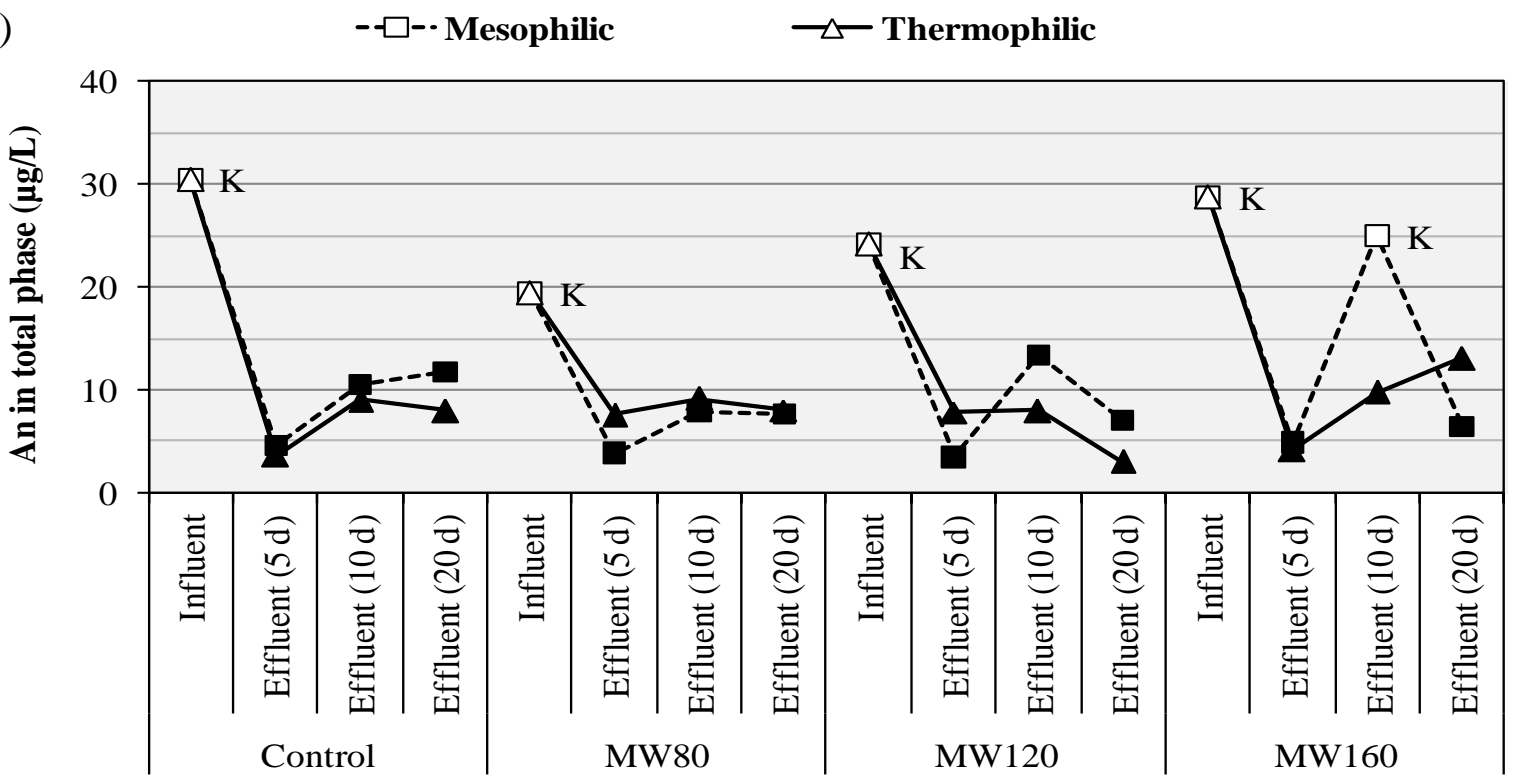

Figure B.2 Concentrations of androsterone (An) in a) soluble phase and b) total phase of the influent and effluents $(\mu \mathrm{g} / \mathrm{L})$ at different sludge retention times (SRTs) (80, 120 and 160 are ultimate pretreatment temperatures in ${ }^{\circ} \mathrm{C}$ unit; black filled data points were below reporting limit (RL); RL varied as $0.271-31.9 \mu \mathrm{g} / \mathrm{L}$ in soluble phases; $\mathrm{K}$ flagged data points represent estimated maximum concentration) 
a)

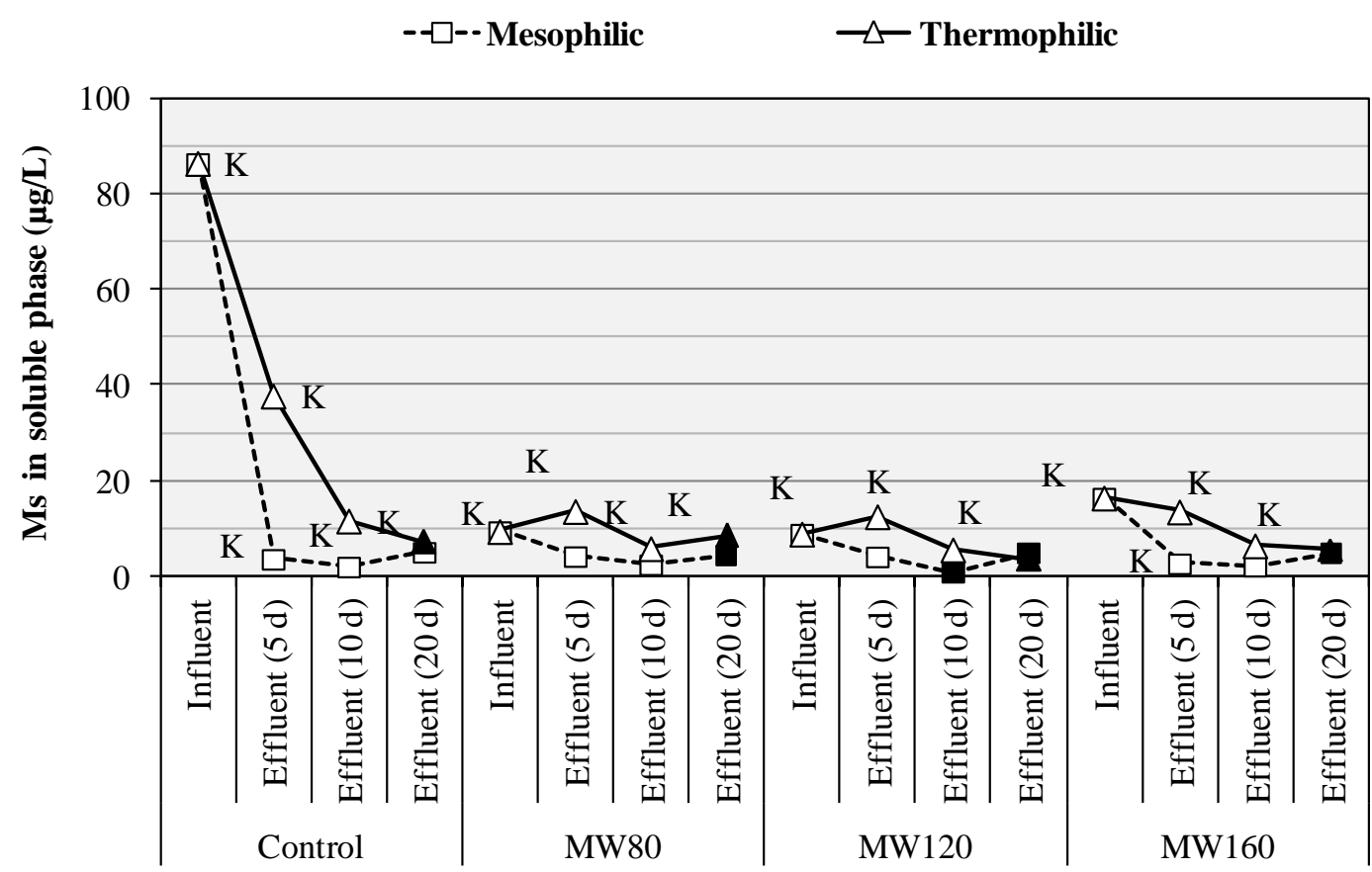

b)

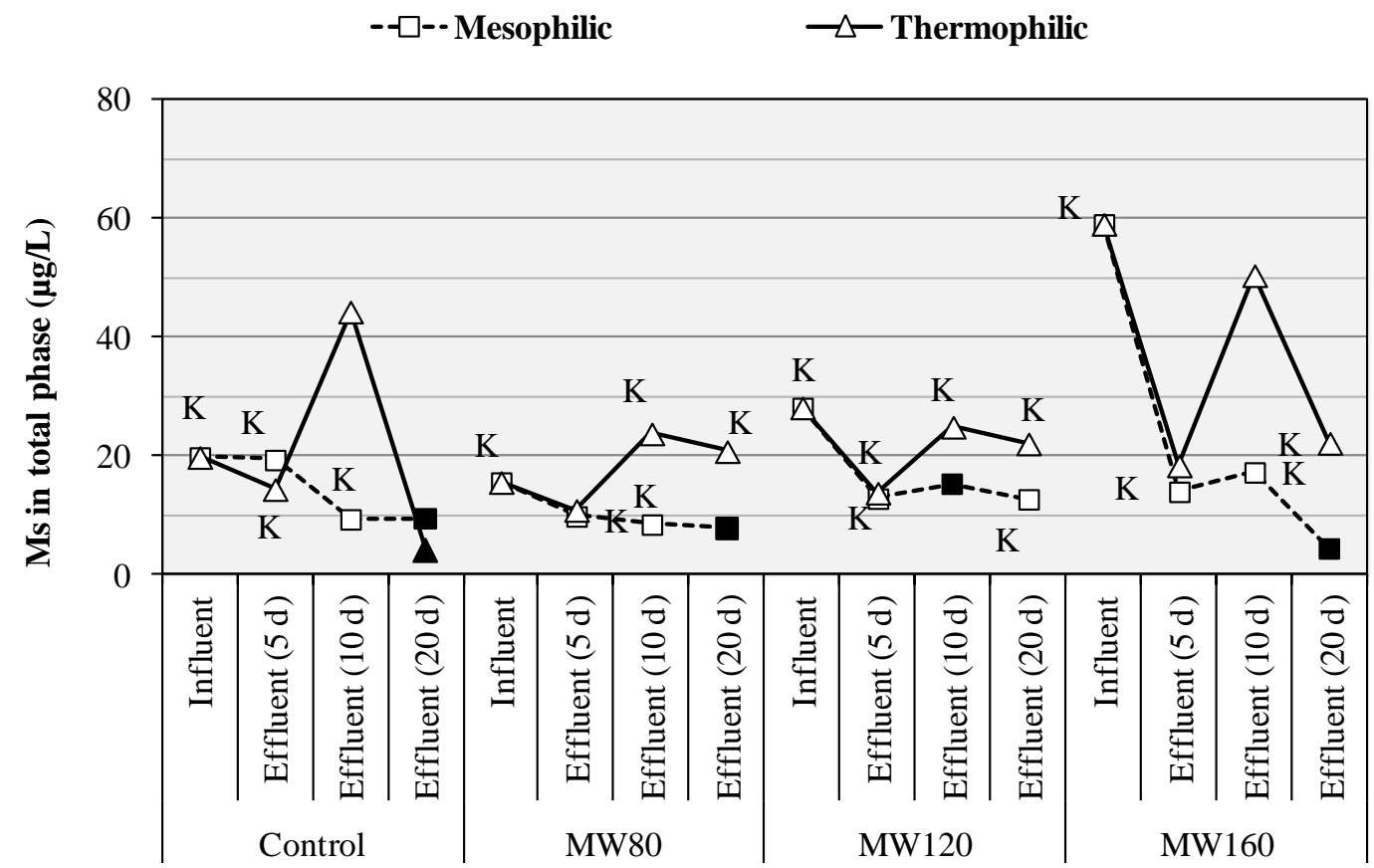

Figure B.3 Concentrations of mestranol (Ms) in a) soluble phase and b) total phase of the influent and effluents $(\mu \mathrm{g} / \mathrm{L})$ at different sludge retention times (SRTs) (80, 120 and 160 are ultimate pretreatment temperatures in ${ }^{\circ} \mathrm{C}$ unit; black filled data points were below reporting limit (RL); RL varied as $0.745-8.5 \mu \mathrm{g} / \mathrm{L}$ in soluble phases; $\mathrm{K}$ flagged data points represent estimated maximum concentration) 


\section{Appendix C: Analysis of variance}

Table C.1 Analysis of variance for removal efficiency of androstenedione (Ad) from soluble phase ${ }^{\mathrm{a}}$

\begin{tabular}{lccc}
\hline Factor & Unit & Levels & Values \\
\hline Digester (operating) temperature & ${ }^{\circ} \mathrm{C}$ & 2 & $35 \pm 2$ (mesophilic), 55 \pm 2 (thermophilic) \\
Sludge retention time (SRT) & days & 3 & $20,10,5$ \\
Microwave temperature (MW) & ${ }^{\circ} \mathrm{C}$ & 4 & Control (un-pretreated), 80, 120, 160 \\
\hline
\end{tabular}

\begin{tabular}{lccccc}
\hline Source & DF & SS & MS & F & P \\
\hline Digester temperature & 1 & 148626 & 148626 & 4.59 & 0.076 \\
SRT & 2 & 1194801 & 597400 & 18.46 & 0.003 \\
MW & 3 & 1054529 & 351510 & 10.87 & 0.008 \\
Digester temperature $\times$ SRT & 2 & 418639 & 209320 & 6.47 & 0.032 \\
Digester temperature $\times$ MW & 3 & 228627 & 76209 & 2.35 & 0.171 \\
SRT $\times$ MW & 6 & 995421 & 165903 & 5.13 & 0.034 \\
Error & 6 & 194213 & 32369 & & \\
Total & 23 & 4235240 & & & \\
\hline
\end{tabular}

${ }^{a} \mathrm{DF}$ : degrees of freedom; SS: sum of square; MS: adjusted mean of square; F: observed F value, P: probability value

Table C.2 Analysis of variance for removal efficiency of estrone (E1) from soluble phase ${ }^{a}$

\begin{tabular}{lccc}
\hline Factor & Unit & Levels & Values \\
\hline Digester (operating) temperature & ${ }^{\circ} \mathrm{C}$ & 2 & $35 \pm 2$ (mesophilic), $55 \pm 2$ (thermophilic) \\
Sludge retention time (SRT) & days & 3 & $20,10,5$ \\
Microwave temperature (MW) & ${ }^{\circ} \mathrm{C}$ & 4 & Control (un-pretreated), 80, 120, 160 \\
\hline
\end{tabular}

\begin{tabular}{lccccc}
\hline Source & DF & SS & MS & F & P \\
\hline Digester temperature & 1 & 16136 & 16136 & 8.89 & 0.025 \\
SRT & 2 & 5115 & 2558 & 1.41 & 0.315 \\
MW & 3 & 86389 & 28796 & 15.86 & 0.003 \\
Digester temperature $\times$ SRT & 2 & 3327 & 1664 & 0.92 & 0.450 \\
Digester temperature $\times$ MW & 3 & 13718 & 4573 & 2.52 & 0.155 \\
SRT $\times$ MW & 6 & 12249 & 2041 & 1.12 & 0.445 \\
Error & 6 & 10895 & 1816 & & \\
Total & 23 & 147830 & & & \\
\hline
\end{tabular}

${ }^{a}$ DF: degrees of freedom; SS: sum of square; MS: adjusted mean of square; F: observed F value, P: probability value 


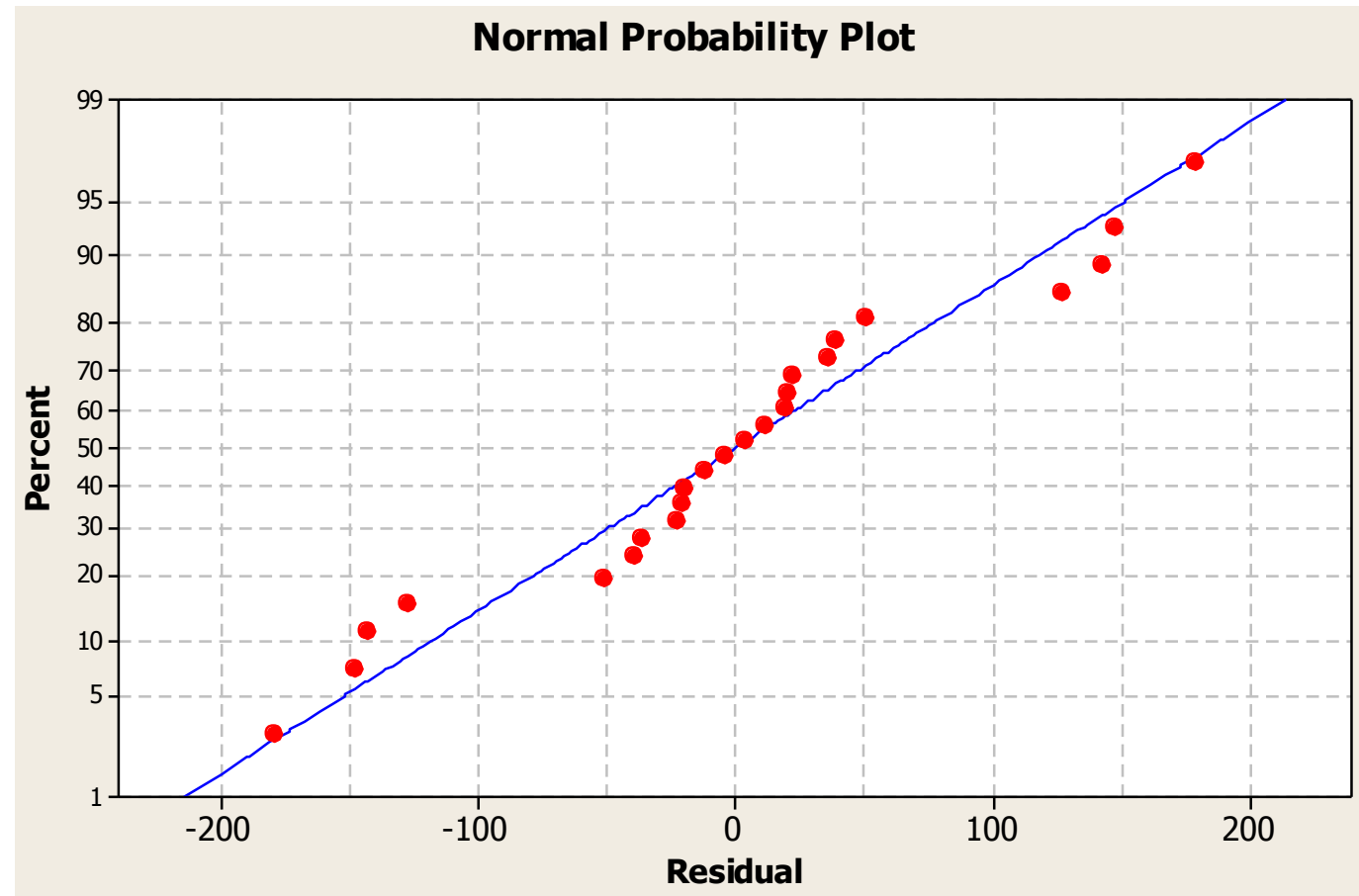

Figure C.1 Normal probability plot for analysis of variance of removal efficiency of androstenedione (Ad) from soluble phase

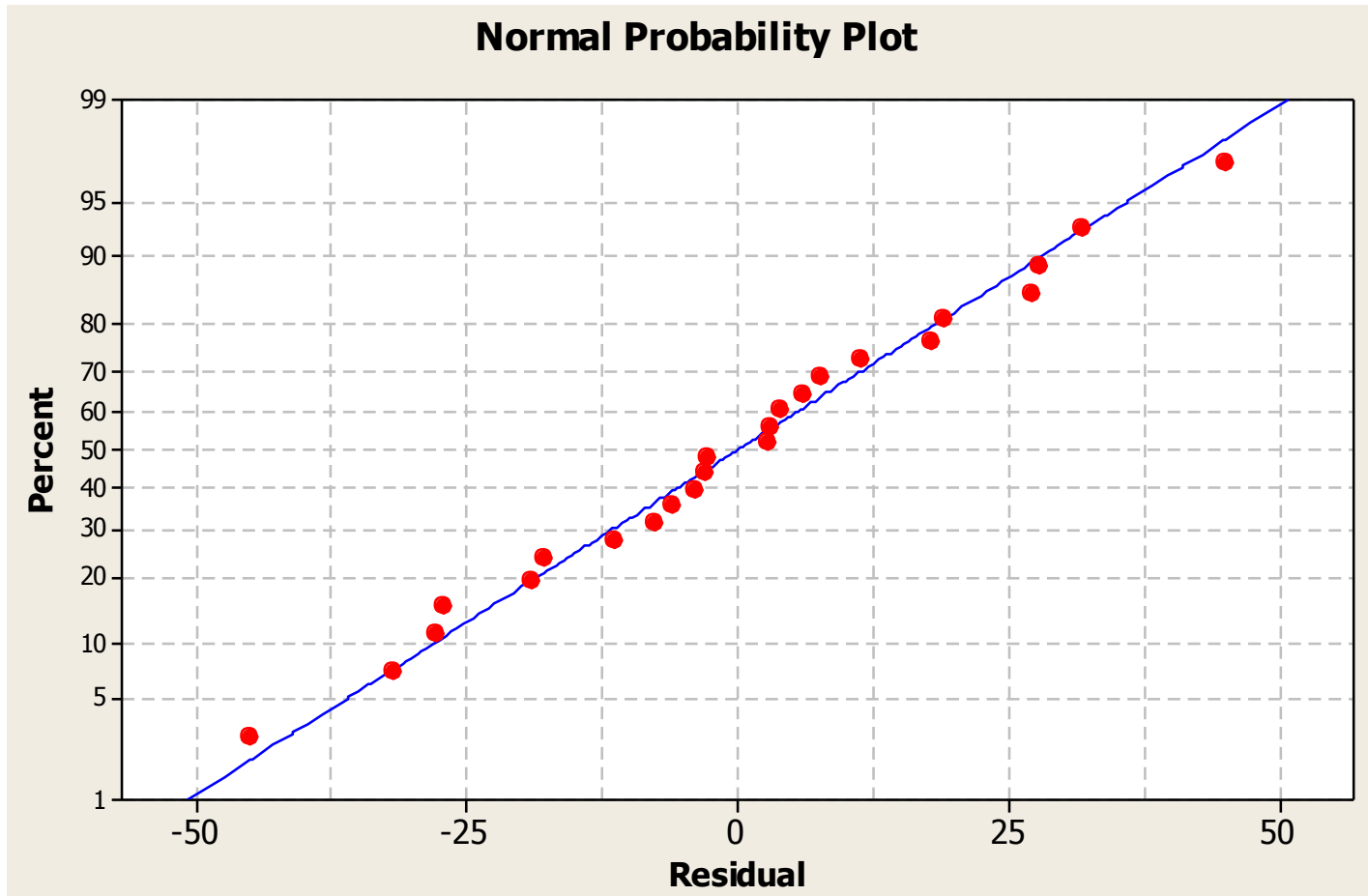

Figure C.2 Normal probability plot for analysis of variance of removal efficiency of estrone (E1) from soluble phase 


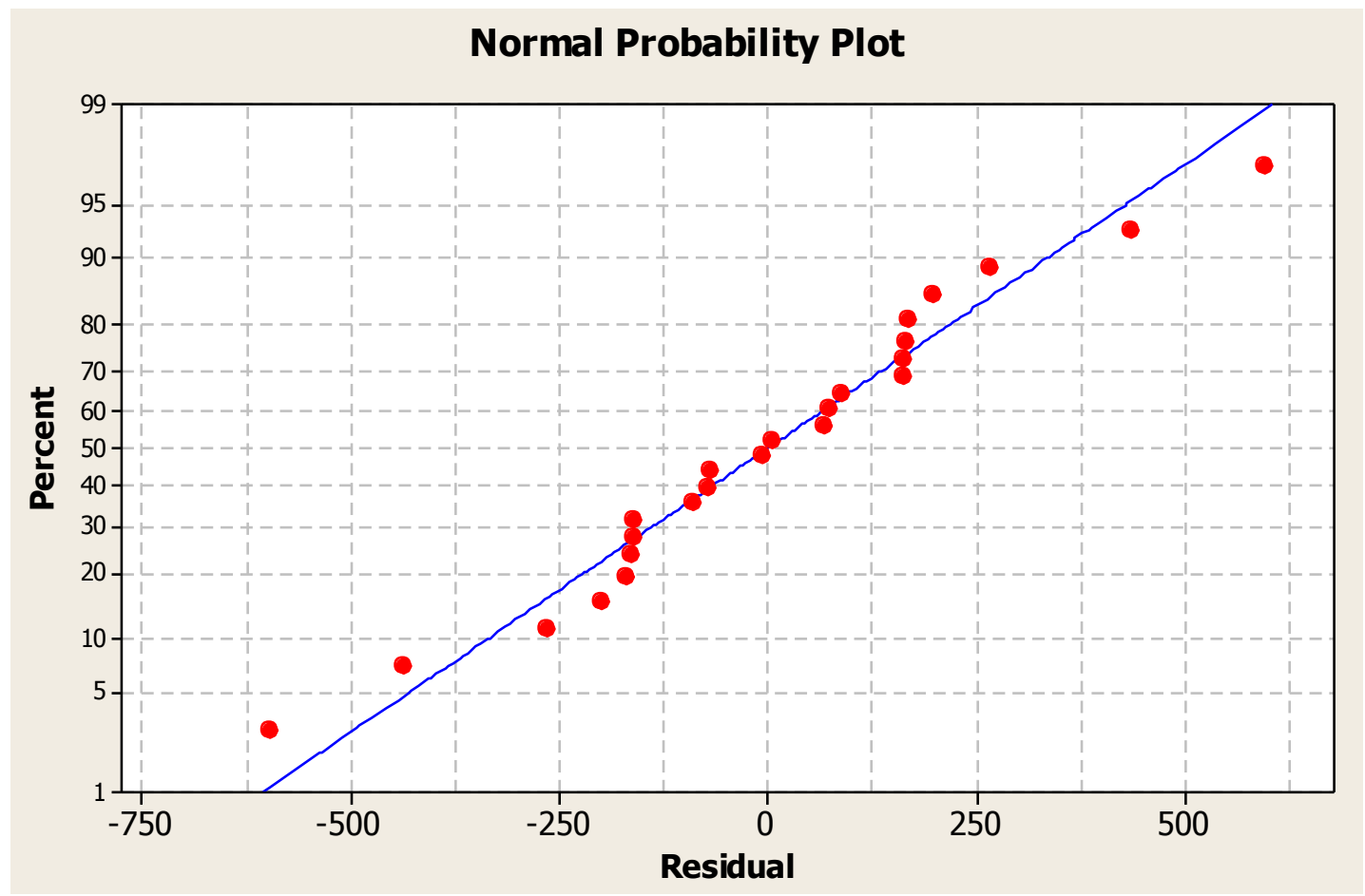

Figure C.3 Normal probability plot for analysis of variance of removal efficiency of progesterone $(\mathrm{Pr})$ from total phase 